\title{
New developments in sacral neuromodulation for lower urinary tract dysfunction
}

Citation for published version (APA):

Marcelissen, T. A. T. (2011). New developments in sacral neuromodulation for lower urinary tract dysfunction. [Doctoral Thesis, Maastricht University]. Maastricht University. https://doi.org/10.26481/dis.20110930tm

Document status and date:

Published: 01/01/2011

DOI:

10.26481/dis.20110930tm

Document Version:

Publisher's PDF, also known as Version of record

\section{Please check the document version of this publication:}

- A submitted manuscript is the version of the article upon submission and before peer-review. There can be important differences between the submitted version and the official published version of record.

People interested in the research are advised to contact the author for the final version of the publication, or visit the DOI to the publisher's website.

- The final author version and the galley proof are versions of the publication after peer review.

- The final published version features the final layout of the paper including the volume, issue and page numbers.

Link to publication

\footnotetext{
General rights rights.

- You may freely distribute the URL identifying the publication in the public portal. please follow below link for the End User Agreement:

www.umlib.nl/taverne-license

Take down policy

If you believe that this document breaches copyright please contact us at:

repository@maastrichtuniversity.nl

providing details and we will investigate your claim.
}

Copyright and moral rights for the publications made accessible in the public portal are retained by the authors and/or other copyright owners and it is a condition of accessing publications that users recognise and abide by the legal requirements associated with these

- Users may download and print one copy of any publication from the public portal for the purpose of private study or research.

- You may not further distribute the material or use it for any profit-making activity or commercial gain

If the publication is distributed under the terms of Article $25 \mathrm{fa}$ of the Dutch Copyright Act, indicated by the "Taverne" license above, 
New Developments in Sacral Neuromodulation for Lower Urinary Tract Dysfunction

Tom Marcelissen 


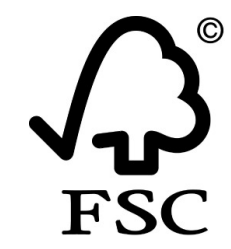

(C) 2011 Tom Marcelissen

ISBN: 978-94-6108-208-4

Printed by: Gildeprint Drukkerijen - Enschede

Cover design: Tom Marcelissen en Martijn Smits 


\section{New Developments in Sacral Neuromodulation for Lower Urinary Tract Dysfunction}

\section{Proefschrift}

ter verkrijging van de graad van doctor aan de Universiteit Maastricht, op gezag van Rector Magnificus, prof. mr. G.P.M.F. Mols volgens het besluit van het College van Decanen in het openbaar te verdedigen op vrijdag 30 september 2011 om 16.00 uur precies door

Tom A.T. Marcelissen 


\section{Promotores:}

Prof. dr. P.E.V. Van Kerrebroeck

Prof. dr. S.G.G. de Wachter

\section{Beoordelingscommissie:}

Prof. dr. C.G.M.I. Baeten (voorzitter)

Prof. dr. E. Chartier-Kastler (Faculté Pierre et Marie Curie, Université Paris VI)

Prof. dr. A.A.B. Lycklama à Nijeholt (Universiteit Leiden)

Prof. dr. V.E.R.M. Visser-Vandewalle

\section{Financial support:}

Abbott, Astellas, AstraTech, AstraZeneca, Coloplast, Covidien, Eurocept, Ferring, GlaxoSmithKline, Hollister, Medtronic, Pfizer, stichting Wetenschappelijke Activiteiten Maastrichtse Urologie (WAMU), Zambon. 


\section{CONTENTS}

Chapter 1 General Introduction and aims of the thesis

Chapter 2 Long-term results of sacral neuromodulation

with the tined lead procedure

J Urol. 2010 Nov;184(5):1997-2000

Chapter 3

Is the method of screening in sacral

43

neuromodulation a prognostic factor for long-term success?

J Urol. 2011 Feb;185(2):583-7

Chapter $4 \quad$ Psychological and psychiatric factors as predictors

for success in sacral neuromodulation

BJU Int. 2011 Aug 2. Epub ahead of print.

Chapter 5

The effect of pulse rate changes on clinical outcome in sacral neuromodulation J Urol. 2011 May;185(5):1781-5

Chapter 6

The use of bilateral sacral nerve stimulation in patients with loss of unilateral treatment efficacy J Urol. 2011 Mar;185(3):976-80

Chapter 7

Sacral neuromodulation as a treatment for chronic pelvic pain: a review of the literature J Urol. 2011 Aug;186(2):387-93

Chapter $8 \quad$ General discussion

Chapter 9

Summary

Chapter 10

Nederlandse samenvatting

Dankwoord

Lijst van publicities

Curriculum Vitae 


\section{LIST OF ABBREVIATIONS}

\begin{tabular}{ll} 
ABQ & Amsterdam Biographical Questionnaire \\
APF & Antiproliferative Factor \\
BPS & Bladder Pain Syndrome \\
BTX & Botulinum toxin \\
CPP & Chronic Pelvic Pain \\
FDA & Food and Drug Administration \\
GRA & Global Response Assessment \\
HB-EGF & Heparin-Binding Epidermal Growth Factor \\
IC & Interstitial Cystitis \\
ICSI & Interstitial Cystitis Symptom Inventory \\
ICPI & Interstitial Cystitis Problem Index \\
INS & Implantable Neurostimulator \\
OAB & Overactive Bladder \\
PNE & Percutaneous Nerve Evaluation \\
PNS & Pudendal Nerve Stimulation \\
PUF & Pain Urgency Frequency \\
SCL-90-R & Symptom Check-list-90-Revised \\
SNM & Sacral Neuromodulation \\
TLP & Tined Lead Procedure \\
VAS & Visual Analogue Scale \\
& \\
\hline
\end{tabular}


GENERAL INTRODUCTION AND AIMS OF THE THESIS 

Chapter 1 


\section{INTRODUCTION}

Sacral neuromodulation (SNM) offers an alternative treatment for patients with lower urinary tract dysfunction with symptoms refractory to conservative treatment including pharmacotherapy, pelvic floor re-education and clean intermittent self-catheterization. ${ }^{1,2,3}$ SNM is based on the application of electrical currents to the sacral nerves in order to modulate reflexes involved in lower urinary tract control. Initially, more invasive surgical procedures such as bladder augmentation or urinary diversion have been advocated for patients with refractory symptoms. However, these procedures have variable success rates and have been associated with significant morbidity and risk. Therefore, SNM must be considered prior to more invasive surgery. ${ }^{4}$

SNM was developed in the early 1980s and now has become a well-established treatment modality. S3 sacral neuromodulation received approval by the US Food and Drug Administration (FDA) for the treatment of urgency incontinence in 1997 and for urgency/frequency and non-obstructive urinary retention in 1999. The efficacy of SNM treatment has been shown in clinical trials, with a reported five year success rate of approximately $70 \% .^{5}$

\section{HISTORICAL OVERVIEW}

The first application of the use of electrical currents in medicine dates back to 46 A.D., when Scribonius Largus, a Roman physician, recorded the use of torpedo fish for treatment of headaches and gout in his Compositiones Medicae. ${ }^{6}$ The concept of electrical stimulation of the bladder started in 1878. The Danish surgeon Saxtorph reported on the use of intravesical electrostimulation in patients with acontractile bladder and complete urinary retention. ${ }^{7}$ A specially designed catheter was inserted transurethrally with a metal electrode inside and a neutral electrode placed suprapubically. In 1959 this technique was again used by Katona, who described a technique of intraluminal electrotherapy for various disorders of the gastrointestinal tract. ${ }^{8} \mathrm{He}$ also applied this treatment in newborns with meningomyelocoele to enhance detrusor reflexes. Since then, 
intravesical electrostimulation has been researched by others with inconsistent results. ${ }^{9,10}$

With the growing experience of direct bladder stimulation, alternative methods such as stimulation of the spinal cord and pelvic nerves have been evaluated. A study by Nashold et al. reported successful implantation of a neural prosthesis in the sacral segment of the spinal cord. ${ }^{11}$ In order to achieve greater coordination, stimulation was directed at the sacral micturition centre. The first implants were used to activate voiding in patients with spinal cord injury. However, simultaneous activation of the detrusor as well as the urethral sphincter prevented adequate success. It was Jonas and Tanagho who further evaluated this prosthesis, and found that voiding was possible in patients with spinal cord lesions at the end of each stimulus due to an earlier decline in urethral sphincter pressure. ${ }^{12}$ Ultimately, Tanagho and Schmidt demonstrated that stimulation of the third sacral root (S3) generally modulates detrusor and sphincter activity and could stabilize the whole micturition reflex mechanism in patients with overactivity of the lower urinary tract. With an implantable stimulator connected to an electrode positioned in the sacral foramen, the S3 root can be stimulated continuously (figure 1). ${ }^{13,14}$ Due to technological advancements, the technique has now become minimally-invasive and easy to perform. Currently, this therapy has been successfully used for more than twenty years. 
Figure 1. Stimulation of the third sacral nerve root (S3) with an implantable neurostimulator.



\section{INDICATIONS}

Sacral neuromodulation is an established treatment for patients with chronic bladder disorders who have failed to respond to traditional treatments. Although SNM currently only has FDA approval for overactive bladder and urinary retention, clinical benefit has been observed for various other chronic pelvic floor disorders, including faecal incontinence, chronic pelvic pain and interstitial cystitis.

\section{Overactive bladder}

Overactive bladder $(\mathrm{OAB})$ syndrome involves a group of symptoms including frequency, urgency, and leakage immediately preceded by urgency. ${ }^{15}$ Bladder overactivity can occur with urine incontinence (OAB wet), or without (OAB dry). Epidemiological data from Europe and the US estimated an OAB prevalence of approximately $16-17 \%$ in the adult population, of which a third (predominantly 
women) have complaints of urgency urinary incontinence. ${ }^{16,17} \mathrm{OAB}$ is a distressing syndrome and has a significant negative impact on quality of life. ${ }^{18-20}$ The cause of $O A B$ is often idiopathic. It can also be neurogenic, involving the central nervous system, the peripheral nervous system, or the end organ itself. Myogenic changes of the bladder are also important in the aetiology, particularly in the elderly. ${ }^{21}$ Often, a combination of these factors account for the development of OAB.

Before considering treatment, a proper clinical evaluation should be performed in order to rule out underlying causes, such as infections, malignancies or anatomical obstruction. This includes a voiding diary, urinalysis, physical examination and urodynamics. Conservative management is initially advocated since it carries minimal risks. ${ }^{22,23}$ Behavioural and lifestyle interventions are recommended, followed by bladder and pelvic floor training or pharmacological treatment with antimuscarinic drugs. Often, these conservative treatments do not result in a sufficient relief of symptoms, with many patients unable to tolerate the side effects of antimuscarinic drugs. ${ }^{24,25}$ When conservative treatments fail after 8-12 weeks, alternative therapies can be considered. ${ }^{15}$ At present, minimally invasive techniques available include SNM, posterior tibial nerve stimulation (PTNS) and intravesical injections with botulinum toxin (BTX). Although BTX is currently not approved by the FDA for the treatment of OAB, the clinical results are promising. ${ }^{26-28}$ The most common adverse events are urinary tract infections and urinary retention, necessitating the use of intermittent self-catheterization.

Although it is unknown which OAB patients are most suitable for SNM, important observations have been made. Scheepens et al. identified several predictive factors in a retrospective study evaluating 211 patients ${ }^{29}$. They found that a history of intervertebral disc prolapse surgery, and the duration of complaints are factors that may affect the chance of success. Everaert et al. reported that patients with a history of surgery for stress incontinence had significantly better long-term outcomes with SNM, whatever their symptoms were ${ }^{30}$. In a group of 100 patients undergoing test stimulation, Koldewijn et al. did not show any predictors of success, although it appeared that patients with detrusor overactivity and urethral instability responded best to SNM. ${ }^{31}$ Groenendijk et al. studied the predictive value of urethral instability and other urodynamic 
parameters on the efficacy of sacral nerve stimulation in 19 patients. $^{32}$ They found that 12 of the 13 successfully treated patients showed urethral instability at baseline, compared to 1 of the 6 patients with failure of SNM. It has been postulated that increasing age has an adverse effect on neurologic integrity both within the central nervous system and to the bladder. Amundsen et al. demonstrated that age greater than 55 was associated with a poorer response to $\mathrm{SNM}^{33}{ }^{33}$ In predictive factor studies in the treatment of faecal incontinence, older age has also been identified as a negative predictor for success. ${ }^{34,35}$ For now, a trial stimulation remains the only reliable factor in predicting success with permanent treatment.

\section{Urinary retention}

Voiding can be impaired by either bladder outlet obstruction or insufficient contractility of the detrusor muscle. In turn, bladder outlet obstruction can be of anatomical or functional origin. Anatomical obstruction is often caused by an enlarged prostate, urinary tract tumours, bladder neck stenosis or urethral strictures. Although poorly understood, functional aetiologies include detrusor external sphincter dyssynergia or detrusor bladder neck dyssynergia. In addition, pelvic floor dysfunction can cause inhibition of detrusor function, resulting in difficult voiding and varying degrees of urinary retention. Fowler et al. described overactivity of the urethral sphincter as a cause of urinary retention, especially in young women (Fowler's syndrome). ${ }^{36,37}$ Women with this disorder show abnormal activity of the external urethral sphincter on electromyography. As a result, the urethral sphincter is unable to relax, which causes inadequate bladder emptying.

Besides urological causes, neurological disorders (e.g. spinal cord disease, spinal disc hernation, multiple sclerosis, small fibre neuropathy) should be considered as a possible basis for non-obstructive urinary retention. Patients with "idiopathic" urinary retention often experienced a triggering event such as pelvic surgery or emotional stress. In addition, they frequently report a history of dysfunctional disorders in their childhood, such as lifelong constipation or urinary tract infections. Multiple authors have demonstrated the association of childhood dysfunctional elimination symptoms and adult bladder symptoms. ${ }^{38}$ 
Prior to SNM there was no effective treatment for functional urinary retention apart from clean intermittent self catheterization, as pharmacological agents including a -blockers and muscle relaxants, often gave poor results. More invasive treatments, such as urethral dilatation and bladder neck incisions have been associated with inconsistent results, a high relapse rate and complications. Sacral neuromodulation has been recognized as an effective treatment for patients with functional urinary retention. A large multicentre clinical trial in 1999 resulted in FDA approval of SNM for this indication. ${ }^{39}$ Later, the clinical efficacy was confirmed in several studies, and now SNM has become a well-established treatment modality for patients with non-obstructive urinary retention. ${ }^{1,2,5,40}$ No predictors of success have currently been identified. It is important to note that an elevated cystometric capacity or absence of signs of detrusor contractility on urodynamic investigation do not predict failure of SNM. However, Bertapelle et al. demonstrated that patients who showed a lack of detrusor response to acute stimulation of the sacral nerve roots, might have a lower chance of treatment success. ${ }^{41}$ Patients with pelvic floor hypertonicity, such as in Fowler's syndrome, appear to have a higher success rate. ${ }^{42}$

\section{Neurogenic bladder dysfunction}

Originally, SNM was not considered an option for neurogenic bladder dysfunction, because it has been assumed that the efficacy of SNM relies on the integrity of the spinal and supraspinal reflex arcs. ${ }^{43}$ Furthermore, SNM has been previously attempted without success in patients with complete spinal cord lesions. ${ }^{44}$ Nevertheless, several studies have demonstrated that SNM can be used successfully in patients with voiding symptoms due to neurological disorders. ${ }^{45-47}$ Chartier-Kastler showed that SNM was successful in 9 patients with neurogenic urgency incontinence due to diseases that affect the spinal cord. ${ }^{48}$ After a mean follow-up of 44 months, all patients had clinically significant improvement of incontinence, and 5 were completely dry. Lombardi et al. evaluated the effect of SNM in 24 patients with lower urinary tract dysfunction due to spinal cord injury with a mean follow-up of 61 months. ${ }^{49}$ Of the 13 patients with urinary retention, 9 (69\%) were successfully treated, with a significant decrease in the number of catheterizations and a significant increase in voided 
volume. Amongst the 11 patients with overactive bladder symptoms an $80 \%$ reduction in daytime frequency was observed, with 3 out of 7 patients remaining completely dry during the study period. In a recent review and meta-analysis by Kessler et al., the efficacy of SNM for neurogenic voiding dysfunction was evaluated. ${ }^{51}$ The pooled success rate of 26 studies was $68 \%$ for the test phase and $92 \%$ for permanent SNM, with a mean follow-up of 26 months. However, the number of investigated patients was low with high between-study heterogeneity and lack of randomized controlled trials.

Hohenfeller et al. found less promising results. They evaluated 27 patients with neurogenic bladder dysfunction after a follow-up of 89 months. ${ }^{50}$ The underlying neurologic disorders were lesions of the spinal cord in 16, pelvic surgery in 6 , cerebral lesions in 3, and inflammatory disease of the central nervous system in 2 patients. In 8 patients (30\%), symptoms of lower urinary tract dysfunction significantly improved for 54 months. After this time period, all implants became ineffective, except in one patient. This study illustrates that while SNM may be effective for neurogenic bladder dysfunction, the results may be temporary.

\section{Functional bowel disorders}

In 1995 Matzel et al. adapted SNM for the treatment of functional disorders of the lower gastrointestinal tract. Patients who do not respond to maximal conservative treatments such as pelvic floor training, drugs, or retrograde colonic irrigation are eligible candidates for SNM. Several studies demonstrated treatment success in patients with faecal incontinence. ${ }^{52-54}$ A review of patients with faecal incontinence who received a permanent implant reported that complete continence for solids and liquid motions was reported in $41 \%$ to $75 \%$ of patients. ${ }^{55}$ More recently, SNM has also been successfully used in patients with constipation. $^{56,57}$ For patients with idiopathic slow transit constipation who received permanent implants, evacuations increased 5-fold. The Cleveland Clinic Constipation score also improved, with less abdominal pain and bloating. ${ }^{55}$ Some studies reported on the treatment of patients with mixed urinary and faecal incontinence. Ganio et al. evaluated 40 patients with faecal incontinence, of whom 12 had concomitant voiding symptoms, including retention and incontinence. ${ }^{58}$ During test stimulation, 6 of the 12 had complete resolution of 
symptoms and 1 reported improvement. Uludag et al. evaluated the effect of permanent SNM in 50 patients with faecal incontinence, of whom 18 had concomitant urinary incontinence. ${ }^{59}$ After a median follow-up of 12 months, 9 patients $(50 \%)$ showed improvement in urinary leakage, although bladder symptoms were not recorded by using voiding diaries. In a recent study by ElGazzaz et al., 24 patients who received implants for urinary incontinence associated with faecal incontinence were studied. Seven patients (31.8\%) experienced improvement in both urinary and faecal incontinence symptoms. There was no improvement in urinary symptoms in 11 patients $(50 \%)$ and faecal incontinence symptoms did not improve in 12 patients (54.5\%). ${ }^{60}$

Still, the efficacy of SNM for the management of double incontinence depends on patient selection. For example, when the main indication for implantation is faecal incontinence, the results for urinary incontinence can be disappointing because patient selection has not been made according to these symptoms. As a result, the voiding symptoms may not necessarily have features suggesting improvement with SNM. Further prospective trials are needed to determine which patients with combined problems will most likely benefit.

\section{Pelvic pain}

Pelvic floor dysfunction if often associated with both voiding symptoms and pelvic pain symptoms. Hypertonia of the pelvic floor is a common source of pelvic pain and is also an important feature in the aetiology of lower urinary tract disorders. ${ }^{61}$ SNM has been postulated to inhibit inappropriate excitation of the pelvic floor muscles, therefore facilitating voiding by interrupting the outflow to

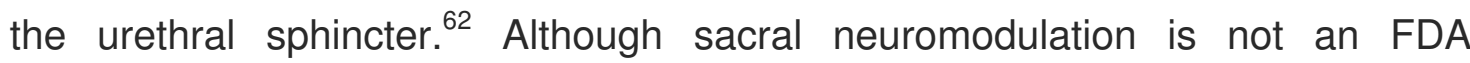
approved treatment for urological pain syndromes, several authors have reported on the 'off label' treatment of these conditions. Maher et al. prospectively evaluated the effect of test stimulation with PNE in 15 patients with interstitial cystitis who were unresponsive to standard oral or intravesical therapy. ${ }^{63}$ Besides an improvement in voiding symptoms, a significant reduction in mean bladder pain from 8.9 to 2.4 on a scale of 0 to 10 was reported. There was at least a $50 \%$ decrease in bladder pain in $87 \%$ of the cases and at least a $50 \%$ decrease in 24-hour urinary voiding in $47 \%$ after PNE. Everaert et al. 
performed a test stimulation in 26 patients after failure of conservative treatment for intractable chronic pelvic pain (including genital, urethral, inguinal and perineal pain) ${ }^{64}$ Significant pain relief was obtained in 16 patients (62\%). After a follow-up of 37 months, $73 \%$ of the implanted patients were satisfied with the treatment. Although these initial results seem promising, larger prospective trials are needed to determine the efficacy of SNM in the treatment of pelvic pain.

\section{MECHANISM OF ACTION}

Although the exact mechanism of SNM is not well understood, it seems to involve modulation of the spinal cord reflexes and brain networks by peripheral afferents, rather than direct stimulation of the motor response of the detrusor or urethral sphincter. ${ }^{36}$ In patients with overactive bladder, SNM is thought to inhibit detrusor activity without affecting urethral resistance or the strength of detrusor contractions during voiding. ${ }^{65}$ In patients with complete spinal cord injury, early bilateral SNM (initiated during the spinal shock phase) could prevent the development of detrusor overactivity. This might indicate modulation at the level of the spinal cord itself. ${ }^{66}$ Other studies suggested that SNM acts at a supraspinal level. PET-studies indicated that in the brain, the activity of centres involved in activation or inhibition of the micturition reflex, can be enhanced or reduced with SNM. ${ }^{67,68}$ This results in the activation or inhibition of lower urinary tract activity. Blok et al. compared the effect of acute and chronic SNM on brain activity by evaluating the regional cerebral blood flow with PET. ${ }^{69}$ Their findings suggested that acute SNM predominantly modulates areas involved in sensorimotor learning, whereas chronic SNM influences areas related to the awareness of bladder filling, the urge to void and the timing of micturition.

For urinary retention, different theories on the mechanism of action have been proposed. SNM has been postulated to suppress the guarding reflex, resulting in decreased urethral sphincter tone, and thereby facilitating voiding. Animal studies indicated that the guarding reflexes can be modulated by afferent nerve activation and inhibit bladder activity by spinal or supraspinal pathways. ${ }^{70,71}$ In contrast, the results of a study of 30 women with Fowler's syndrome showed that the maximum urethral closure pressure did not change significantly. Instead, the 
return of voiding ability seemed to be attributable to a small increase in detrusor contractility. ${ }^{72}$ In a recent study, functional MRI was used to evaluate brain responses to bladder filling in patients with Fowler's syndrome. ${ }^{73}$ The data showed abnormal brain responses in these patients, which are most likely caused by abnormally strong inhibition of the bladder afferents by overactivity of the urethral sphincter. The authors suggested that SNM acts at a sacral level, by blocking the urethral inhibition of afferent information from the bladder. Because the transmission of afferent information to the brain is restored, bladder sensations return as well as the ability to void.

A possible working mechanism for neuromodulation in the treatment of pain is based on the gate-control theory. This theory states that pain perception depends on a pattern of peripheral nervous input. It is assumed that a gatecontrol mechanism at the spinal segment level is present, which regulates the interaction between afferent nerve signals and pain sensation. ${ }^{74}$ Interneurons of the spinal cord dorsal horn create gating components, and inhibition or facilitation of afferent fibres modulates the input to the spinal transmission neurons. Furthermore, it is postulated that the impulses from the dorsal horn are controlled by a descending system containing fibres from the brainstem, thalamus and limbic lobes. ${ }^{75}$ Neuromodulation is supposed to restore the control at the spinal segmental 'gate' as well as at supraspinal sites such as the brainstem and the limbic system nuclei.

To summarize, the exact mechanism of action of SNM in the treatment of lower urinary tract dysfunction is complex, and still remains unclear. Most likely, it involves a combination of different modes of action, involving the neuroaxis at different levels. 


\section{NEUROMODULATION TECHNIQUE}

In sacral neuromodulation, one of the sacral nerves (usually S3) is stimulated with a quadripolar lead, which is positioned in the sacral foramen. The lead is connected to an implantable, reprogrammable device. The device can be implanted by creating a subcutaneous pocket in the lower abdomen or buttock. Patients are selected for SNM treatment based on their response to test stimulation with a temporary electrode (figure 2). ${ }^{1,2,76,77}$ During the test procedure, a needle is inserted into the third sacral foramen. Next, it is connected to an external stimulator and current is applied. Correct placement is confirmed by evaluating the sensory and motor responses to stimulation. Typical responses are: paraesthesia in the anal, vaginal or perineal area, contraction of the levator ani muscle, and flexion of the great toe on the ipsilateral side of stimulation. ${ }^{78} \mathrm{In}$ addition, correct position of the needle can be confirmed by fluoroscopy. When adequate responses have been obtained, the electrode is inserted through the needle and the needle is removed. In turn, the electrode is connected to an external stimulator. During the trial stimulation, which lasts for a minimum of 3 days, the response to sub-chronic stimulation can be evaluated.

Initially, test stimulation was performed with the "percutaneous nerve evaluation" (PNE), in which a basic wire electrode (Medtronic ${ }^{\mathrm{TM}}$ number 041828-004) is connected to an external stimulator. However, due to the high risk of lead migration, the test duration is rather limited and the reported success rate is between 40 and 50\%. ${ }^{2,79}$ In 1997, the two stage procedure was introduced, which aims at screening with the permanent electrode during a first stage. ${ }^{79,80}$ If the patient is considered eligible for definitive SNM, the implantable neurostimulator (INS) is inserted in a second stage. This procedure enables prolonged screening for up to one month, resulting in a success rate of approximately $80 \%$, which is significantly higher than with PNE testing. ${ }^{79,80}$

Originally, the permanent lead was implanted under direct vision and in turn secured to the sacral periosteum during an open surgical technique. ${ }^{81,82}$ Spinelli et al. introduced a self-anchoring "tined" lead in 2002, allowing percutaneous placement of the lead under radiological guidance (figure 3). ${ }^{83,84}$ Potential advantages of the tined lead include a shorter operation time, reduced risk of 
infection, less pain and shorter post-operative recovery time. In addition, the lead can be inserted under local anesthesia, enabling evaluation of the sensory responses to acute stimulation.

At the end of the test stimulation period, the patient is evaluated for symptom improvement by using voiding diaries. In patients with urinary retention, a pressure-flow urodynamic investigation is additionally used to evaluate adequate voiding. If the voiding diaries and urodynamics show significant improvement, patients are considered eligible for definitive SNM treatment. A permanent stimulator and lead are implanted in the subcutaneous area of the buttock. ${ }^{85}$ The permanent lead has four electrodes at the tip which can be used as an anode or cathode during stimulation. After implantation, the electrode settings (polarity) and stimulation parameters (amplitude, pulse rate and pulse width) are programmed and patients are taught how to use their personal programmer. Patients can turn their stimulator on and off, and are able to increase or decrease the amplitude within preset limits. The other stimulation parameters can only be altered by the physician. 
Figure 2. Percutaneous technique of lead implantation. A. After correct positioning of the patient, a test needle is used to probe and localise the third sacral foramen. B. A lead introducer is inserted over a guide wire to provide access for the test lead into the sacral foramen. $\mathbf{C}$. The guide wire is removed. $\mathbf{D}$. The test lead is inserted through the introducer, and the contact points of the electrode are tested by applying electrical current.

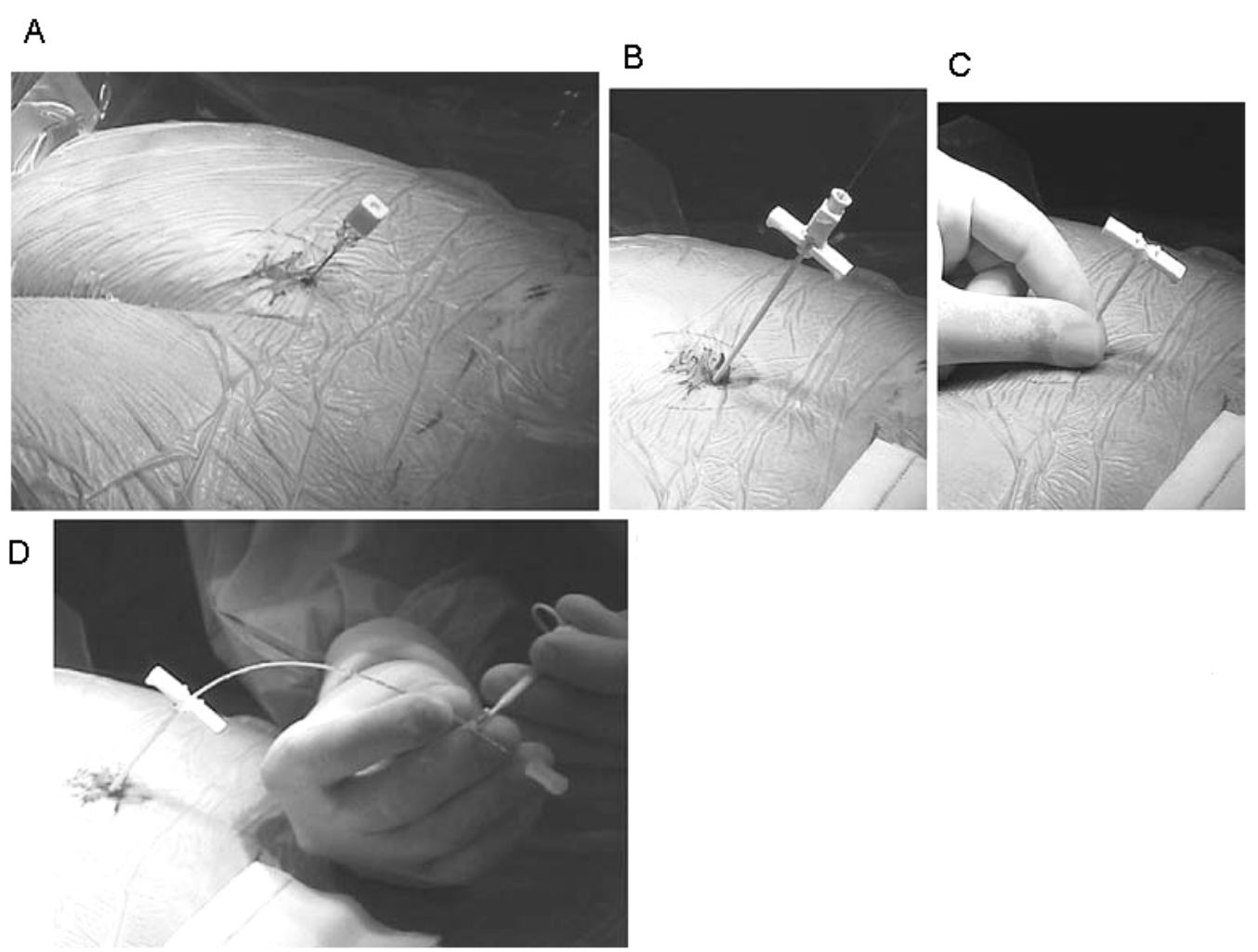

Figure 3. Tined lead. Due to silicone barbs ("tines") the lead is self-anchored in the subcutaneous tissue. The tines deploy after removal of the introducer.

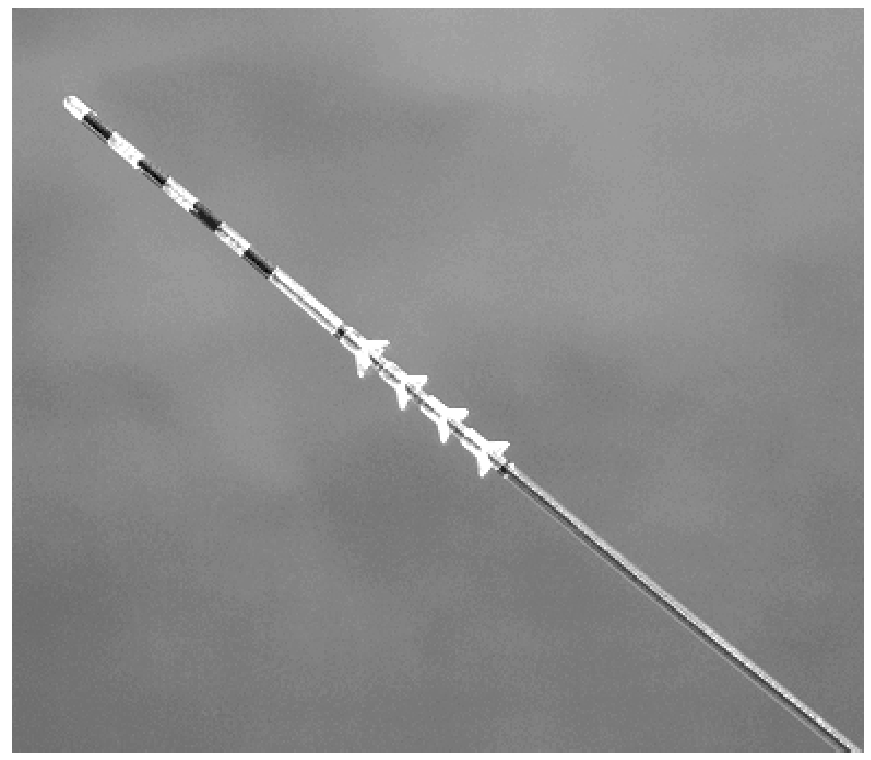




\section{CLINICAL RESULTS}

If more than $50 \%$ improvement in voiding symptoms is observed during the test period, patients are considered eligible candidates for SNM treatment. The voiding symptoms are measured by using voiding diaries, which are selfrecorded by the patient. Preceding the test stimulation, patients keep a voiding diary to assess baseline symptoms. By comparing the results of the voiding diary that is kept during test stimulation, the degree of improvement can be evaluated. Depending on the type of complaint, different primary voiding parameters are used to evaluate the clinical effect. In patients with urgency incontinence improvement of incontinence parameters is considered most important (number of leakages per day and the number of pads per day). In patients with urgency/frequency, the voiding frequency and voided volume per void are relevant parameters. In patients with chronic urinary retention, reduction in the volume per catheterization and increase in voided volume are considered relevant.

Numerous reports on the clinical efficacy of SNM have been published. In early studies on SNM by Tanagho et al., stimulation of the S3 root resulted in restoration of continence in patients with detrusor overactivity due to suprasacral spinal cord injury. ${ }^{14}$ In 1995, Bosch et al. evaluated 18 implanted patients with urgency incontinence. ${ }^{86}$ The voiding diaries of these patients showed a highly significant drop in leakage episodes and frequency, with a significant increase in the average voided volume. The number of pads used per day dropped significantly as well. The effect was durable, as 13 patients who were followed for more than 2 years maintained the same initial improvement. Similar results were shown by Elabaddy et al. and Shaker et al. ${ }^{87,88}$ In addition, early studies reported on the use of SNM for the restoration of voiding in patients with nonobstructive urinary retention. Thon et al. reported long-lasting improvement in $70 \%$ of 33 implanted patients. ${ }^{89}$ Shaker et al. and Jonas et al. also reported a high success rate in these patients. ${ }^{2,90}$

The long-term outcome of SNM has been assessed in several clinical trials. Table 1 presents an overview of a number of studies that evaluated the longterm efficacy. All studies showed that SNM treatment is safe and effective for 
patients with $\mathrm{OAB}$ as well as patients with urinary retention, and most studies showed a higher success rate in the retention group. The largest prospective study, including 17 centers worldwide, reported a long-term success rate of approximately $70 \%{ }^{5}$

Table 1. Long-term results of SNM treatment. Success of treatment was defined as the percentage of patients that had a successful outcome at last follow-up visit (more than $50 \%$ improvement in key voiding diary variables).

\begin{tabular}{lllll}
\hline Study & Year & $\begin{array}{l}\text { No. of } \\
\text { patients }\end{array}$ & $\begin{array}{l}\text { Success of } \\
\text { treatment \% }\end{array}$ & $\begin{array}{l}\text { Follow-up } \\
\text { (month) }\end{array}$ \\
\hline Siegel et al. ${ }^{1}$ & 2000 & 112 & 62 & 26 \\
Bosch et al. ${ }^{76}$ & 2000 & 45 & 60 & 47 \\
Dasgupta et al. ${ }^{91}$ & 2004 & 26 & 77 & 37 \\
Van Kerrebroeck et al. ${ }^{5}$ & 2007 & 105 & 70 & 49 \\
Sutherland et al. ${ }^{92}$ & 2007 & 104 & 69 & 22 \\
\hline
\end{tabular}

\section{FOLLOW-UP AND ADVERSE EVENTS}

Directly after implantation, the implantable neurostimulator (INS) is activated, and optimal stimulation settings are chosen. These settings are determined by evaluating the sensory response to different combinations. The tip of the implanted lead contains 4 stimulation points and each one can be used as a cathode or anode. Also, the case of the stimulator can be used as an anode, which results in unipolar type of stimulation. When the lead itself is used for both the cathode and anode, bipolar stimulation is the result. The stimulation setting (uni- or bipolar) that gives the best sensory response (anal, vaginal or perineal), at the lowest amplitude is considered optimal. The amplitude of stimulation is initially set just above sensory threshold. Not much is known about the optimal pulse rate with chronic stimulation. Although it is generally advised to set the pulse rate between $10-16 \mathrm{~Hz}$, the effect of different pulse rates on treatment 
efficacy has never been evaluated in clinical studies. This also applies for the pulse width, which is advised to set at $210 \mathrm{msec}$. Patients receive a 'patient programmer' which they can use to turn the INS on or off when necessary. Also, the programmer grants the ability to make small alterations in the stimulation amplitude. Patients are advised to keep the INS on both during the day and at night.

Patient follow-up after implantation of the neurostimulator is scheduled at 6 weeks, 6 months and yearly thereafter. During each follow-up visit, the stimulation parameters are checked in order to evaluate patient compliance and correct use of the patient programmer. Next, the impedance is measured. If the impedance is less than 50 Ohms or more than 4000 Ohms, there may be a short cut or an open circuit respectively. An abnormal impedance can be an indication for a broken wire, and a reoperation may be required to replace the damaged lead. In case of decreased efficacy, the impedances and battery life span are checked. When there are no signs of lead damage and the sensory response is preserved, parameter settings can be adjusted in attempt to restore efficacy. Different stimulation settings can be tried for 2 weeks. Also, an X-ray can be considered to rule out lead migration. If all these changes do not lead to any improvement, and all parameters and sensory responses are correct, it is often challenging to find a satisfactory solution. First of all, the patient's symptoms have to be re-evaluated to rule out other causes of therapy failure (e.g. stress incontinence, neurological disease), especially in patients who have been treated with SNM for several years. Subsequently, replacement of the lead or contralateral placement of a new lead can be considered. Before definitive placement of a new lead, a test stimulation can be conducted to assess the clinical response. Also, bilateral stimulation can be attempted. Although this has never been evaluated in clinical studies, data from animal studies suggest a stronger modulatory effect of bilateral stimulation ${ }^{93,94}$. If successful, a second device can be implanted and connected to the contralateral lead or a TWIN (Medtronic $^{\mathrm{TM}}$ ) stimulator can be used.

Pain after implantation is not uncommon, occurring in $24-34 \%$ after long-term follow-up. ${ }^{1,5,30}$ Pain can be located at the site of the INS or at the site where the stimulation sensation is perceived. The cause of the pain can be differentiated by 
turning the stimulator off. If pain symptoms persist, they are often a result of mechanical discomfort of the INS. If pain symptoms decrease, they are often stimulation-related. The physician can attempt to relieve pain symptoms by altering the stimulation settings. If no pain relief occurs, repositioning of the INS or lead can be necessary.

\section{AIM OF THIS THESIS}

Sacral neuromodulation (SNM) is a well-established treatment for patients with lower urinary tract dysfunction. Since SNM is a relatively young treatment modality, it is important to explore innovations that can improve treatment efficacy and patient comfort. This thesis focuses on the identification and assessment of new developments in SNM. Chapters 2 and 3 describe the results of a new, minimally-invasive implantation technique. In Chapter 2 the efficacy and safety of this new technique are evaluated including the long-term results and adverse events. Chapter 3 tries to find out whether the method of screening (PNE vs. TLP) has an influence on long-term outcome with SNM. In addition, the predictive value of different voiding diary parameters during test stimulation are evaluated. Chapter 4 investigates the role of various psychological factors (e.g. depression, anxiety, anger) in SNM. In addition, the impact of psychiatric comorbidity on treatment success is evaluated. Chapters 5 and 6 deal with technical aspects of SNM. Chapter 5 evaluates whether different pulse rate settings can improve treatment efficacy, whereas Chapter 6 investigates if bilateral stimulation of the sacral nerves can restore treatment efficacy in patients with failure after initial success. Finally, Chapter 7 explores the use of SNM as a new treatment for patients with chronic pelvic pain.

\section{REFERENCES}

1. Siegel SW, Catanzaro F, Dijkema HE, Elhilali MM, Fowler CJ, Gajewski JB, Hassouna MM, Janknegt RA, Jonas U, van Kerrebroeck PE, Lycklama a Nijeholt AA, Oleson KA and Schmidt RA: Long-term results of a multicenter study on sacral nerve 
stimulation for treatment of urinary urge incontinence, urgency-frequency, and retention. Urology. 56: 87-91, 2000.

2. Jonas U, Fowler CJ, Chancellor MB, Elhilali MM, Fall M, Gajewski JB, Grunewald V, Hassouna MM, Hombergh U, Janknegt R, van Kerrebroeck PE, Lylcklama a Nijeholt AA, Siegel SW and Schmidt RA: Efficacy of sacral nerve stimulation for urinary retention: results 18 months after implantation. J Urol. 165: 15-9, 2001.

3. Schmidt RA, Jonas U, Oleson KA, Janknegt RA, Hassouna MM, Siegel SW and van Kerrebroeck PE: Sacral nerve stimulation for treatment of refractory urinary urge incontinence. Sacral Nerve Stimulation Study Group. J Urol. 162: 352-7, 1999.

4. Van Kerrebroeck PE: A treatment algorithm for the overactive bladder. BJU Int. 83 Suppl 2: 29-30, 1999.

5. van Kerrebroeck PE, van Voskuilen AC, Heesakkers JP, Lycklama a Nijholt AA, Siegel S, Jonas U, Fowler CJ, Fall M, Gajewski JB, Hassouna MM, Cappellano F, Elhilali MM, Milam DF, Das AK, Dijkema HE and van den Hombergh U: Results of sacral neuromodulation therapy for urinary voiding dysfunction: outcomes of a prospective, worldwide clinical study. J Urol. 178: 2029-34, 2007.

6. Bullock $\mathrm{TH}$ : The future of research on electroreception and electrocommunication. $J$ Exp Biol. 202: 1455-8, 1999.

7. Saxtorph: Stricture urethrae - Fistula perinee - Retentio urinae. Clinsk Chirurgi, Gyldendalske Fortag Copenhagen: 265-80, 1878.

8. Katona F: Stages of vegatative afferentation in reorganization of bladder control during intravesical electrotherapy. Urol Int. 30: 192-203, 1975.

9. van Balken MR, Vergunst $\mathrm{H}$ and Bemelmans BL: The use of electrical devices for the treatment of bladder dysfunction: a review of methods. J Urol. 172: 846-51, 2004.

10. Ascoli R: [Treatment of Neurogenic Bladder.]. Acta Urol Belg. 33: 76-83, 1965.

11. Nashold BS, Jr., Friedman $\mathrm{H}$ and Boyarsky S: Electrical activation of micturition by spinal cord stimulation. J Surg Res. 11: 144-7, 1971.

12. Jonas U, Heine JP and Tanagho EA: Studies on the feasibility of urinary bladder evacuation by direct spinal cord stimulation. I. Parameters of most effective stimulation. Invest Urol. 13: 142-50, 1975.

13. Schmidt RA, Bruschini $H$ and Tanagho EA: Sacral root stimulation in controlled micturition. Peripheral somatic neurotomy and stimulated voiding. Invest Urol. 17: 130-4, 1979.

14. Tanagho EA, Schmidt RA and Orvis BR: Neural stimulation for control of voiding dysfunction: a preliminary report in 22 patients with serious neuropathic voiding disorders. J Urol. 142: 340-5, 1989.

15. Abrams P, Andersson KE, Birder L, Brubaker L, Cardozo L, Chapple C, Cottenden A, Davila W, de Ridder D, Dmochowski R, Drake M, Dubeau C, Fry C, Hanno P, Smith JH, Herschorn S, Hosker G, Kelleher C, Koelbl H, Khoury S, Madoff R, Milsom I, 
Moore K, Newman D, Nitti V, Norton C, Nygaard I, Payne C, Smith A, Staskin D, Tekgul S, Thuroff J, Tubaro A, Vodusek D, Wein A and Wyndaele JJ: Fourth International Consultation on Incontinence Recommendations of the International Scientific Committee: Evaluation and treatment of urinary incontinence, pelvic organ prolapse, and fecal incontinence. Neurourol Urodyn. 29: 213-40.

16. Milsom I, Abrams P, Cardozo L, Roberts RG, Thuroff $\mathrm{J}$ and Wein AJ: How widespread are the symptoms of an overactive bladder and how are they managed? A population-based prevalence study. BJU Int. 87: 760-6, 2001.

17. Stewart WF, Van Rooyen JB, Cundiff GW, Abrams P, Herzog AR, Corey R, Hunt TL and Wein AJ: Prevalence and burden of overactive bladder in the United States. World J Urol. 20: 327-36, 2003.

18. Bump RC and Norton PA: Epidemiology and natural history of pelvic floor dysfunction. Obstet Gynecol Clin North Am. 25: 723-46, 1998.

19. Grimby A, Milsom I, Molander U, Wiklund I and Ekelund P: The influence of urinary incontinence on the quality of life of elderly women. Age Ageing. 22: 82-9, 1993.

20. Temml C, Haidinger G, Schmidbauer J, Schatzl G and Madersbacher S: Urinary incontinence in both sexes: prevalence rates and impact on quality of life and sexual life. Neurourol Urodyn. 19: 259-71, 2000.

21. Elbadawi A, Yalla SV and Resnick NM: Structural basis of geriatric voiding dysfunction. III. Detrusor overactivity. J Urol. 150: 1668-80, 1993.

22. Karram MM, Partoll $L$ and Rahe J: Efficacy of nonsurgical therapy for urinary incontinence. J Reprod Med. 41: 215-9, 1996.

23. Robert M, Ross S, Farrel SA, Easton WA, Epp A, Girouard L, Gupta C, Lajoie F, Lovatsis D, MacMillan B, Schachter J, Schulz J and Wilkie DH: Conservative management of urinary incontinence. J Obstet Gynaecol Can. 28: 1113-25, 2006.

24. Resnick NM: Improving treatment of urinary incontinence. Jama. 280: 2034-5, 1998.

25. Sutherland SE and Goldman HB: Treatment options for female urinary incontinence. Med Clin North Am. 88: 345-66, 2004.

26. Sahai A, Khan MS and Dasgupta P: Efficacy of botulinum toxin-A for treating idiopathic detrusor overactivity: results from a single center, randomized, doubleblind, placebo controlled trial. J Urol. 177: 2231-6, 2007.

27. Brubaker L, Richter HE, Visco A, Mahajan S, Nygaard I, Braun TM, Barber MD, Menefee S, Schaffer J, Weber AM and Wei J: Refractory idiopathic urge urinary incontinence and botulinum A injection. J Urol. 180: 217-22, 2008.

28. Flynn MK, Amundsen CL, Perevich M, Liu F and Webster GD: Outcome of a randomized, double-blind, placebo controlled trial of botulinum $A$ toxin for refractory overactive bladder. J Urol. 181: 2608-15, 2009. 
29. Scheepens WA, Jongen MMGJ, Nieman FHM, de Bie RA, Weil EHJ and van Kerrebroeck PEV: Predictive factors for sacral neuromodulation in chronic lower urinary tract dysfunction. Urology. 60: 598, 2002.

30. Everaert K, De Ridder D, Baert L, Oosterlinck W and Wyndaele JJ: Patient satisfaction and complications following sacral nerve stimulation for urinary retention, urge incontinence and perineal pain: a multicenter evaluation. Int Urogynecol J Pelvic Floor Dysfunct. 11: 231-5; discussion 236, 2000.

31. Koldewijn EL, P. F. Rosier, et al.: Predictors of success with neuromodulation in lower urinary tract dysfunction: results of trial stimulation in 100 patients. J Urology. 152: 2071-2075., 1994.

32. Groenendijk PM, Heesakkers JP and Lycklama ANAA: Urethral instability and sacral nerve stimulation-a better parameter to predict efficacy? J Urol. 178: 568-72; discussion 572, 2007.

33. Amundsen CL, Romero AA, Jamison MG and Webster GD: Sacral neuromodulation for intractable urge incontinence: are there factors associated with cure? Urology. 66: 746-50, 2005.

34. Govaert B, Melenhorst J, Nieman FH, Bols EM, van Gemert WG and Baeten CG: Factors associated with percutaneous nerve evaluation and permanent sacral nerve modulation outcome in patients with fecal incontinence. Dis Colon Rectum. 52: 168894, 2009.

35. Gourcerol G, Gallas S, Michot F, Denis P and Leroi AM: Sacral nerve stimulation in fecal incontinence: are there factors associated with success? Dis Colon Rectum. 50: 3-12, 2007.

36. Kessler TM and Fowler CJ: Sacral neuromodulation for urinary retention. Nat Clin Pract Urol. 5: 657-66, 2008.

37. Swinn MJ and Fowler CJ: Isolated urinary retention in young women, or Fowler's syndrome. Clin Auton Res. 11: 309-11, 2001.

38. Minassian VA, Lovatsis D, Pascali D, Alarab M and Drutz HP: Effect of childhood dysfunctional voiding on urinary incontinence in adult women. Obstet Gynecol. 107: 1247-51, 2006.

39. Tanagho EA and Schmidt RA: Electrical stimulation in the clinical management of the neurogenic bladder. J Urol. 140: 1331-9, 1988.

40. Kessler TM, Buchser E, Meyer S, Engeler DS, Al-Khodairy AW, Bersch U, Iselin CE, Roche B, Schmid DM, Schurch B, Zrehen S and Burkhard FC: Sacral neuromodulation for refractory lower urinary tract dysfunction: results of a nationwide registry in Switzerland. Eur Urol. 51: 1357-63, 2007.

41. Bertapelle $\mathrm{P}$, Bodo $\mathrm{G}$ and Carone R: Detrusor acontractility in urinary retention: detrusor contractility test as exclusion criteria for sacral neurostimulation. J Urol. 180: 215-6, 2008. 
42. Swinn MJ, Kitchen ND, Goodwin RJ and Fowler CJ: Sacral neuromodulation for women with Fowler's syndrome. Eur Urol. 38: 439-43, 2000.

43. Schmidt RA and Doggweiler R: Neurostimulation and neuromodulation: a guide to selecting the right urologic patient. Eur Urol. 34 Suppl 1: 23-6, 1998.

44. Schurch B, Reilly I, Reitz A and Curt A: Electrophysiological recordings during the peripheral nerve evaluation (PNE) test in complete spinal cord injury patients. World $\mathrm{J}$ Urol. 20: 319-22, 2003.

45. Roth TM: Sacral neuromodulation and lower urinary tract dysfunction in cerebral palsy. Int Urogynecol J Pelvic Floor Dysfunct. 18: 567-9, 2007.

46. Wallace PA, Lane FL and Noblett KL: Sacral nerve neuromodulation in patients with underlying neurologic disease. Am J Obstet Gynecol. 197: 96 e1-5, 2007.

47. Marinkovic SP and Gillen LM: Sacral neuromodulation for multiple sclerosis patients with urinary retention and clean intermittent catheterization. Int Urogynecol J Pelvic Floor Dysfunct. 21: 223-8, 2009.

48. Chartier-Kastler EJ, Ruud Bosch JL, Perrigot M, Chancellor MB, Richard F and Denys $P$ : Long-term results of sacral nerve stimulation (S3) for the treatment of neurogenic refractory urge incontinence related to detrusor hyperreflexia. J Urol. 164: 1476-80, 2000.

49. Lombardi $G$ and Del Popolo G: Clinical outcome of sacral neuromodulation in incomplete spinal cord injured patients suffering from neurogenic lower urinary tract symptoms. Spinal Cord. 47: 486-91, 2009.

50. Hohenfellner M, Humke J, Hampel C, Dahms S, Matzel K, Roth S, Thuroff JW and Schultz-Lampel D: Chronic sacral neuromodulation for treatment of neurogenic bladder dysfunction: long-term results with unilateral implants. Urology. 58: 887-92, 2001.

51. Kessler TM, La Framboise D, Trelle S, Fowler CJ, Kiss G, Pannek J, Schurch B, Sievert KD and Engeler DS: Sacral Neuromodulation for Neurogenic Lower Urinary Tract Dysfunction: Systematic Review and Meta-analysis. Eur Urol, 2010.

52. Melenhorst J, Koch SM, Uludag O, van Gemert WG and Baeten CG: Sacral neuromodulation in patients with faecal incontinence: results of the first 100 permanent implantations. Colorectal Dis. 9: 725-30, 2007.

53. Kenefick $\mathrm{NJ}$ : Sacral nerve neuromodulation for the treatment of lower bowel motility disorders. Ann R Coll Surg Engl. 88: 617-23, 2006.

54. Matzel KE, Kamm MA, Stosser M, Baeten CG, Christiansen J, Madoff R, Mellgren A, Nicholls RJ, Rius $\mathrm{J}$ and Rosen $\mathrm{H}$ : Sacral spinal nerve stimulation for faecal incontinence: multicentre study. Lancet. 363: 1270-6, 2004.

55. Jarrett ME, Mowatt G, Glazener CM, Fraser C, Nicholls RJ, Grant AM and Kamm MA: Systematic review of sacral nerve stimulation for faecal incontinence and constipation. Br J Surg. 91: 1559-69, 2004. 
56. Kenefick NJ, Nicholls RJ, Cohen RG and Kamm MA: Permanent sacral nerve stimulation for treatment of idiopathic constipation. Br J Surg. 89: 882-8, 2002.

57. Malouf AJ, Wiesel PH, Nicholls T, Nicholls RJ and Kamm MA: Short-term effects of sacral nerve stimulation for idiopathic slow transit constipation. World J Surg. 26: 16670, 2002.

58. Ganio E, Masin A, Ratto C, Altomare DF, Ripetti V, Clerico G, Lise M, Doglietto GB, Memeo V, Landolfi V, Del Genio A, Arullani A, Giardiello G and de Seta F: Short-term sacral nerve stimulation for functional anorectal and urinary disturbances: results in 40 patients: evaluation of a new option for anorectal functional disorders. Dis Colon Rectum. 44: 1261-7, 2001.

59. Uludag O, Koch SM, van Gemert WG, Dejong $\mathrm{CH}$ and Baeten CG: Sacral neuromodulation in patients with fecal incontinence: a single-center study. Dis Colon Rectum. 47: 1350-7, 2004.

60. El-Gazzaz G, Zutshi M, Salcedo L, Hammel J, Rackley R and Hull T: Sacral neuromodulation for the treatment of fecal incontinence and urinary incontinence in female patients: long-term follow-up. Int J Colorectal Dis. 24: 1377-81, 2009.

61. Butrick CW: Pathophysiology of pelvic floor hypertonic disorders. Obstet Gynecol Clin North Am. 36: 699-705, 2009.

62. Leng WW and Chancellor MB: How sacral nerve stimulation neuromodulation works. Urol Clin North Am. 32: 11-8, 2005.

63. Maher CF, Carey MP, Dwyer PL and Schluter PL: Percutaneous sacral nerve root neuromodulation for intractable interstitial cystitis. The Journal of Urology. 165: 884886, 2001.

64. Everaert K, Devulder J, De Muynck M, Stockman S, Depaepe H, De Looze D, Van Buyten $\mathrm{J}$ and Oosterlinck W: The Pain Cycle: Implications for the Diagnosis and Treatment of Pelvic Pain Syndromes. International Urogynecology Journal. 12: 9-14, 2001.

65. Groen J, Ruud Bosch JL and van Mastrigt R: Sacral neuromodulation in women with idiopathic detrusor overactivity incontinence: decreased overactivity but unchanged bladder contraction strength and urethral resistance during voiding. J Urol. 175: 10059; discussion 1009, 2006.

66. Sievert KD, Amend B, Gakis G, Toomey P, Badke A, Kaps HP and Stenzl A: Early sacral neuromodulation prevents urinary incontinence after complete spinal cord injury. Ann Neurol. 67: 74-84, 2010.

67. Blok BF: Central pathways controlling micturition and urinary continence. Urology. 59: 13-7, 2002.

68. Dasgupta R, Critchley HD, Dolan RJ and Fowler CJ: Changes in brain activity following sacral neuromodulation for urinary retention. J Urol. 174: 2268-72, 2005. 
69. Blok BF, Groen J, Bosch JL, Veltman DJ and Lammertsma AA: Different brain effects during chronic and acute sacral neuromodulation in urge incontinent patients with implanted neurostimulators. BJU Int. 98: 1238-43, 2006.

70. De Groat WC and Ryall RW: Recurrent inhibition in sacral parasympathetic pathways to the bladder. J Physiol. 196: 579-91, 1968.

71. de Groat WC: Mechanisms underlying recurrent inhibition in the sacral parasympathetic outflow to the urinary bladder. J Physiol. 257: 503-13, 1976.

72. DasGupta R and Fowler CJ: Urodynamic study of women in urinary retention treated with sacral neuromodulation. J Urol. 171: 1161-4, 2004.

73. Kavia R, Dasgupta R, Critchley H, Fowler C and Griffiths D: A functional magnetic resonance imaging study of the effect of sacral neuromodulation on brain responses in women with Fowler's syndrome. BJU Int. 105: 366-72, 2010.

74. Melzack R and Wall PD: Pain mechanisms: a new theory. Science. 150: 971-9, 1965.

75. van der Pal F, Heesakkers JP and Bemelmans BL: Current opinion on the working mechanisms of neuromodulation in the treatment of lower urinary tract dysfunction. Curr Opin Urol. 16: 261-7, 2006.

76. Bosch JL and Groen J: Sacral nerve neuromodulation in the treatment of patients with refractory motor urge incontinence: long-term results of a prospective longitudinal study. J Urol. 163: 1219-22, 2000.

77. Hassouna MM, Siegel SW, Nyeholt AA, Elhilali MM, van Kerrebroeck PE, Das AK, Gajewski JB, Janknegt RA, Rivas DA, Dijkema H, Milam DF, Oleson KA and Schmidt RA: Sacral neuromodulation in the treatment of urgency-frequency symptoms: a multicenter study on efficacy and safety. J Urol. 163: 1849-54, 2000.

78. Schmidt RA, Senn E and Tanagho EA: Functional evaluation of sacral nerve root integrity. Report of a technique. Urology. 35: 388-92, 1990.

79. Janknegt RA, Weil EH and Eerdmans PH: Improving neuromodulation technique for refractory voiding dysfunctions: two-stage implant. Urology. 49: 358-62, 1997.

80. Kessler TM, Madersbacher H and Kiss G: Prolonged sacral neuromodulation testing using permanent leads: a more reliable patient selection method? Eur Urol. 47: 660-5, 2005.

81. Grunewald V, Hofner K, Thon WF, Kuczyk MA and Jonas U: Sacral electrical neuromodulation as an alternative treatment option for lower urinary tract dysfunction. Restor Neurol Neurosci. 14: 189-193, 1999.

82. Schmidt RA: Advances in genitourinary neurostimulation. Neurosurgery. 19: 1041-4, 1986.

83. Spinelli M, Giardiello G, Gerber M, Arduini A, van den Hombergh U and Malaguti S: New sacral neuromodulation lead for percutaneous implantation using local anesthesia: description and first experience. J Urol. 170: 1905-7, 2003. 
84. Spinelli M, Weil E, Ostardo E, Del Popolo G, Ruiz-Cerda JL, Kiss G and Heesakkers $\mathrm{J}$ : New tined lead electrode in sacral neuromodulation: experience from a multicentre European study. World J Urol. 23: 225-9, 2005.

85. Scheepens WA, Weil EH, van Koeveringe GA, Rohrmann D, Hedlund HE, Schurch B, Ostardo E, Pastorello M, Ratto C, Nordling J and van Kerrebroeck PE: Buttock placement of the implantable pulse generator: a new implantation technique for sacral neuromodulation--a multicenter study. Eur Urol. 40: 434-8, 2001.

86. Bosch JL and Groen J: Sacral (S3) segmental nerve stimulation as a treatment for urge incontinence in patients with detrusor instability: results of chronic electrical stimulation using an implantable neural prosthesis. J Urol. 154: 504-7, 1995.

87. Shaker HS and Hassouna M: Sacral nerve root neuromodulation: an effective treatment for refractory urge incontinence. J Urol. 159: 1516-9, 1998.

88. Elabbady AA, Hassouna MM and Elhilali MM: Neural stimulation for chronic voiding dysfunctions. J Urol. 152: 2076-80, 1994.

89. Thon WF, Baskin LS, Jonas U, Tanagho EA and Schmidt RA: Neuromodulation of voiding dysfunction and pelvic pain. World J Urol. 9, 1991.

90. Shaker HS and Hassouna M: Sacral root neuromodulation in idiopathic nonobstructive chronic urinary retention. J Urol. 159: 1476-8, 1998.

91. Dasgupta R, Wiseman OJ, Kitchen $\mathrm{N}$ and Fowler $\mathrm{CJ}$ : Long-term results of sacral neuromodulation for women with urinary retention. BJU Int. 94: 335-7, 2004.

92. Sutherland SE, Lavers A, Carlson A, Holtz C, Kesha J and Siegel SW: Sacral nerve stimulation for voiding dysfunction: One institution's 11-year experience. Neurourol Urodyn. 26: 19-28; discussion 36, 2007.

93. Schultz-Lampel D: Neurophysiologische Grundlagen und Klinische Anwendung der sakralen Neuromodulation zur Therapie der Blasenfunctionsstörungen: Klinik für Urologie und Kinderurologie. Wuppertal, Universität Witten/Herdecke, 1997.

94. Kaufmann S, Naumann CM, Hamann MF, Seif C, Braun PM, Junemann KP and van der Horst C: Unilateral vs bilateral sacral neuromodulation in pigs with formalininduced detrusor hyperactivity. BJU Int. 103: 260-3, 2009. 


\section{LONG-TERM RESULTS OF SACRAL NEUROMODULATION WITH THE TINED LEAD PROCEDURE}

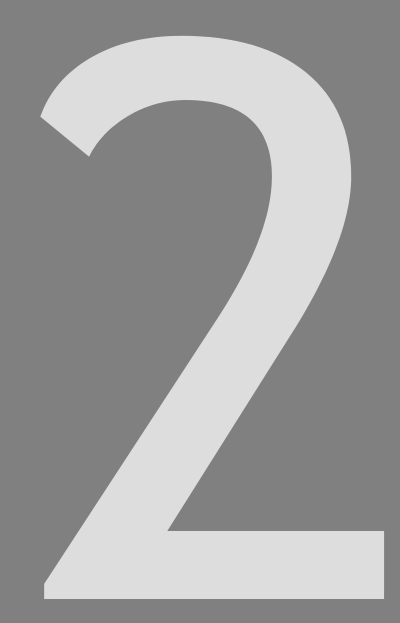

T. Marcelissen

R. Leong

R. de Bie

P. Van Kerrebroeck

S. De Wachter

J Urol. 2010 Nov;184(5):1997-2000 


\section{ABSTRACT}

Purpose: To present long-term follow-up data on the outcome of sacral neuromodulation using the tined lead procedure.

Materials and Methods: Single center study including all patients who received an implantable neurostimulator (INS) between 2002 and 2005 using the tined lead technique. Treatment efficacy was evaluated by comparing the data of a three-day voiding diary filled out in May 2009 to the data before the onset of SNM treatment (baseline). Clinical success was defined as $>50 \%$ improvement in at least one of the relevant voiding diary parameters.

Results: Sixty-four patients were implanted with an INS using the tined lead. The mean follow-up was 53 months (range 35-77 months). Five patients died of causes unrelated to SNM, and were not included in the analysis. Seven patients underwent INS removal and three patients stopped using their INS. Voiding diary analysis showed that 38 of the 59 patients (64\%) were successfully treated. Twenty-one patients (33\%) underwent a surgical revision due to an adverse event. One patient (1.6\%) underwent lead revision because of suspected lead migration.

Conclusion: Sacral neuromodulation with the tined lead procedure is a safe and effective treatment for patients with overactive bladder symptoms or urinary retention. 


\section{INTRODUCTION}

Sacral neuromodulation (SNM) is an accepted treatment option for patients with idiopathic overactive bladder syndrome $(\mathrm{OAB})$ or chronic non-obstructive urinary retention who are refractory to conservative treatment. ${ }^{1-3}$ Since FDA approval in 1997, an increasing number of patients have been treated with SNM. Initially, the permanent lead was implanted by an open surgical technique, with an incision being made in the midline over the sacrum and the lead placed under direct vision into the sacral foramen. The lead was then secured with a suture to the sacral periosteum. The long-term success rate for this initial procedure is reported to be $60-70 \%{ }^{4-6}$

In 2002, a new technique was introduced, which enabled percutaneous placement of a self-anchoring, tined silicone lead. ${ }^{7,8}$ This lead can be easily placed in the third sacral foramen under radiologic guidance. Potential advantages of the tined lead procedure (TLP) include a shorter operation time, reduced risk of infection, less pain and shorter post-operative recovery time. In addition, the lead can be inserted under local anesthesia, enabling evaluation of the sensory responses to acute stimulation.

Short-term studies showed a decrease in the numbers of adverse events and the occurrence of lead migration with TLP. ${ }^{9,10}$ However, the efficacy and number of adverse events in the long-term are currently unevaluated.

The primary objective of this study was to assess the long-term efficacy and adverse events of SNM with the tined lead procedure. A Secondary objective was to correlate the degree of improvement during test stimulation with longterm outcome.

\section{METHODS}

This single center observational study included all patients that were screened for SNM therapy between 2002 and 2005. The study was approved by the ethical committee and all participants signed an informed consent. Patients included are those with idiopathic $O A B$ symptoms, with ( $O A B$ wet) or without incontinence $(O A B$ dry) and patients with chronic non-obstructive urinary 
retention. All were refractory to conservative treatments or could not tolerate the side effects. All patients in the retention group performed clean intermittent catheterization, and had $>100 \mathrm{ml}$ residual volume. None had signs of anatomical obstruction.

Patients received an implantable neurostimulator (INS) after showing a successful response to PNE or first stage tined lead screening tests. Success was defined as more than $50 \%$ improvement in at least one of the relevant voiding diary parameters compared to baseline. For OAB wet patients these included: a reduction in the daily episodes of incontinence or pad usage, for OAB dry patients: a reduction in the number of daily voids or an increase in voided volume per void, and for patients with non-obstructive urinary retention: a reduction in the number of daily catheterizations or increase in voided volume.

Between 2002 and 2005 all patients were initially screened with a PNE test, unless they were at high risk for lead migration (for instance, patients who were obese or underweight). Patients who showed a negative response to PNE were additionally screened with TLP. The tined lead placement was executed as previously described $^{7,8}$. The lead (Model 3889, Medtronic) was placed in the left or right S3 foramen with the help of fluoroscopy. All procedures were performed under local anesthesia in an outpatient setting.

After implantation, patients visited the outpatient clinic after 6 weeks, 6 months and yearly thereafter. In case of decreased efficacy, the impedances and battery life span were checked. Parameter settings were adjusted in an attempt to restore efficacy. In case of permanent loss of efficacy, electrode position and cable integrity were checked using fluoroscopy. Adverse events and reoperations were reported for all implanted cases.

In May 2009, all patients who were still using their INS were asked to keep a voiding diary to record the effect of SNM on urinary symptoms. SNM therapy was considered successful if $50 \%$ or more improvement was noted compared to baseline in any of the primary voiding diary variables. The variables at baseline and follow-up were compared using the Wilcoxon signed rank test. Patients who were explanted or discontinued SNM therapy were considered unsuccessful and were assumed to return to baseline symptoms. 


\section{RESULTS}

\section{Screening and follow-up}

Between 2002 and 2005, 92 patients were screened for SNM, of which 64 (70\%) responded successfully and received an INS using the tined lead. Of the 64 patients, 53 were female and 11 were male with a mean age of 49 years (range 22-75, SD 12). Table 1 shows an overview of the follow-up of all 64 patients. Five patients died during follow-up of causes unrelated to neuromodulation. These patients were not included in the evaluation of treatment efficacy, since no objective data could be obtained. Of the remaining 59 patients, 45 had overactive bladder syndrome (40 OAB wet and $5 \mathrm{OAB}$ dry), and 14 had nonobstructive urinary retention.

By May 2009, 49 of 59 patients were still using their INS. Seven patients had the INS explanted: one due to psychiatric reasons, one due to repeated need for MRI-evaluation, three due to loss of efficacy (one after a vaginal wall correction and two after minor trauma), and two patients because of persistent stimulation related pain. Three patients turned their INS off permanently: two due to loss of efficacy and one after trauma requiring a suprapubic catheter due to reduced mobility. These patients preferred not to undergo INS removal.

Table 1. Overview of the long-term results for all 64 patients divided into 3 subgroups: OAB wet, $\mathrm{OAB}$ dry and urinary retention. $V D=$ voiding diary.

\begin{tabular}{llllll}
\hline Group & Died & $\begin{array}{l}\text { Explant/ } \\
\text { stimulator } \\
\text { off }\end{array}$ & $\begin{array}{l}<50 \% \\
\text { improvement in } \\
\text { VD }\end{array}$ & $\begin{array}{l}>50 \% \\
\text { improvement in } \\
\text { VD }\end{array}$ & Total \\
\hline OAB wet & 3 & 6 & 9 & 25 & $43(67 \%)$ \\
OAB dry & 1 & 0 & 1 & 4 & $6(9 \%)$ \\
Retention & 1 & 4 & 1 & 9 & $15(24 \%)$ \\
Total & $5(8 \%)$ & $10(16 \%)$ & $11(17 \%)$ & $38(59 \%)$ & $64(100 \%)$ \\
\hline
\end{tabular}




\section{Voiding diary analysis}

The voiding diary was filled out by 49 patients. Patients who were explanted or turned their INS off were assumed to return to baseline symptoms. The mean follow-up was 51 months (range 35-74, SD 11). The changes in voiding diary parameters for each sub-group are illustrated in table 2.

Table 2. The results of voiding diary analysis at baseline, test stimulation and in May 2009 (follow-up) are illustrated for each subgroup. Patients who were explanted or turned their INS off were assumed to return to baseline symptoms. $S D=$ standard deviation. Statistical significant differences in the parameters between baseline and test stimulation or follow-up are indicated with * $(p<0.05)$ and ${ }^{* *}(p<0.01)$.

\begin{tabular}{|c|c|c|c|}
\hline & Baseline & Test stimulation & Follow-up \\
\hline$O A B$ wet $(n=40)$ & Mean (SD) & Mean (SD) & Mean (SD) \\
\hline voided volume/void (ml) & $151(70)$ & $228(68)^{\star \star}$ & $183(72)^{*}$ \\
\hline number of voids/day & $11.2(6.1)$ & $7.7(3.3)^{*}$ & $9.2(3.6)$ \\
\hline number of leakages/day & $7.7(5.0)$ & $2.1(2.1)^{\star *}$ & $4.0(3.8)^{* *}$ \\
\hline number of pads/day & $4.6(3.0)$ & $0.7(0.8)^{* \star}$ & $2.3(2.8)^{\star *}$ \\
\hline \multicolumn{4}{|l|}{ OAB dry $(n=5)$} \\
\hline voided volume/void (ml) & $131(17)$ & $231(28)^{*}$ & $195(35)^{\star}$ \\
\hline number of voids/day & $16.5(2.3)$ & $7.0(1.4)^{*}$ & $9.1(3.2)^{*}$ \\
\hline number of leakages/day & $0.0(0.0)$ & $0(0.0)$ & $0.0(0.0)$ \\
\hline \multicolumn{4}{|l|}{ Retention $(n=14)$} \\
\hline voided volume/void (ml) & $96(101)$ & $267(109)^{* *}$ & $203(126)^{\star *}$ \\
\hline number of voids/day & $4.2(3.5)$ & $6.8(2.3)^{\star}$ & $5.9(2.8)^{*}$ \\
\hline number of cath/day & $4.7(2.0)$ & $4.5(2.1)$ & $1.9(2.8)^{\star *}$ \\
\hline
\end{tabular}

\section{Safety and complications}

Adverse events and re-operations were evaluated for all 64 patients. No serious or life-threatening adverse events occurred. In three patients a haematoma was seen perioperatively, which was treated with antibiotics. One patient developed a wound infection which required INS removal. Postoperatively, 23 re-operations were performed in 21 patients (33\% re-operation rate). In seven patients the INS was removed, in another seven the INS was repositioned for pain at the INS site 
and five required a lead revision (one due to lead migration, three due to decreased efficacy and one due to pain). In four patients the INS had to be replaced because of battery depletion. The mean follow-up before battery replacement was 62.3 months (range 49-75).

Seventeen patients (27\%) reported pain during follow-up. Pain at the site of the INS was reported most commonly, followed by pain caused by bothersome stimulation. Nine of these patients were treated by changing the stimulation parameters. The remaining eight patients required a surgical intervention, as reprogramming the INS was insufficient. Readjustment of stimulation parameters was evaluated for each patient since implantation. The mean number of reprogramming sessions was 2.8 per patient ( 0.7 per year), and the most common reasons were loss of efficacy and painful stimulation. Eleven patients $(17 \%)$ did not require any readjustment of the parameters, 41 patients $(66 \%)$ required up to five reprogramming visits, and 12 patients $(17 \%)$ required more than five reprogramming visits. Of the latter, none were successfully treated by merely adjustment of the stimulation parameters.

\section{DISCUSSION}

Due to the introduction of the TLP, sacral neuromodulation has become a minimally invasive treatment for patients with overactive bladder syndrome or urinary retention. Although some advantages of this new technique have been demonstrated in short-term trials, the efficacy of treatment and the sufficiency of lead fixation in the long-term are unclear. In our study, we found a success rate of $64 \%$ (38 of 59 implanted patients), which is comparable to previous long-term studies evaluating the non-tined lead. ${ }^{4-6}$ This suggests that the minimally invasive nature of the TLP does not decrease treatment efficacy. However, it does permit adequate placement of the lead to be performed under local anesthesia using guidance by both fluoroscopy and clinical sensory and motor responses.

The number of adverse events appears to decrease with the TLP compared to the non tined lead, since in the current study electrode migration was seen in 
only one patient (1.6\%). Long-term studies conducted before the introduction of the tined lead showed electrode migration rates between $6.7 \%$ and $27 \%$. $^{4-6,11}$ The low rate of electrode migration in our study could be a result of better electrode fixation with the new tined lead technique, and similar results were previously shown in short-term studies with the TLP. ${ }^{10,12,13}$

The number of patients requiring surgery due to an adverse event was $33 \%$, which is only slightly lower than reported revision rates using the non-tined lead, which range from $38 \%$ to $40 \% .^{4-6}$ Comparison between the different studies may be difficult due to differences in patient selection and surgical procedures. Furthermore, replacement of the INS due to battery depletion was included in the number of adverse events in our study. A long-term study conducted in our centre using the non-tined lead showed a revision rate of $48 \%{ }^{11}$ The new tined lead technique therefore seems to result in a lower revision rate, mostly due to a decrease in the number of infections and lead migrations.

In 1999, the location of INS placement was changed from the lower abdomen to the buttock, which facilitated the surgical procedure and was thought to reduce device related pain. ${ }^{14}$ In the current study, each INS was placed in the buttock, but still the operation rate for repositioning the INS due to pain $(11 \%)$ was almost similar to the rate $(12 \%)$ reported in a worldwide long-term study using the initial technique. ${ }^{4}$ Therefore, it is questionable if buttock placement actually decreases device-related pain.

Since no true algorithm exists for adjustment of the stimulation parameters, the number of reprogramming visits in our study varied per patient. Most patients $(82 \%)$ required one or more reprogramming sessions. In all patients who had more than five reprogramming visits, parameter adjustment failed to resolve the adverse event. Therefore, in our opinion, performing more than five reprogramming visits for the same adverse event seems ineffective.

\section{CONCLUSION}

Long-term sacral neuromodulation with the tined lead is a safe and effective treatment for patients with overactive bladder symptoms or urinary retention. Using the tined lead appears to reduce the occurrence of lead migration, but 
does not increase the long-term success rate when compared to previous reports using the non-tined lead.

\section{REFERENCES}

1. Hasan ST, Robson WA, Pridie AK and Neal DE: Transcutaneous electrical nerve stimulation and temporary S3 neuromodulation in idiopathic detrusor instability. J Urol. 155: 2005-11, 1996.

2. Jonas U, Fowler CJ, Chancellor MB, Elhilali MM, Fall M, Gajewski JB, Grunewald V, Hassouna MM, Hombergh U, Janknegt R, van Kerrebroeck PE, Lylcklama a Nijeholt AA, Siegel SW and Schmidt RA: Efficacy of sacral nerve stimulation for urinary retention: results 18 months after implantation. J Urol. 165: 15-9, 2001.

3. Hassouna MM, Siegel SW, Nyeholt AA, Elhilali MM, van Kerrebroeck PE, Das AK, Gajewski JB, Janknegt RA, Rivas DA, Dijkema H, Milam DF, Oleson KA and Schmidt RA: Sacral neuromodulation in the treatment of urgency-frequency symptoms: a multicenter study on efficacy and safety. J Urol. 163: 1849-54, 2000.

4. van Kerrebroeck PE, van Voskuilen AC, Heesakkers JP, Lycklama a Nijholt AA, Siegel S, Jonas U, Fowler CJ, Fall M, Gajewski JB, Hassouna MM, Cappellano F, Elhilali MM, Milam DF, Das AK, Dijkema HE and van den Hombergh U: Results of sacral neuromodulation therapy for urinary voiding dysfunction: outcomes of a prospective, worldwide clinical study. J Urol. 178: 2029-34, 2007.

5. Siegel SW, Catanzaro F, Dijkema HE, Elhilali MM, Fowler CJ, Gajewski JB, Hassouna MM, Janknegt RA, Jonas U, van Kerrebroeck PE, Lycklama a Nijeholt AA, Oleson KA and Schmidt RA: Long-term results of a multicenter study on sacral nerve stimulation for treatment of urinary urge incontinence, urgency-frequency, and retention. Urology. 56: 87-91, 2000.

6. Bosch JL and Groen J: Sacral nerve neuromodulation in the treatment of patients with refractory motor urge incontinence: long-term results of a prospective longitudinal study. J Urol. 163: 1219-22, 2000.

7. Spinelli M, Giardiello G, Gerber M, Arduini A, van den Hombergh U and Malaguti S: New sacral neuromodulation lead for percutaneous implantation using local anesthesia: description and first experience. J Urol. 170: 1905-7, 2003.

8. Spinelli M, Weil E, Ostardo E, Del Popolo G, Ruiz-Cerda JL, Kiss G and Heesakkers $\mathrm{J}$ : New tined lead electrode in sacral neuromodulation: experience from a multicentre European study. World J Urol. 23: 225-9, 2005.

9. Sutherland SE, Lavers A, Carlson A, Holtz C, Kesha J and Siegel SW: Sacral nerve stimulation for voiding dysfunction: One institution's 11-year experience. Neurourol Urodyn. 26: 19-28; discussion 36, 2007. 
10. Hijaz A and Vasavada S: Complications and troubleshooting of sacral neuromodulation therapy. Urol Clin North Am. 32: 65-9, 2005.

11. van Voskuilen AC, Oerlemans DJ, Weil EH, de Bie RA and van Kerrebroeck PE: Long term results of neuromodulation by sacral nerve stimulation for lower urinary tract symptoms: a retrospective single center study. Eur Urol. 49: 366-72, 2006.

12. Dudding TC, Pares D, Vaizey CJ and Kamm MA: Comparison of clinical outcome between open and percutaneous lead insertion for permanent sacral nerve neurostimulation for the treatment of fecal incontinence. Dis Colon Rectum. 52: 463-8, 2009.

13. Deng DY, Gulati M, Rutman M, Raz $S$ and Rodriguez LV: Failure of sacral nerve stimulation due to migration of tined lead. J Urol. 175: 2182-5, 2006.

14. Scheepens WA, Weil EH, van Koeveringe GA, Rohrmann D, Hedlund HE, Schurch B, Ostardo E, Pastorello M, Ratto C, Nordling J and van Kerrebroeck PE: Buttock placement of the implantable pulse generator: a new implantation technique for sacral neuromodulation--a multicenter study. Eur Urol. 40: 434-8, 2001. 
IS THE METHOD OF SCREENING IN SACRAL NEUROMODULATION A PROGNOSTIC FACTOR FOR LONG-TERM SUCCESS?

T. Marcelissen

R. Leong

J. Serroyen

P. Van Kerrebroeck

S. De Wachter

J Urol. 2011 Feb;185(2):583-7 


\section{ABSTRACT}

Purpose: To evaluate if there is a difference in long-term outcome between patients screened with the percutaneous nerve evaluation (PNE) and first stage tined lead procedure (TLP). We also evaluated the outcome in patients who only responded to screening with TLP after failure of initial PNE.

Materials and methods: We evaluated all patients screened for eligibility to receive sacral neuromodulation (SNM) treatment since the introduction of the tined lead technique in our centre in 2002. In May 2009, all implanted patients were asked to keep a voiding diary to record the effect of SNM on urinary symptoms. Chi square analysis was used to evaluate differences in long-term outcome for the separate screening methods.

Results: In total, 92 patients were screened for SNM. Of the 76 patients who were screened with PNE, 35 (46\%) met the criteria for permanent implantation, whereas 11 of the 16 patients (69\%) who underwent direct screening with TLP had permanent stimulators placed. Of the 41 patients who failed PNE and subsequently underwent screening with TLP, 18 (44\%) were implanted with a neurostimulator after showing a successful response. Statistical analysis showed no difference between type of screening and long-term success $(p=0.94)$.

Conclusion: First stage TLP is a more sensitive screening tool than PNE. However, the long-term success rate seems to be independent on the screening method, and patients who initially failed PNE but responded to prolonged screening with TLP, appear to be as successful as patients who directly responded to PNE or TLP. 


\section{INTRODUCTION}

Sacral Neuromodulation (SNM) is a well established treatment for patients with idiopathic overactive bladder syndrome $(\mathrm{OAB})$ or non-obstructive urinary retention. ${ }^{1-3}$ Patients are selected for SNM treatment based on their response to test stimulation with a temporary electrode. ${ }^{2-5}$ If more than $50 \%$ improvement in voiding symptoms is observed during the test period, they are considered eligible candidates for SNM treatment. This is at present the only reliable predictive factor for long-term success. ${ }^{6}$ Initially, screening was performed with the percutaneous nerve evaluation (PNE) test, in which a basic wire electrode is connected to an external stimulator. However, due to the high risk of lead migration, the test duration is rather limited and the reported success rate is between 40 and 50\%., ${ }^{3,7}$ Later, the two stage implantation procedure was introduced, which enables screening with the permanent electrode during the first stage. ${ }^{7,8}$ If the patient is considered eligible for definitive SNM, the implantable neurostimulator (INS) is inserted in a second stage. This procedure enables prolonged screening for more than one month, resulting in a success rate of $80 \%$, which is significantly higher than with PNE testing. Before the introduction of the tined lead, the permanent lead was implanted under direct vision and in turn secured to the sacral periosteum during an open surgical technique. ${ }^{9,10}$ Spinelli et al. introduced a self-anchoring "tined" lead in 2002, allowing a percutaneous placement of the lead under radiological guidance. ${ }^{11,12}$ Due to the minimally invasive nature of this tined lead procedure (TLP), prolonged first stage screening became more accessible.

As a result of the increased success rate by using the first stage TLP, a higher number of candidates for SNM are selected and more patients with refractory voiding symptoms are offered the possibility of a satisfactory treatment. ${ }^{13}$ However, it is unknown if patients who initially fail PNE but subsequently respond to TLP, are in the long-term as successful as patients who directly respond to PNE.

The purpose of this study was to evaluate whether there is a difference in longterm outcome between patients screened with the percutaneous nerve evaluation (PNE) and first stage tined lead procedure (TLP). Furthermore, we 
wanted to investigate the relation between the degree of symptom improvement during test stimulation and long-term success.

\section{METHODS}

This study presents a sub-analysis of the data of a prospective study that was recently conducted in our centre evaluating the long-term efficacy of sacral neuromodulation [Marcelissen et al., 2011]. The results of the voiding diary analysis and the number of adverse events are therefore not demonstrated in this study. All patients who were screened with PNE or TLP test stimulation since the introduction of the tined lead technique in our centre in 2002 were evaluated. To assess the long-term efficacy of SNM, only patients with a followup of 3 years or more were included. Patients included were those with idiopathic $O A B$ symptoms and patients with urinary retention. All were refractory to conservative treatments or could not tolerate the side effects.

An implantable neurostimulator (INS) was placed if patients showed a successful response to PNE or first stage tined lead screening tests. Success was defined as more than $50 \%$ improvement in at least one of the relevant voiding diary parameters compared to baseline. All patients were initially screened with a PNE test, unless they were, to our experience, at high risk for lead migration (patients who were obese or underweight). Patients who showed a positive response to PNE were implanted with both the permanent lead and INS in one stage. Patients who showed a negative response to PNE were additionally screened with a first stage TLP. The tined lead procedure was executed as previously described by Spinelli et al. ${ }^{11}$ The lead (Model 3889, Medtronic) was placed in the left or right S3 foramen with the help of fluoroscopy. All procedures were performed under local anaesthesia in an outpatient setting. To evaluate long-term efficacy, in May 2009 all implanted patients were asked to keep a voiding diary to record the effect of SNM on urinary symptoms. SNM therapy was considered successful if $50 \%$ or more improvement was noted compared to baseline in at least one of the key voiding diary variables. Patients who underwent INS removal or patients who stopped using their INS were considered treatment failures. 
In order to investigate the relation between method of screening and long-term success, we divided all patients into three subgroups: patients who showed a positive response to direct screening with PNE, patients who showed a positive response to direct screening with TLP, and patients who showed a positive response to screening with TLP after failure of PNE.

The relation between the degree of improvement during test stimulation and long-term outcome was evaluated by dividing patients into two subgroups: patients who showed more than $90 \%$ improvement during test stimulation and patients who showed between $50-90 \%$ improvement. This was carried out by comparing the voiding diary data filled out during test stimulation with the voiding diary data at baseline. Data were analyzed by Chi square or Fisher's exact test. A p-value of less than 0.05 was considered to be statistically significant. For all data analyses SPSS software version 16.0 was used.

\section{RESULTS}

In total, 92 patients were screened for SNM treatment with PNE and/or first stage TLP, and figure 1 depicts an overview of the screening algorithm. Sixtyfour of the $92(70 \%)$ patients went from test stimulation to permanent INS implantation. Of the 76 patients who were screened with PNE, 35 (46\%) met the criteria for permanent implantation, whereas 11 of the 16 patients $(69 \%)$ who underwent direct screening with TLP had permanent stimulators placed. Of the 41 patients who failed PNE and subsequently underwent screening with TLP, 18 (44\%) were implanted with an INS after showing a successful response.

The mean follow-up of all implanted patients at the time of voiding diary analysis was 53 months (range 35-77 months). Five patients died during follow-up and were not included in the analysis. Of the remaining 59 patients, 45 had $O A B$ symptoms (40 OAB wet and $5 \mathrm{OAB}$ dry), and 14 had chronic non-obstructive urinary retention. The overall long-term success rate was $64 \%$, and patients who were successfully treated, stratified for screening method, are illustrated in figure 2. Statistical analysis showed no relation between the method of screening and long-term success (Chi square test, $\mathrm{p}=0.94$ ). 
Figure 1. Overview of all patients screened for SNM treatment. In total, sixty-four patients showed a positive response to screening and received an implant.

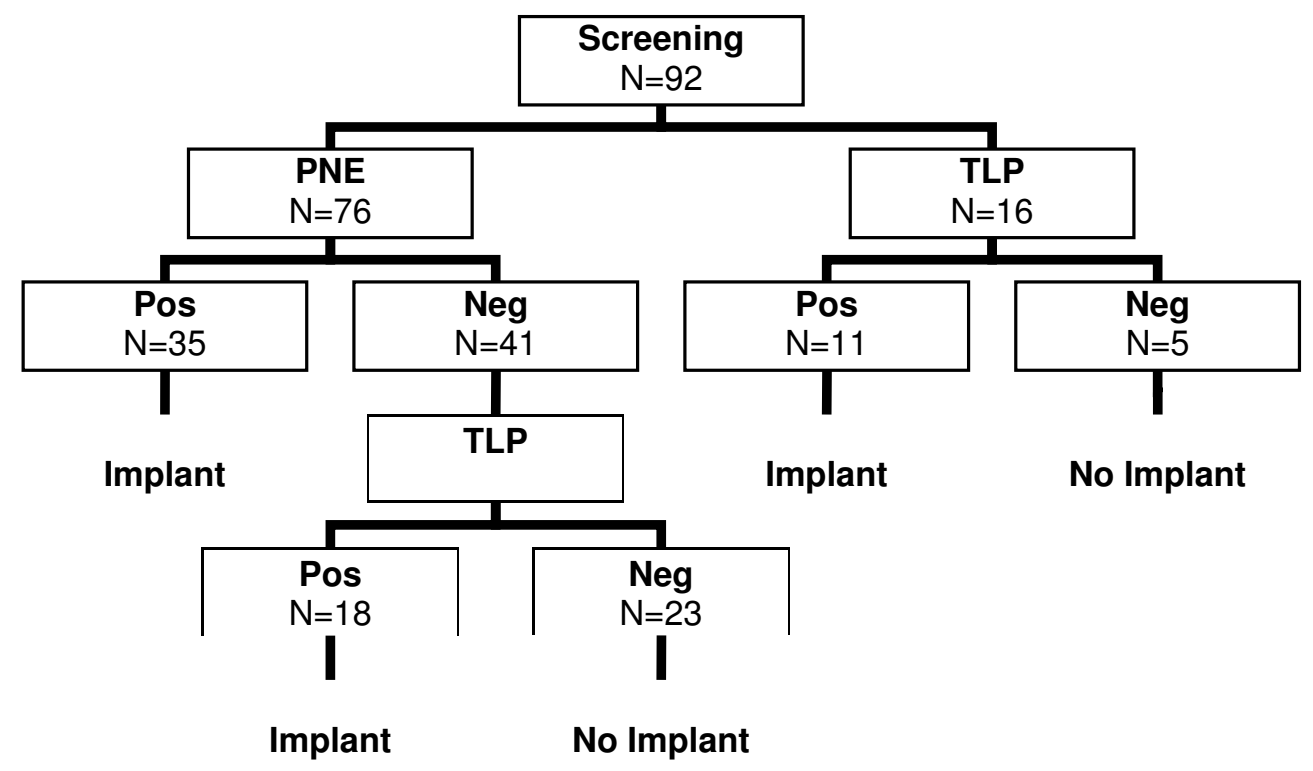

Figure 2. Long-term success for all patients divided into three subgroups: patients who showed a positive response to PNE ( $P N E$ ), patients who showed a positive response to TLP after failure of PNE (TLP after PNE) and patients who showed a positive response to direct screening with TLP (direct TLP). Odds ratios $(O R)$ are shown for success, with $95 \%$ confidence intervals between brackets.

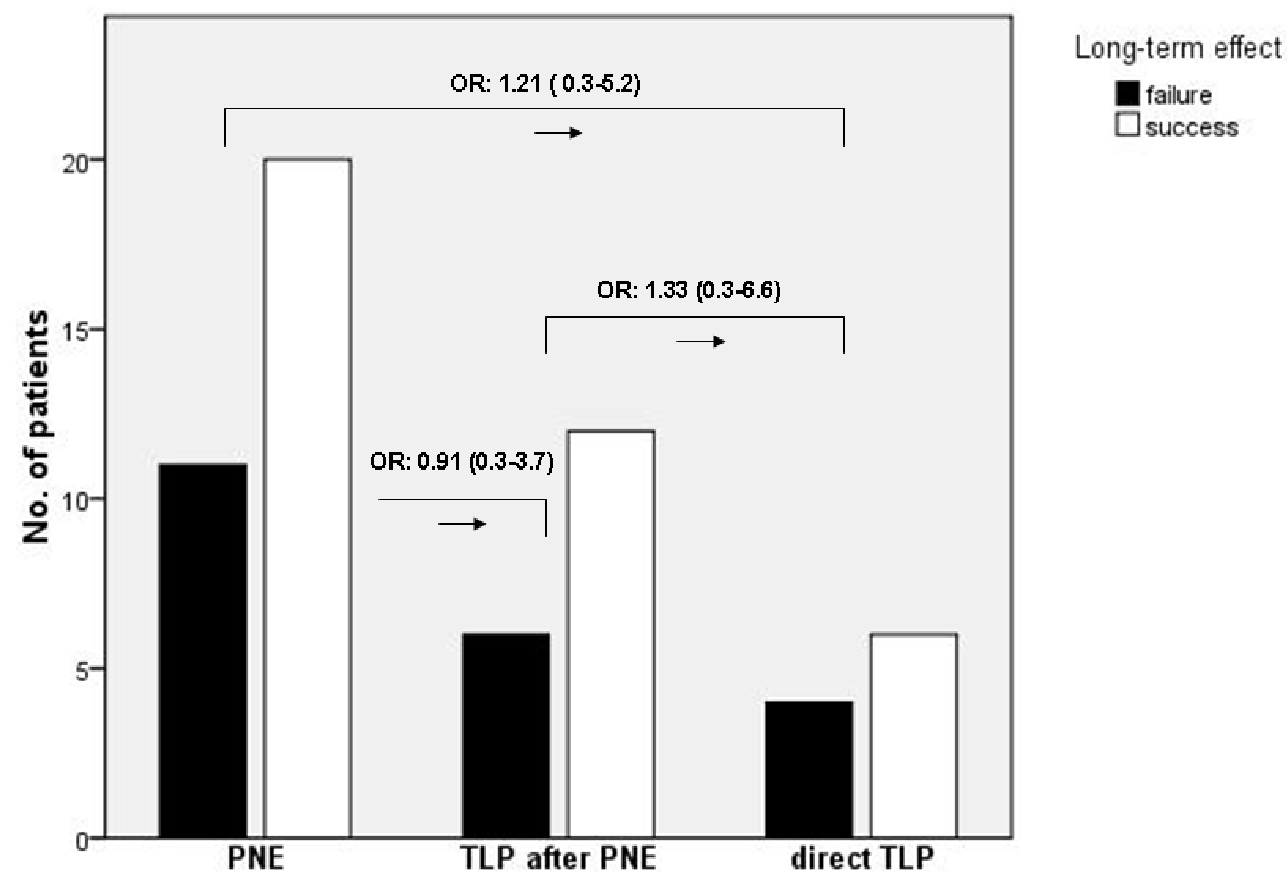


Figure 3 illustrates the long-term success rate for patients who showed $>90 \%$ improvement during test stimulation and patients who showed between 50-90\% improvement. The long-term success rate for each group was $80 \%$ and $52 \%$ respectively. A borderline significant relation was found between patients with $>90 \%$ improvement during test stimulation and long-term success (Fisher's exact test, $p=0.05$ ).

Figure 3. Long-term success rate for patients who showed $>90 \%$ improvement compared to patients who showed $50-90 \%$ improvement during test stimulation. Odds ratio $(O R)$ is shown for success, with $95 \%$ confidence intervals between brackets.

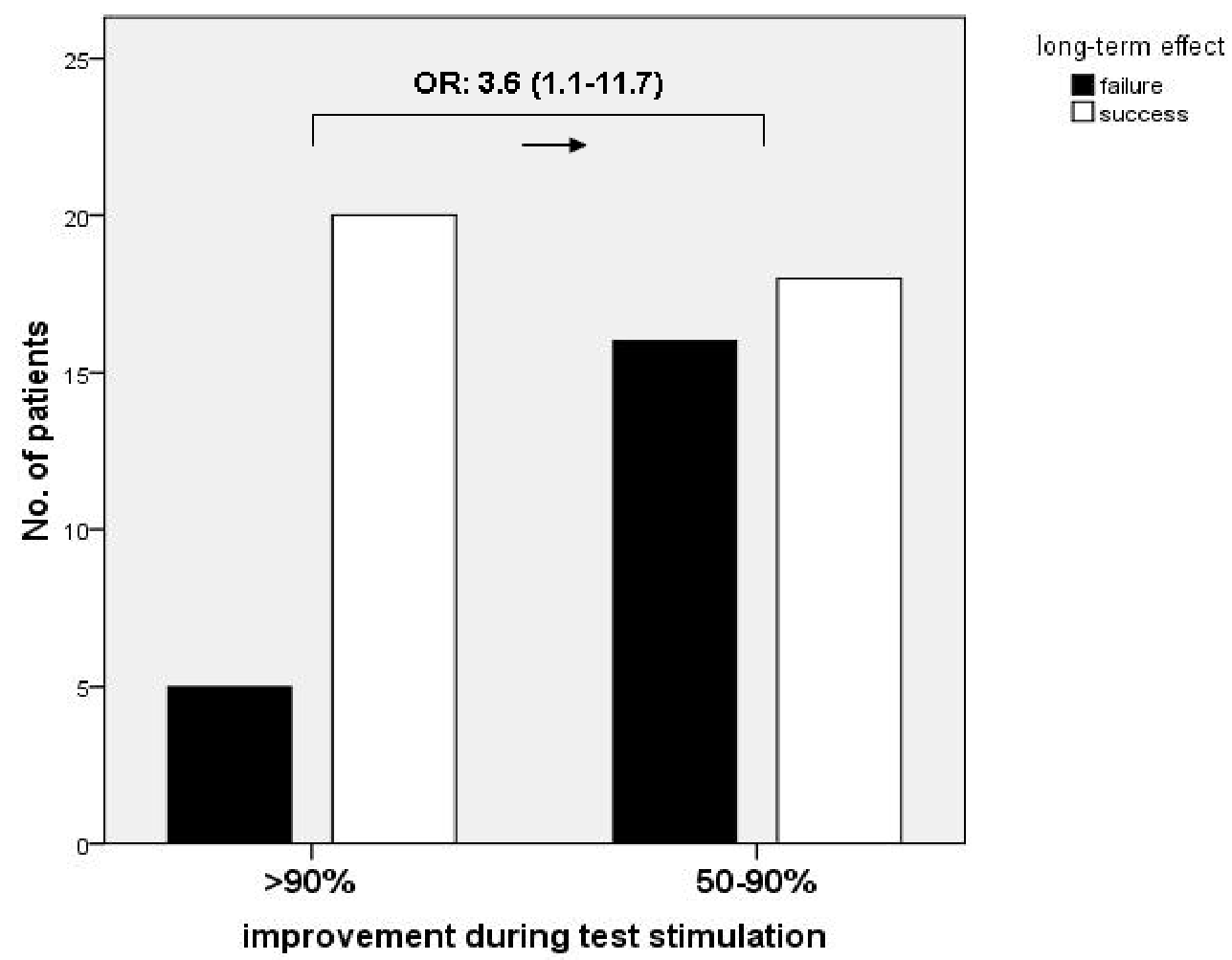


For patients in the OAB wet group, a successful response was determined by looking only at the incontinence parameters (number of daily leakages and pad use). Because the response to SNM can also be evaluated by looking at the number of daily voids and the voided volume per void, we also evaluated the improvement of these secondary parameters with respect to long-term success. Sixteen of the 38 OAB wet patients (42\%) showed more than $50 \%$ improvement in one of the secondary parameters (fig. 4). Patients who showed a concomitant improvement in one of the secondary parameters during test stimulation had a significantly higher chance of long-term success compared to patients who only showed an improvement in the incontinence parameters (Fisher's exact test, $\mathrm{p}=0.006)$.

Figure 4. Long-term success rate for $O A B$ wet patients who concomitantly showed $>50 \%$ improvement in secondary parameters compared to patients who only showed $>50 \%$ improvement in incontinence parameters during test stimulation. Odds ratio $(O R)$ is shown for success, with $95 \%$ confidence intervals between brackets.

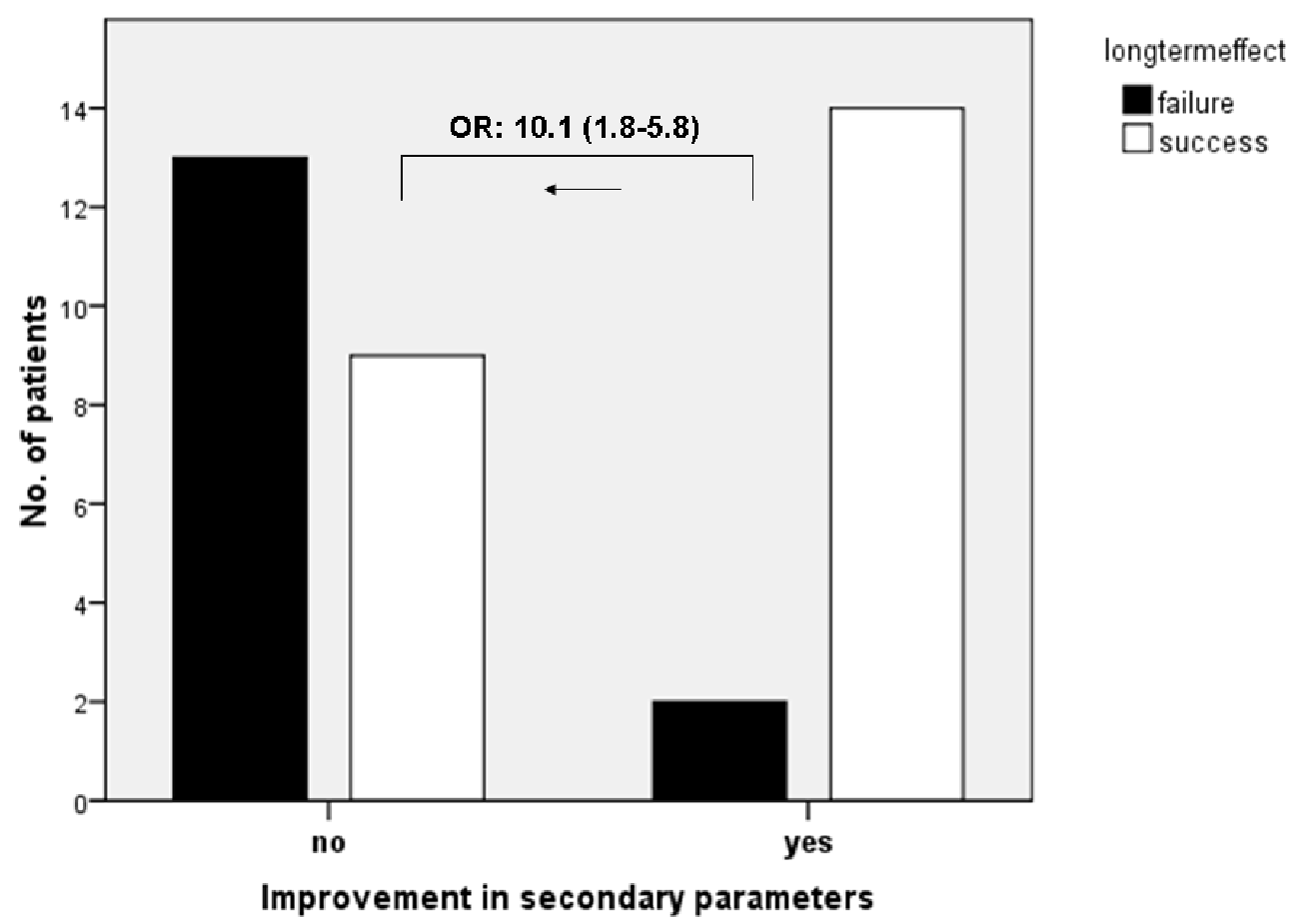




\section{DISCUSSION}

It has previously been shown that prolonged testing using permanent leads is more sensitive than test stimulation with PNE. ${ }^{7,8}$ The difference in response rate between PNE and TLP is thought to be attributed to the type of lead that is used. ${ }^{8}$ The lead that is used during PNE is a basic electrical wire electrode that has a potential to migrate, particularly with prolonged testing. In contrast, the quadripolar tined lead contains silicone barbs designed to prevent dislocation, which are deployed during placement of the lead. ${ }^{11}$ Although the success rate of test stimulation with TLP was higher than with PNE in our study, the method of test stimulation did not have an influence on long-term outcome. Recently, Powell et al. showed that the long-term success of patients screened with TLP was similar to patients screened with PNE in a population with painful bladder syndrome. ${ }^{14}$ Therefore, test stimulation with TLP does not seem to be an independent predictor for success of chronic SNM treatment.

Due to the introduction of the tined lead, minimally invasive screening with the permanent lead became possible, which resulted in a higher percentage of patients considered eligible for SNM treatment. Consequently, more patients were able to benefit from SNM treatment. Originally, patients with a failed PNE test were considered unsuitable candidates and were denied SNM therapy. In our group, 18 patients showed a negative response to an initial PNE test and would have been excluded from treatment with SNM. However, based on a subsequent positive TLP test, they received definitive SNM treatment. After a follow-up of 53 months, twelve of these patients (67\%) had a successful outcome, which was not statistically different from the success rate in patients showing a positive response to an initial PNE or TLP test. These data suggest that patients who initially failed PNE but respond to prolonged screening with TLP, appear to be as successful in the long-term as patients who directly respond to PNE. Although these data seem to reduce the importance of the $\mathrm{PNE}$, we believe that due to its fully non-invasive character and low costs, it still has a value in patient selection, while filtering unsuitable candidates at an early 
stage of the assessment. Examples of unsuitable candidates are patients who cannot tolerate electrical stimulation or are unable to cope with the equipment.

Although the primary aim of treating patients with functional bladder disorders is to improve satisfaction and quality of life, eligibility to receive SNM treatment is based on the degree of symptom improvement during test stimulation relative to baseline. More than $50 \%$ improvement in the key voiding diary variables is considered a clinically significant response, and only patients who show a significant response are implanted. However, it is unknown how symptom relief relates to satisfaction and quality of life. Do patients with $90 \%$ symptom relief have a larger increase in quality of life, or are they more satisfied with the treatment than patients who show a borderline improvement of $50 \%$ ? In our study, patients who showed a large improvement during screening (>90\% compared to baseline) tended to do better in the long-term than patients who showed between 50 and $90 \%$ improvement $(p=0.05)$. Presumably, patients who show a high response to test stimulation are more sensitive to respond to sacral neuromodulation, and therefore treatment failure is less likely in these patients. It is also possible that treatment efficacy gradually decreases over time with SNM. Hence, in patients who showed a borderline response during test stimulation, the degree of symptom improvement might decline to a level below the margin of $50 \%$ after several years of treatment. It would also be interesting to evaluate how quality of life changes in both groups and to study these questions in a larger patient group. However, our results already point out the importance of good patient selection and might aid the clinician in future decision making.

For patients with OAB wet symptoms, the response to SNM is evaluated by looking mainly at the improvement of incontinence parameters. For patients with OAB dry symptoms, the voiding frequency and voided volume are considered the key voiding diary variables. Since all patients with $O A B$ symptoms (both wet and dry) are assumed to share the same pathophysiology, one would expect that patients in the OAB wet group show improvement in all four of the parameters mentioned above. However, only 16 of the 40 patients showed more than $50 \%$ improvement in the voiding frequency or voided volume. And most importantly, these patients had a significantly higher chance of long-term success compared 
to patients who only showed improvement of incontinence parameters $(p=0.006)$. This indicates that patients with urgency incontinence who show improvement in all of the OAB parameters during test stimulation, appear to be more suitable candidates for chronic SNM, and again stresses the importance of good patient selection.

Nevertheless, we are aware of the fact that this study has its limitations. Evaluation of the subgroups in a randomized controlled fashion would be more solid, however, since this is not clinically feasible, we believe that the results of our study are of importance in clinical practice.

\section{CONCLUSION}

Test stimulation with TLP appears to be a more sensitive screening tool than PNE, although the long-term success rate does not seem to be depend on the screening method. Patients who initially fail PNE but respond to prolonged screening with TLP, appear to be at least as successful in the long-term as patients who directly responded to PNE or TLP.

\section{REFERENCES}

1. Schmidt RA, Jonas U, Oleson KA, Janknegt RA, Hassouna MM, Siegel SW and van Kerrebroeck PE: Sacral nerve stimulation for treatment of refractory urinary urge incontinence. Sacral Nerve Stimulation Study Group. J Urol. 162: 352-7, 1999.

2. Hassouna MM, Siegel SW, Nyeholt AA, Elhilali MM, van Kerrebroeck PE, Das AK, Gajewski JB, Janknegt RA, Rivas DA, Dijkema H, Milam DF, Oleson KA and Schmidt RA: Sacral neuromodulation in the treatment of urgency-frequency symptoms: a multicenter study on efficacy and safety. J Urol. 163: 1849-54, 2000.

3. Jonas U, Fowler CJ, Chancellor MB, Elhilali MM, Fall M, Gajewski JB, Grunewald V, Hassouna MM, Hombergh U, Janknegt R, van Kerrebroeck PE, Lylcklama a Nijeholt $A A$, Siegel SW and Schmidt RA: Efficacy of sacral nerve stimulation for urinary retention: results 18 months after implantation. J Urol. 165: 15-9, 2001. 
4. Bosch JL and Groen J: Sacral nerve neuromodulation in the treatment of patients with refractory motor urge incontinence: long-term results of a prospective longitudinal study. J Urol. 163: 1219-22, 2000.

5. Siegel SW, Catanzaro F, Dijkema HE, Elhilali MM, Fowler CJ, Gajewski JB, Hassouna MM, Janknegt RA, Jonas U, van Kerrebroeck PE, Lycklama a Nijeholt AA, Oleson KA and Schmidt RA: Long-term results of a multicenter study on sacral nerve stimulation for treatment of urinary urge incontinence, urgency-frequency, and retention. Urology. 56: 87-91, 2000.

6. Scheepens WA, Jongen MM, Nieman FH, de Bie RA, Weil EH and van Kerrebroeck $\mathrm{PE}$ : Predictive factors for sacral neuromodulation in chronic lower urinary tract dysfunction. Urology. 60: 598-602, 2002.

7. Janknegt RA, Weil EH and Eerdmans PH: Improving neuromodulation technique for refractory voiding dysfunctions: two-stage implant. Urology. 49: 358-62, 1997.

8. Kessler TM, Madersbacher $\mathrm{H}$ and Kiss G: Prolonged sacral neuromodulation testing using permanent leads: a more reliable patient selection method? Eur Urol. 47: 660-5, 2005.

9. Grunewald V, Hofner K, Thon WF, Kuczyk MA and Jonas U: Sacral electrical neuromodulation as an alternative treatment option for lower urinary tract dysfunction. Restor Neurol Neurosci. 14: 189-193, 1999.

10. Schmidt RA: Advances in genitourinary neurostimulation. Neurosurgery. 19: 1041-4, 1986.

11. Spinelli M, Giardiello G, Gerber M, Arduini A, van den Hombergh U and Malaguti S: New sacral neuromodulation lead for percutaneous implantation using local anesthesia: description and first experience. J Urol. 170: 1905-7, 2003.

12. Spinelli M, Weil E, Ostardo E, Del Popolo G, Ruiz-Cerda JL, Kiss G and Heesakkers $\mathrm{J}$ : New tined lead electrode in sacral neuromodulation: experience from a multicentre European study. World J Urol. 23: 225-9, 2005.

13. Kessler TM, Burkhard FC, Madersbacher H, Kofler A, Poewe W and Kiss G: Safety of prolonged sacral neuromodulation tined lead testing. Curr Med Res Opin. 24: 343-7, 2008.

14. Powell CR and Kreder KJ: Long-term outcomes of urgency-frequency syndrome due to painful bladder syndrome treated with sacral neuromodulation and analysis of failures. J Urol. 183: 173-6, 2010 


\section{PSYCHOLOGICAL AND PSYCHIATRIC}

FACTORS AS PREDICTORS FOR SUCCESS IN SACRAL NEUROMODULATION



T. Marcelissen

R. Leong

F. Nieman

J. van Lankveld

P. Van Kerrebroeck

S. De Wachter

BJU Int. 2011 Aug 2. Epub ahead of print. 


\section{ABSTRACT}

Purpose: To evaluate if psychological and psychiatric factors can predict the outcome of test stimulation or permanent treatment with sacral neuromodulation.

Materials and methods: Between 2006 and 2009, patients with overactive bladder syndrome or non-obstructive urinary retention who were eligible for test stimulation were included. Before test stimulation, all patients completed the Amsterdam Biographic Questionnaire $(A B Q)$, which measures the personality traits of the patient, and the Symptom Check-List-90-Revised (SCL-90-R), which is a screening instrument for neuroticism, and for current level of complaints. The results of the questionnaires were related to the outcome of test stimulation and permanent treatment. Besides the questionnaires, we also included the psychiatric history as a potential predictive factor.

Results: Fifty-four patients (10 men and 44 women) were included. In total, 38 patients $(70 \%)$ were diagnosed with overactive bladder syndrome and $16(30 \%)$ with chronic non-obstructive urinary retention. Fifteen patients $(28 \%)$ reported a psychiatric disorder in their medical history. Univariate analysis showed no relation between the psychological characteristics and the outcome of test stimulation or the occurrence of adverse events with permanent treatment. $A$ history of psychiatric disease was not related to the outcome of test stimulation, but was shown to be a positive predictor for the occurrence of adverse events with permanent SNM treatment.

Conclusion: We found no evidence in this study that psychological screening with the ABQ or SCL-90-R can predict the outcome of SNM treatment. However, patients with a history of psychiatric disease appear to be more likely to encounter adverse events with permanent SNM treatment. 


\section{INTRODUCTION}

Since the early 90's sacral neuromodulation (SNM) has become a therapeutic option for patients with chronic lower urinary tract symptoms who are refractory to conservative treatment. ${ }^{1-5}$ Patients with symptoms of overactive bladder and patients with non-obstructive urinary retention can benefit from SNM. Before a patient is implanted with a permanent neurostimulator, a percutaneous test stimulation is routinely performed. The goal of this procedure is to evaluate the clinical response to temporary stimulation of the sacral nerves in order to select eligible candidates for chronic SNM. Patients qualify for a definitive implant when they show an improvement of at least $50 \%$ in their key voiding diary variables. Although several predictive factors for success in SNM have been identified, the test stimulation has found to be the only constant factor in predicting success. ${ }^{6-8}$ Nevertheless, the selection of eligible candidates could be improved by identifying more factors that can predict a successful response.

Functional disorders of the lower urinary tract often coincide with psychological and emotional lability. There is considerable evidence that a variety of psychological states frequently occur in patients with overactive bladder syndrome, including depression, anxiety and anger. ${ }^{9-11}$ This relation has also been demonstrated in patients with functional urinary retention. ${ }^{12}$ It is still unclear if psychological factors contribute to the occurrence or maintenance of urinary dysfunction, or play a causative role.

Presumably, the incidence and degree of psychological problems might have an effect on treatment outcome of sacral neuromodulation, and psychiatric comorbidity has previously been proposed as a negative predictor by some authors. ${ }^{7,13}$ However, these results were based on small patients groups, with retrospective data. In the current study, we prospectively evaluated the role of a broad spectrum of psychological factors in relation to SNM treatment by using validated psychological screening questionnaires. We also assessed the relation between psychiatric history and the outcome of chronic SNM treatment. 


\section{MATERIALS AND METHODS}

Between 2006 and 2009, patients with symptoms of overactive bladder (OAB) or chronic non-obstructive urinary retention who were considered eligible for test stimulation were included. They all were refractory to conservative treatments or could not tolerate the side effects. All patients agreed to participate and signed an informed consent before the start of the study. The test stimulation was carried out by using the percutaneous nerve evaluation (PNE). A successful response was defined as more than $50 \%$ improvement in the key voiding diary variables compared to baseline. For OAB wet patients these included: a reduction in the daily episodes of incontinence or pad usage, for OAB dry patients: a reduction in the number of daily voids or an increase in voided volume per void, and for patients with non-obstructive urinary retention: a reduction in the catheterized volume per catheterization. X-ray was used before and at the end of the test stimulation in order to rule out lead migration. Patients with lead migration, either suspected by X-ray or by loss or change in stimulation sensation, were excluded from the analysis.

In patients who received a definite implant after showing a successful response to PNE, all device-related adverse events were documented. These included: decrease in treatment efficacy, implant/lead removal or relocation, lead migration, pain at the side of the implant or painful stimulation.

Preceding the test stimulation, patients were asked to fill out two validated psychological screening questionnaires. These included the Amsterdam Biographical Questionnaire $(A B Q)^{14}$ and the Symptom Check-List-90-Revised $(\mathrm{SCL}-90-\mathrm{R})^{15}$. The $\mathrm{ABQ}$ is a self-report personality inventory, which measures different personality traits and consists of 107 questions that can be answered with 'yes' or 'no'. For the present study, three subscales were selected: Neuroticism (ABQ-N), Somatisation (ABQ-NS) and Extraversion (ABQ-E). The SCL-90-R is a widely used psychological status symptom inventory. It is a 90 item multidimensional questionnaire designed to screen for a broad range of current psychological problems, using the last week as a window of reference. Each of the 90 items is rated on a five-point Likert scale of distress, ranging from 
'not at all' (1) to 'extremely' (5). Next, the answers are combined in nine primary symptom scales: Anxiety (ANX), Depression (DEP), Somatization (SOM), Obsessive-Compulsive (OC), Interpersonal Sensitivity (IS), Phobic Anxiety (PHO), Anger-Hostility (AH), and Sleeping problems (SLE). The total score of the primary symptom scales was used as a general measure of neuroticism. Gender specific norms are provided for a non-patient population and a population of ambulatory psychiatric patients.

An independent medical psychologist interpreted the outcome of the questionnaires. In addition to the questionnaires, the psychiatric history of all patients was documented from the patient records, and included as a possible predictive factor in the analysis.

\section{Statistical analysis}

Univariate interval-type of data are presented as means and standard deviations (SD). Categorical data are presented as frequencies and percentages. Univariate relationships between PNE success (1) and failure (0) and potentially relevant predictors were calculated as odds ratios (OR) with 95\% confidence intervals $(\mathrm{Cl})$. Multivariate analysis was done by logistic regression analysis using backward elimination log-likelihood chi-squares. The best-fitting model contains only predictors with statistically significant effects. This final model is presented also in a categorized way, as far as the predictors are of interval type of data. A p-value of $<0.05$ is regarded as statistically significant. All data were analyzed with SPSS-pc version 16.0. 


\section{RESULTS}

\section{Test stimulation outcome}

Fifty-four patients (10 men and 44 women) were included, with a mean age of 56.1 years (SD 14.0, range 24 to 83 ). In total, 38 patients (70\%) were diagnosed with overactive bladder syndrome and 16 (30\%) with chronic non-obstructive urinary retention. Fifteen patients (28\%) reported a psychiatric disorder in their medical history, which is specified in table 1.

Table 1. Specification of psychiatric disorders in patients with a psychiatric history $(n=15)$. One patient was diagnosed with 3 different psychiatric disorders. Of the 10 patients with a mood disorder, 9 had a depressive disorder and 1 had a bipolar disorder.

\begin{tabular}{lc}
\hline Psychiatric history & number of patients \\
\hline Mood disorder & 10 \\
Anxiety disorder & 3 \\
Pain disorder & 3 \\
Gender Identity disorder & 1 \\
\hline
\end{tabular}

Thirteen of these patients had OAB syndrome and 2 had urinary retention. All patients underwent a classic PNE test, and 29 patients (54\%) showed a successful response. The mean scores of the SCL-90-R scales are presented in table 2, together with the norms of a population of non-patients and a population of ambulatory psychiatric patients. These norms were provided by the SCL-90-R manual ${ }^{15}$. 
Table 2. Mean scores of the SCL-90-R questionnaire scales in our study (study). The norms of a population non-patients (normal) and a population ambulatory psychiatric patients (psych) are shown below. Standard deviations are between brackets.

\begin{tabular}{|c|c|c|c|c|c|c|c|c|c|c|}
\hline scale & gender & ANX & DEP & SOM & OC & IS & $\mathrm{PHO}$ & $\mathrm{AH}$ & SLE & total \\
\hline \multirow[t]{2}{*}{ Study } & $M$ & $\begin{array}{l}\mathbf{1 4 . 3} \\
(3.9)\end{array}$ & $\begin{array}{c}\mathbf{2 7 . 5} \\
(11.1)\end{array}$ & $\begin{array}{l}23.4 \\
(9.4)\end{array}$ & $\begin{array}{l}14.9 \\
(5.2)\end{array}$ & $\begin{array}{l}27.7 \\
(9.2)\end{array}$ & $\begin{array}{l}8.2 \\
(2.8)\end{array}$ & $\begin{array}{c}7.6 \\
(1.3)\end{array}$ & $\begin{array}{c}8.5 \\
(4.2)\end{array}$ & $\begin{array}{l}145.2 \\
(36.7)\end{array}$ \\
\hline & $\mathrm{F}$ & $\begin{array}{l}16.4 \\
(7.3)\end{array}$ & $\begin{array}{c}28.8 \\
(13.8)\end{array}$ & $\begin{array}{l}23.7 \\
(9.3)\end{array}$ & $\begin{array}{l}16.8 \\
(7.9)\end{array}$ & $\begin{array}{c}28.9 \\
(13.2)\end{array}$ & $\begin{array}{c}9.5 \\
(3.5)\end{array}$ & $\begin{array}{c}7.8 \\
(2.4)\end{array}$ & $\begin{array}{c}7.6 \\
(3.6)\end{array}$ & $\begin{array}{l}152.7 \\
(56.2)\end{array}$ \\
\hline \multirow[t]{2}{*}{ Normal $^{15}$} & $M$ & $\begin{array}{l}13.0 \\
(4.3)\end{array}$ & $\begin{array}{l}20.7 \\
(6.3)\end{array}$ & $\begin{array}{l}16.6 \\
(5.7)\end{array}$ & $\begin{array}{l}13.2 \\
(4.6)\end{array}$ & $\begin{array}{l}24.6 \\
(6.8)\end{array}$ & $\begin{array}{c}7.9 \\
(2.1)\end{array}$ & $\begin{array}{c}7.5 \\
(2.5)\end{array}$ & $\begin{array}{c}4.6 \\
(2.4)\end{array}$ & $\begin{array}{l}117.2 \\
(27.3)\end{array}$ \\
\hline & $F$ & $\begin{array}{l}14.6 \\
(5.7)\end{array}$ & $\begin{array}{l}23.8 \\
(8.6)\end{array}$ & $\begin{array}{l}18.7 \\
(7.1)\end{array}$ & $\begin{array}{l}14.1 \\
(5.1)\end{array}$ & $\begin{array}{l}26.3 \\
(8.8)\end{array}$ & $\begin{array}{c}8.7 \\
(3.4)\end{array}$ & $\begin{array}{c}7.6 \\
(2.4)\end{array}$ & $\begin{array}{c}5.2 \\
(2.8)\end{array}$ & $\begin{array}{l}128.9 \\
(36.4)\end{array}$ \\
\hline \multirow[t]{2}{*}{ Psych $^{15}$} & M & $\begin{array}{l}24.5 \\
(9.5)\end{array}$ & $\begin{array}{c}39.3 \\
(14.4)\end{array}$ & $\begin{array}{l}25.4 \\
(9.6)\end{array}$ & $\begin{array}{l}21.2 \\
(7.9)\end{array}$ & $\begin{array}{c}37.3 \\
(14.7)\end{array}$ & $\begin{array}{l}13.0 \\
(6.7)\end{array}$ & $\begin{array}{l}11.3 \\
(5.1)\end{array}$ & $\begin{array}{c}7.6 \\
(3.6)\end{array}$ & $\begin{array}{l}196.4 \\
(62.1)\end{array}$ \\
\hline & $\mathrm{F}$ & $\begin{array}{c}27.4 \\
(10.2)\end{array}$ & $\begin{array}{c}\mathbf{4 4 . 4} \\
(15.2)\end{array}$ & $\begin{array}{c}27.8 \\
(10.2)\end{array}$ & $\begin{array}{l}22.2 \\
(8.5)\end{array}$ & $\begin{array}{c}40.9 \\
(16.0)\end{array}$ & $\begin{array}{l}14.9 \\
(7.7)\end{array}$ & $\begin{array}{l}11.8 \\
(5.5)\end{array}$ & $\begin{array}{c}8.0 \\
(3.8)\end{array}$ & $\begin{array}{l}215.3 \\
(67.6)\end{array}$ \\
\hline
\end{tabular}

Univariate statistics of the questionnaire scores and psychiatric history within the success and failure group for PNE are shown in table 3. No significant relation was found between any of the questionnaire scales or psychiatric history and PNE outcome. Only age was identified as a predictive factor (OR $0.95,95 \% \mathrm{Cl}$ $0.90-0.99, p=0.008)$. Patients with a higher age had a significantly lower chance of successful PNE outcome. Optimal dichotomous categorizing of age resulted in a cut-off point of 65 years. In the final regression model, age was the only statistically significant predictor. 
Table 3. Univariate statistics showing the relationship between PNE success and potentially relevant predictors $(n=54)$.

\begin{tabular}{|c|c|c|c|c|c|c|c|}
\hline & & $\mathrm{n}$ & $\begin{array}{l}\% \text { PNE } \\
\text { success }\end{array}$ & $\begin{array}{c}\text { Log } \\
\text { likelihood } \\
X^{2} \\
\end{array}$ & p-value & OR & $95 \% \mathrm{Cl}$ \\
\hline Age & & 54 & - & 6.99 & 0.008 & 0.95 & $0.90-0.99$ \\
\hline Gender & $\begin{array}{l}\text { Male } \\
\text { Female }\end{array}$ & $\begin{array}{l}10 \\
44\end{array}$ & $\begin{array}{l}30 \\
59\end{array}$ & $\begin{array}{c}- \\
2.81\end{array}$ & $\overline{-} \cdot \overline{09}$ & $3 . \overline{37}$ & $\begin{array}{c}- \\
0.77- \\
14.81\end{array}$ \\
\hline Diagnosis & $\begin{array}{l}\mathrm{OAB} \\
\text { retention }\end{array}$ & $\begin{array}{l}38 \\
16\end{array}$ & $\begin{array}{l}58 \\
44\end{array}$ & $0 . \overline{91}$ & 0.34 & $0 . \overline{57}$ & $\begin{array}{c}- \\
0.17-1.84\end{array}$ \\
\hline $\begin{array}{l}\text { Psychiatric } \\
\text { history }\end{array}$ & $\begin{array}{l}\text { no } \\
\text { yes }\end{array}$ & $\begin{array}{l}15 \\
39\end{array}$ & $\begin{array}{l}51 \\
60\end{array}$ & $\overline{-}$ & $\overline{-}$ & 1.43 & $\begin{array}{c}- \\
0.43-4.77\end{array}$ \\
\hline ABQ-N & & 54 & - & 0.00 & 1.00 & 1.00 & $0.98-1.02$ \\
\hline ABQ-NS & & 54 & - & 1.81 & 0.19 & 1.04 & $0.98-1.11$ \\
\hline ABQ-E & & 54 & - & 1.95 & 0.17 & 0.98 & $0.95-1.01$ \\
\hline SCL-ANX & & 54 & - & 0.26 & 0.62 & 1.02 & $0.94-1.11$ \\
\hline SCL-DEP & & 54 & - & 0.46 & 0.50 & 1.01 & $0.97-1.06$ \\
\hline SCL-SOM & & 54 & - & 2.39 & 0.14 & 1.05 & $0.98-1.12$ \\
\hline SCL-OC & & 54 & - & 1.69 & 0.23 & 1.05 & $0.97-1.15$ \\
\hline SCL-IS & & 54 & - & 1.11 & 0.30 & 1.02 & $0.98-1.07$ \\
\hline SCL-PHO & & 54 & - & 2.65 & 0.15 & 1.17 & $0.95-1.44$ \\
\hline SCL-AH & & 54 & - & 0.06 & 0.80 & 0.97 & $0.76-1.24$ \\
\hline SCL-SLE & & 54 & - & 0.07 & 0.79 & 1.02 & $0.88-1.18$ \\
\hline SCL-total & & 54 & - & 1.29 & 0.27 & 1.01 & $0.99-1.01$ \\
\hline
\end{tabular}




\section{Permanent SNM outcome}

All patients who showed a successful response to PNE $(n=29)$ received a permanent implant, except for two patients who eventually refused to undergo surgery. Of the 25 who showed a negative response to test stimulation with PNE, 13 had a borderline effect of PNE (slightly below the 50\% margin), and underwent additional screening with a first stage tined lead. Four of these received a permanent implant after showing a successful response. The remaining 12 patients did not undergo screening with a tined lead because eight had no effect of PNE, and four declined further test stimulation.

In the 31 patients who ultimately received an implant, all device-related adverse events were documented in order to evaluate the outcome of permanent SNM. The mean follow-up after implantation was 22.4 months (SD 9.0, range 12 to 43). Nine patients $(29 \%)$ had at least one adverse event during follow-up. Four experienced a decrease in treatment efficacy, necessitating a lead revision in one patient. In the other 3 patients, treatment efficacy was partially improved by reprogramming the stimulation parameters. Three patients complained of pain at the site of the implantable pulse generator; in 1 patient the pulse generator was moved to the abdomen, and the other 2 were treated conservatively with analgesics.

Two patients complained of pain related to electrical stimulation. The pain typically decreased when turning the stimulator off. Both were treated conservatively by reprogramming the stimulation parameters.

Univariate statistics of the questionnaire scores and psychiatric history for the occurrence of adverse events are shown in table 4. A statistically significant relation was found between a history of psychiatric disease and the occurrence of adverse events (OR 20.0, 95\% Cl 2.68-149.0, $\mathrm{p}=0.001$ ). Patients with a psychiatric history had a $75 \%$ chance of experiencing adverse events vs. $13 \%$ in patients without a psychiatric history. In the multivariate model, the same factors were used as potential predictors for the occurrence of adverse events as for PNE outcome. The duration of follow-up was also included in the regression model, but this did not change the significance of the effect of psychiatric history. None of the questionnaire scales showed significant differences in the occurrence of adverse events. 
Table 4. Univariate statistics showing the relationship between adverse events (AE) of SNM and potentially relevant predictors $(n=31)$.

\begin{tabular}{|c|c|c|c|c|c|c|c|}
\hline & & $\mathrm{n}$ & $\begin{array}{c}\text { \% with } \\
\text { AE }\end{array}$ & $\begin{array}{c}\text { Log } \\
\text { likelihood } \\
X^{2} \\
\end{array}$ & $\begin{array}{c}\mathrm{p}- \\
\text { value }\end{array}$ & OR & $95 \% \mathrm{Cl}$ \\
\hline Age & & 31 & - & 0.85 & 0.36 & 0.98 & $0.92-1.03$ \\
\hline Gender & $\begin{array}{l}\text { Male } \\
\text { Female }\end{array}$ & $\begin{array}{c}2 \\
29\end{array}$ & $\begin{array}{l}50 \\
28\end{array}$ & $-\overline{46}$ & $\begin{array}{c}- \\
0.50\end{array}$ & $\overline{-}$ & $\begin{array}{c}- \\
0.02-6.84\end{array}$ \\
\hline Diagnosis & $\begin{array}{l}\mathrm{OAB} \\
\text { retention }\end{array}$ & $\begin{array}{c}23 \\
8\end{array}$ & $\begin{array}{l}30 \\
25\end{array}$ & 0.09 & 0.77 & $\overline{-}-$ & 0.12-4.75 \\
\hline $\begin{array}{l}\text { Psychiatric } \\
\text { history }\end{array}$ & $\begin{array}{l}\text { no } \\
\text { yes }\end{array}$ & $\begin{array}{c}23 \\
8\end{array}$ & $\begin{array}{l}13 \\
75\end{array}$ & 11.06 & 0.001 & 20.0 & 2.68-149 \\
\hline$A B Q-N$ & & 31 & - & 0.63 & 0.43 & 1.01 & $0.98-1.04$ \\
\hline ABQ-NS & & 31 & - & 0.20 & 0.66 & 1.02 & $0.93-1.13$ \\
\hline$A B Q-E$ & & 31 & - & 0.07 & 0.80 & 1.01 & $0.96-1.05$ \\
\hline SCL-ANX & & 31 & - & 1.16 & 0.28 & 1.06 & $0.96-1.17$ \\
\hline SCL-DEP & & 31 & - & 1.00 & 0.32 & 1.03 & $0.97-1.09$ \\
\hline SCL-SOM & & 31 & - & 0.16 & 0.69 & 1.02 & $0.93-1.11$ \\
\hline SCL-OC & & 31 & - & 0.84 & 0.36 & 1.04 & $0.96-1.13$ \\
\hline SCL-IS & & 31 & - & 0.30 & 0.58 & 1.02 & $0.96-1.07$ \\
\hline SCL-PHO & & 31 & - & 0.16 & 0.70 & 0.95 & $0.71-1.25$ \\
\hline SCL-AH & & 31 & - & 3.5 & 0.08 & 1.37 & $0.96-1.96$ \\
\hline SCL-SLE & & 31 & - & 5.2 & 0.04 & 1.33 & $1.02-1.75$ \\
\hline SCL-total & & 31 & - & 1.00 & 0.32 & 1.01 & $0.99-1.02$ \\
\hline
\end{tabular}




\section{DISCUSSION}

Sacral neuromodulation is an effective treatment option for patients with refractory lower urinary tract symptoms. The safety and durability of this treatment has been proven in long-term studies, and a growing number of patients have been treated worldwide. ${ }^{16-18}$ Still, only $50-70 \%$ of all patients respond to test stimulation, and in approximately 30\% SNM treatment fails after long-term follow-up. ${ }^{16,19,20}$ Currently, a successful response to SNM cannot be accurately predicted, although some authors identified a number of predictive factors. Scheepens et al. identified several predictive factors in a retrospective study evaluating 211 patients. ${ }^{6}$ They found that a history of intervertebral disc prolapse surgery, duration of complaints and the diagnosis of urgency incontinence are factors which may affect the chance of a successful test stimulation. Everaert et al. reported that patients with a history of surgery for stress incontinence had a significantly better long-term outcome with SNM, whatever their symptoms were. ${ }^{7}$ In a group of 100 patients undergoing test stimulation, Koldewijn et al. did not show any predictors of success, although it appeared that patients with detrusor overactivity and urethral instability responded best to SNM. ${ }^{8}$

In our study, age was the only predictor for successful outcome of PNE. Patients with a higher age had a significantly lower chance of showing a successful response $(p=0.015)$. In predictive factor studies of SNM in the treatment of faecal incontinence, older age has also been identified as a negative predictor for PNE outcome. $^{21,22}$ It might be suggested that older patients are less likely to benefit from SNM due to degenerative changes of the nerve system. Another explanation for our findings might be the broad range in age of our study participants, with the youngest being 24 and the oldest 83 years.

It has been shown that patients with functional voiding disorders often have psychological problems. In our study population, the total score of the SCL-90-R questionnaires was considerably higher compared to the norms of a non-patient population (table 2), but lower compared to a population of ambulatory psychiatric patients. In the subscales, we found elevated scores primarily in 
Depression, Somatization and Sleeping problems. These findings correspond with previous findings in the literature, and imply that the SCL-90-R is a valid instrument. $^{9-12}$

Clinical experience suggests that psychological factors might have an influence on the response to SNM. Weil et al. found that 12 of the 16 patients with treatment failure after implantation had a psychiatric disorder in their previous history. ${ }^{13}$ Everaert et al. stated that a decrease in clinical effect directly after implantation compared to the effect during test stimulation was significantly related to a history of psychiatric disease. ${ }^{7}$ In addition, White et al. reported a high rate $(21 \%)$ of implant removal in patients with a psychiatric history, but could not demonstrate a significant relation between psychiatric history and adverse events. ${ }^{23}$ However, they did find that patients who were previously enrolled in a pain clinic had a significantly higher chance of experiencing adverse events. Moreover, Everaert et al. showed that in patients with dysuria or perineal pain, device-related pain was found more frequently. ${ }^{7}$ These findings indicate that psychological factors might play an important role in the selection of eligible candidates for SNM. Yet, this relation has never been clearly evaluated in a prospective study.

In the current study, we found no relation between the scores of the $A B Q$ and SCL-90-R questionnaires and the outcome of test stimulation or chronic SNM. Hence, screening with these instruments for the selection of eligible candidates does not seem useful. However, a history of psychiatric disease was significantly related to the occurrence of adverse events during follow-up $(p=0.001)$. This discrepancy might be explained by the fact that the SCL-90-R only evaluates a 'state of mind', while a psychiatric history might be more informative about the mental constitution. The $A B Q$ only provides dimensional personality traits, and therefore might be insensitive in the screening for psychopathology.

We are aware of the fact that this study has its limitations. Because the number of patients in our study is relatively low, the results from data analysis may be underpowered. Nevertheless, this is the largest prospective study evaluating psychological factors in patients with sacral neuromodulation treatment, and therefore we are confident that our results are of importance in clinical practice. 


\section{CONCLUSION}

We found no evidence in this study that psychological screening with the $A B Q$ or SCL-90-R can predict chances of success with sacral neuromodulation. However, patients with a history of psychiatric disease appear to have a higher chance of encountering adverse events with permanent SNM treatment.

\section{REFERENCES}

1. Bosch $\mathrm{JL}$ and Groen J: Sacral (S3) segmental nerve stimulation as a treatment for urge incontinence in patients with detrusor instability: results of chronic electrical stimulation using an implantable neural prosthesis. J Urol. 154: 504-7, 1995.

2. Shaker HS and Hassouna M: Sacral nerve root neuromodulation: an effective treatment for refractory urge incontinence. J Urol. 159: 1516-9, 1998.

3. Shaker HS and Hassouna M: Sacral root neuromodulation in idiopathic nonobstructive chronic urinary retention. J Urol. 159: 1476-8, 1998.

4. Schmidt RA, Jonas U, Oleson KA, Janknegt RA, Hassouna MM, Siegel SW and van Kerrebroeck PE: Sacral nerve stimulation for treatment of refractory urinary urge incontinence. Sacral Nerve Stimulation Study Group. J Urol. 162: 352-7, 1999.

5. Hassouna MM, Siegel SW, Nyeholt AA, Elhilali MM, van Kerrebroeck PE, Das AK, Gajewski JB, Janknegt RA, Rivas DA, Dijkema H, Milam DF, Oleson KA and Schmidt RA: Sacral neuromodulation in the treatment of urgency-frequency symptoms: a multicenter study on efficacy and safety. J Urol. 163: 1849-54, 2000.

6. Scheepens WA, Jongen MMGJ, Nieman FHM, de Bie RA, Weil EHJ and van Kerrebroeck PEV: Predictive factors for sacral neuromodulation in chronic lower urinary tract dysfunction. Urology. 60: 598, 2002.

7. Everaert K, De Ridder D, Baert L, Oosterlinck W and Wyndaele JJ: Patient satisfaction and complications following sacral nerve stimulation for urinary retention, urge incontinence and perineal pain: a multicenter evaluation. Int Urogynecol J Pelvic Floor Dysfunct. 11: 231-5; discussion 236, 2000.

8. Koldewijn EL, P. F. Rosier, et al.: Predictors of success with neuromodulation in lower urinary tract dysfunction: results of trial stimulation in 100 patients. J Urology. 152: 2071-2075., 1994.

9. Chiverton PA, Wells TJ, Brink CA and Mayer R: Psychological factors associated with urinary incontinence. Clin Nurse Spec. 10: 229-33, 1996. 
10. Perry S, McGrother CW and Turner K: An investigation of the relationship between anxiety and depression and urge incontinence in women: development of a psychological model. Br J Health Psychol. 11: 463-82, 2006.

11. Heymen S: Psychological and cognitive variables affecting treatment outcomes for urinary and fecal incontinence. Gastroenterology. 126: S146-51, 2004.

12. Bilanakis N: Psychogenic urinary retention. Gen Hosp Psychiatry. 28: 259-61, 2006.

13. Weil EH, Ruiz-Cerda JL, Eerdmans PH, Janknegt RA and Van Kerrebroeck PE: Clinical results of sacral neuromodulation for chronic voiding dysfunction using unilateral sacral foramen electrodes. World J Urol. 16: 313-21, 1998.

14. Nijenhuis Jt, Flier, H. van der \& leeuwen, L. van: Comparability of personality test scores for immigrants and majority group members: some Dutch findings. Personality and Individual Differences. 23: 849-859, 1997.

15. Derogatis -L-RL, -R-S; Covi,-L: SCL-90: an outpatient psychiatric rating scale-preliminary report. Psychopharmacol-Bull. Jan 9: 13-28, 1973.

16. van Kerrebroeck PE, van Voskuilen AC, Heesakkers JP, Lycklama a Nijholt AA, Siegel S, Jonas U, Fowler CJ, Fall M, Gajewski JB, Hassouna MM, Cappellano F, Elhilali MM, Milam DF, Das AK, Dijkema HE and van den Hombergh U: Results of sacral neuromodulation therapy for urinary voiding dysfunction: outcomes of a prospective, worldwide clinical study. J Urol. 178: 2029-34, 2007.

17. Siegel SW, Catanzaro F, Dijkema HE, Elhilali MM, Fowler CJ, Gajewski JB, Hassouna MM, Janknegt RA, Jonas U, van Kerrebroeck PE, Lycklama a Nijeholt AA, Oleson KA and Schmidt RA: Long-term results of a multicenter study on sacral nerve stimulation for treatment of urinary urge incontinence, urgency-frequency, and retention. Urology. 56: 87-91, 2000.

18. Bosch JL and Groen J: Sacral nerve neuromodulation in the treatment of patients with refractory motor urge incontinence: long-term results of a prospective longitudinal study. J Urol. 163: 1219-22, 2000.

19. Jonas U, Fowler CJ, Chancellor MB, Elhilali MM, Fall M, Gajewski JB, Grunewald V, Hassouna MM, Hombergh U, Janknegt R, van Kerrebroeck PE, Lylcklama a Nijeholt AA, Siegel SW and Schmidt RA: Efficacy of sacral nerve stimulation for urinary retention: results 18 months after implantation. J Urol. 165: 15-9, 2001.

20. Janknegt RA, Weil EH and Eerdmans PH: Improving neuromodulation technique for refractory voiding dysfunctions: two-stage implant. Urology. 49: 358-62, 1997.

21. Govaert B, Melenhorst J, Nieman FH, Bols EM, van Gemert WG and Baeten CG: Factors associated with percutaneous nerve evaluation and permanent sacral nerve modulation outcome in patients with fecal incontinence. Dis Colon Rectum. 52: 168894, 2009. 
22. Gourcerol G, Gallas S, Michot F, Denis $P$ and Leroi AM: Sacral nerve stimulation in fecal incontinence: are there factors associated with success? Dis Colon Rectum. 50: 3-12, 2007.

23. White WM, Mobley JD, 3rd, Doggweiler R, Dobmeyer-Dittrich C and Klein FA: Incidence and predictors of complications with sacral neuromodulation. Urology. 73: 731-5, 2009. 
Chapter 4 


\section{THE EFFECT OF PULSE RATE CHANGES ON CLINICAL OUTCOME IN SACRAL NEUROMODULATION}

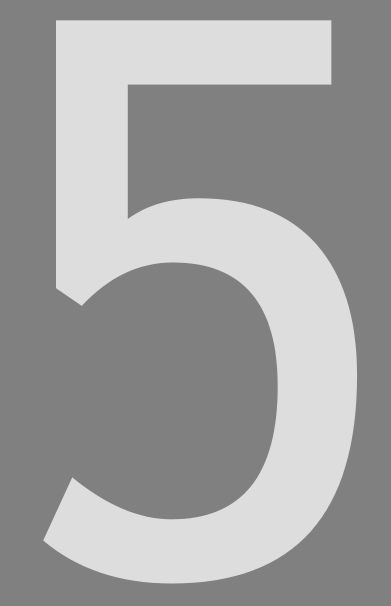

T. Marcelissen

R. Leong

F. Nieman

R. de Bie

P. Van Kerrebroeck

S. de Wachter 


\section{ABSTRACT}

Purpose: To evaluate the effect of pulse rate changes on the clinical response and stimulation related pain symptoms in sacral neuromodulation (SNM) treatment.

Materials and methods: This pilot study evaluated the effect of 4 different pulse rates $(5.2 \mathrm{~Hz}, 10 \mathrm{~Hz}, 21 \mathrm{~Hz}, 40 \mathrm{~Hz})$ in patients with suboptimal response to SNM. The effect of each pulse rate was evaluated over a test period of 6 days. To avoid carry over effect, stimulation was kept off for 24 hours between consecutive test periods. The last 3 days of every test period, a voiding diary and questionnaire was filled in. The changes on clinical response and pain symptoms were compared between the four pulse-rates using multivariate analysis.

Results: Fifty patients were included of which 40 (80\%) were female. Mean age was 55.5yr (SD 12.3). Forty-one patients (82\%) had overactive bladder symptoms and $9(18 \%)$ had chronic non-obstructive urinary retention. No significant difference was found regarding clinical outcome (voiding diary and questionnaire) between the different pulse rates. Furthermore, none of the four pulse rates was significantly related to the occurrence of SNM-related pain. However, on individual basis, patients appear to benefit from changing the pulse rate concerning both treatment efficacy and stimulation related pain.

Conclusions: On group level, none of the four pulse rates in this study appears to have a significantly different effect on clinical outcome or SNM-related pain. However, a tailor-made approach for optimizing treatment efficacy by changing the pulse rate appears to be useful. 


\section{INTRODUCTION}

Patients with refractory overactive bladder symptoms, with or without urgency incontinence and non-obstructive urinary retention who do not respond to conservative treatments such as pharmacotherapy or pelvic floor training, can get symptom relief by sacral neuromodulation (SNM) therapy. ${ }^{1-4}$ The implantable neurostimulator (INS) can have a variety of settings. The waveform that the stimulator produces is a square wave pulse. The pulse-rate can be set between 2.1 and $130 \mathrm{~Hz}$ and the pulse-width between 60 and $450 \mu \mathrm{s}$. Furthermore, the amplitude can be changed from 0.05 to 10.55 Volts.

Most centers that treat patients with SNM commonly use pulse rates between 10 and $16 \mathrm{~Hz}^{5-7}$, a choice that is based on the optimal setting by measuring urethral closure pressure. ${ }^{8}$ In addition, data from animal studies suggest that the pulse rate should not exceed $50 \mathrm{~Hz}$, because this might be detrimental to the stimulated nerve because of the occurrence of early axonal degeneration..$^{9,10}$ Currently, patients with apparently opposite dysfunctions of the lower urinary tract (overactive bladder vs. urinary retention) are treated using the same stimulation parameters, because there are no studies available that clearly evaluated the clinical response to different stimulation parameters. One of the parameters that may have an influence is the pulse rate. The objective of this study was to evaluate the impact of pulse rate changes during sacral neuromodulation on clinical outcome. We also evaluated the effect of changing the pulse rate on the sensory responses and SNM-related pain symptoms.

\section{METHODS}

In this pilot study, patients with a suboptimal effect of SNM treatment using the standard parameter settings were included. Ethical approval for the study was granted and all patients gave written informed consent before the start of the study. Patients with urgency urinary incontinence and patients with chronic nonobstructive urinary retention were recruited during follow-up at our out patient clinic. All subjects had an implantable pulse generator and received sacral neuromodulation therapy for at least 6 months, based on a good response 
during test stimulation defined as more than 50 percent improvement in key voiding diary variables compared to baseline.

Suboptimal effect for patients with incontinence was defined as persistence of some degree of incontinence and for patients with retention the need for catheter use to evacuate residual urine. Only patients with suboptimal effect were included accepting the hypothesis that no symptom improvement can be expected in patients who already experience a full clinical response (patients who had no more symptoms). Patients who experienced decrease in treatment efficacy since implantation were evaluated for technical malfunction or lead migration. Restoration of treatment efficacy was attempted by changing the polarity.

At baseline, the initial settings used were an amplitude just above sensory threshold, frequency of $10 \mathrm{~Hz}$ and a pulse-width of $210 \mu \mathrm{s}$. Patients were asked to keep a voiding diary for 3 days, and to fill in a questionnaire. During the experimental protocol 4 different pulse rates were used, each for a 6-day stimulation period. To avoid carry over effect, stimulation was kept off for 24 hours between the different test periods. For every test period, patients were asked to fill in voiding diaries for 3 days (on day 4, 5 and 6 of the period) and to answer the questionnaire on day 6 . The pulse rates tested during the experimental protocol were: $5.2 \mathrm{~Hz}, 10 \mathrm{~Hz}$ (control setting), $21 \mathrm{~Hz}$ and $40 \mathrm{~Hz}$. The sequence was determined by randomization and was blinded for each patient. The pulse-width was not changed during the whole protocol (210 $\mu \mathrm{s})$ and the patients controlled the amplitude to just above sensory threshold.

The primary outcome was the change in voiding diary parameters between the 4 settings $(5.2 \mathrm{~Hz}$ vs. $10 \mathrm{~Hz}$ vs. $21 \mathrm{~Hz}$ vs. $40 \mathrm{~Hz})$. For patients with urinary incontinence these parameters were the number of voids per day, voided volume per void, daily incontinence episodes and daily pad use. For patients with urinary retention these parameters were the number of catheterizations per day, catheterized volume per catheterization, voided volume per void and the number of voids per day. A change of $20 \%$ or more in the relevant voiding diary parameters compared to baseline was considered clinically significant.

The secondary outcomes were derived from the questionnaire. The first part consisted of questions regarding stimulation-related pain symptoms. With each 
pulse rate, the location of the sensory response and the occurrence of pain or discomfort were documented. The second part consisted of seven questions to value subjective voiding symptoms using visual analogue scores ranging between 0 (worst) to 100 (best).

\section{Statistical analysis}

Since this pilot study was one of the first to analyze the effect of the four pulse rate settings on the response of patients of SNM therapy, it was difficult to perform a power analysis not knowing the strength of the associations of the predictors used in advance. Therefore a tentative initial number of 50 patients was used to gauge the sensibility of the test settings. Paired t-tests were used to compare baseline (control) and $10 \mathrm{~Hz}$ outcomes to check for the validity of the diary results. Repeated measures ANOVA was conducted to test the results between the four pulse-rates. Next, the effects of age and type of complaint ( $O A B$ and non-obstructive urinary retention) subgroups on pulse-rate settings were analyzed. If age had a statistically significant effect, optimal dichotomous categorizing was used to determine cut-off points within age. A level of $p<0.05$ was accepted as statistically significant. For all data analyses SPSS-pc version 16.0 were used.

\section{RESULTS}

\section{Clinical outcome}

Of the 50 patients, 40 were female $(80 \%)$, the average age was 55.5 years (SD 12.3). Forty-one patients (82\%) had urinary incontinence and $9(18 \%)$ had urinary retention. The average post-implant follow-up was 6.2 years (SD 4.8). Of all patients, $38(76 \%)$ experienced clinical improvement (>20\% change in voiding diary parameters) with at least one of the four pulse rate settings. For each pulse rate, the number of patients that experienced clinical improvement is shown in figure 1. Eight of the $41 \mathrm{OAB}$ patients $(20 \%)$ were completely dry with at least one setting, and 2 of the 9 patients with retention (22\%) had no more need for catheterization. 
Figure 1. The effect of each pulse rate setting on clinical outcome measured with voiding diaries $(\mathrm{N}=50)$. Improvement was defined as $>20 \%$ improvement in the relevant voiding diary variables.

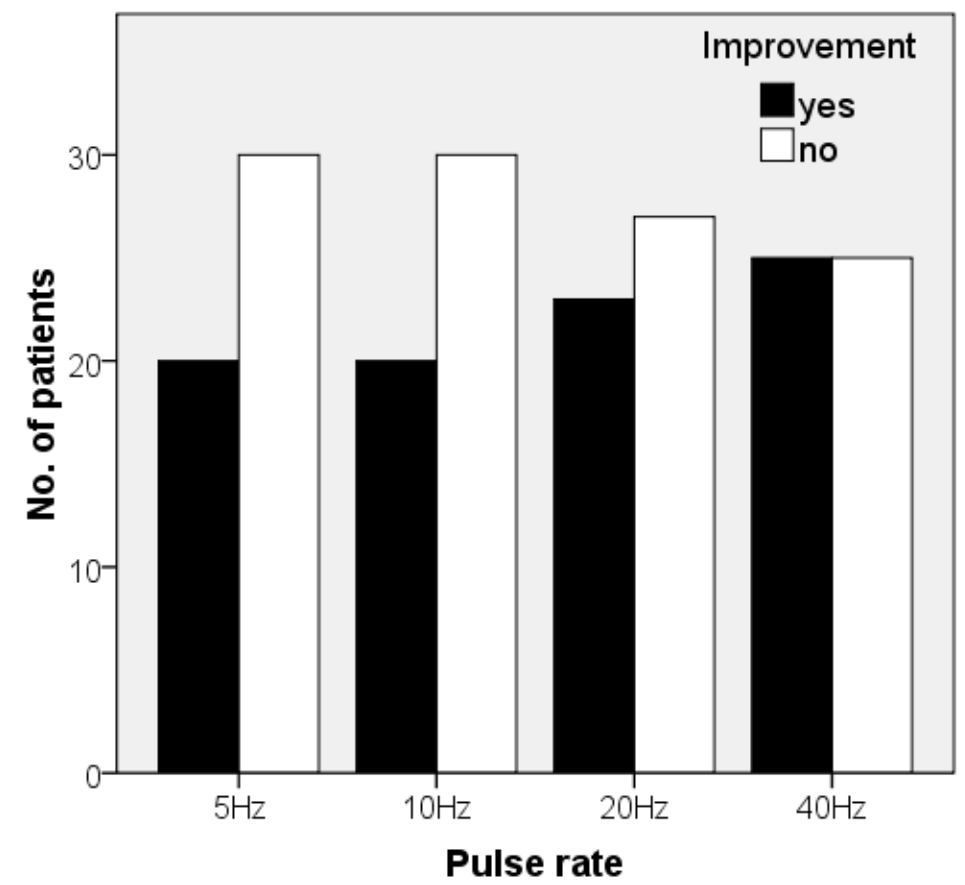

When comparing the effect of the four different pulse rates, no significant relation was found between one of the pulse rates and change in voiding diary parameters (univariate analysis). Multivariate analysis of the voiding diary data, controlled for age and type of complaint, showed a significant difference in number of voids per day with the $40 \mathrm{~Hz}$ setting ( $p=0.036)$, but only for younger patients. For other rates than $40 \mathrm{~Hz}$ this effect was not found. No statistically significant difference was found in the other voiding diary parameters (table 1).

Multivariate analysis of the questionnaire parameters also showed a significant difference in the number of voids per day $(p=0.021)$, only for younger patients. For other rates than $40 \mathrm{~Hz}$ this effect was not found. No statistically significant difference was found for the other VAS parameters (table 1). Optimal dichotomous categorizing of age resulted in a cut-off point of 44 years. 


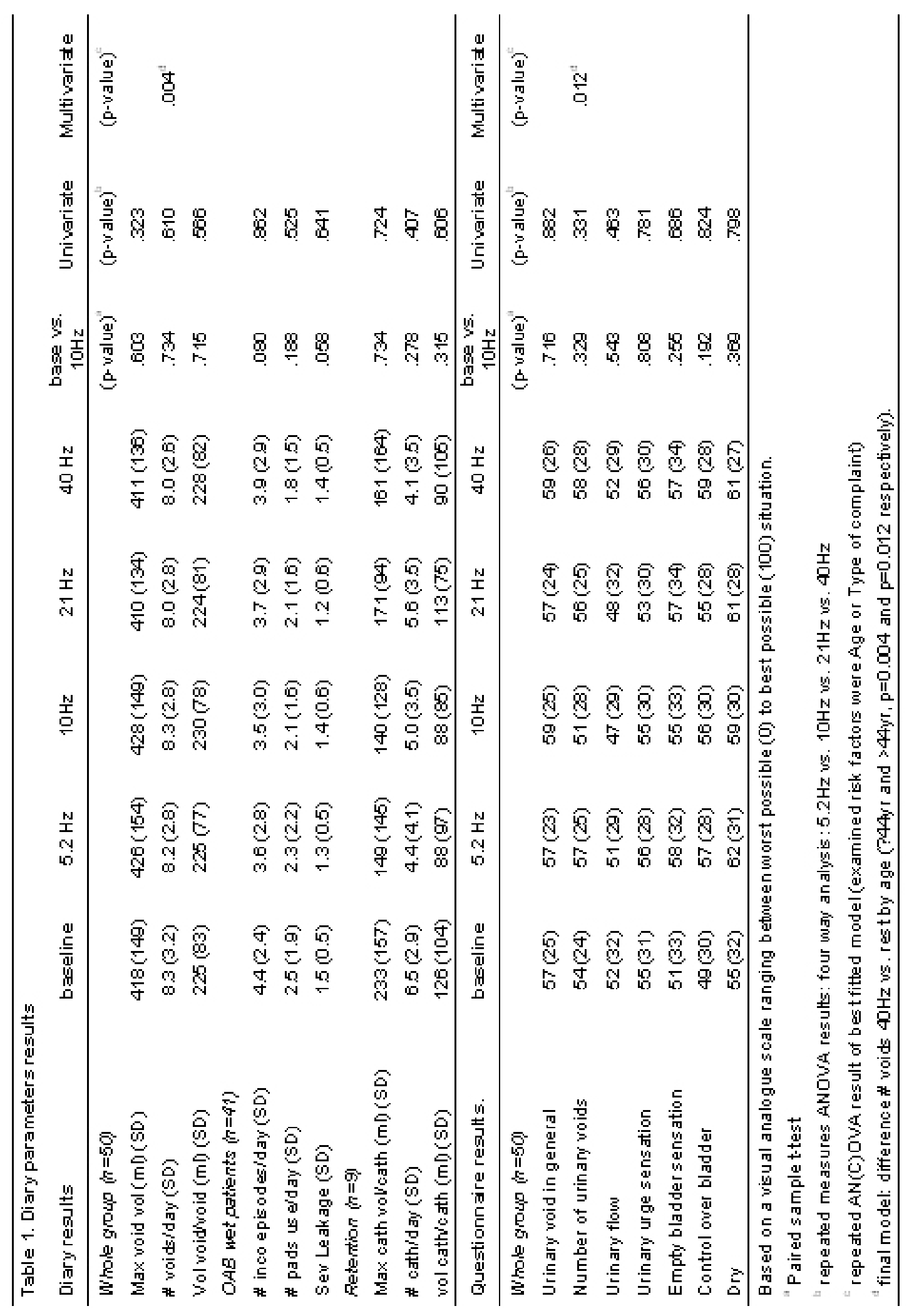




\section{Sensory response}

During reprogramming of the pulse rates, patients were repeatedly asked to locate the sensation site. Their answers were categorized into: 1) anal area, 2) perineal or genital area, 3) buttock area or 4) other area. Thirty-eight of the 50 patients $(76 \%)$ reported a change in the sensation site with at least one of the four pulse rates. Patients reported different sites of sensation with different pulse rates, however, no significant relation between one of the pulse rates and sensation site was seen. Furthermore, no relation was found between the sensation site and clinical effect.

\section{Pain symptoms}

During the study, perceived pain symptoms related to stimulation with different pulse rates were documented. At baseline, 28 patients reported having no pain or discomfort related to electrical stimulation. Of these patients, 12 (43\%) reported 'de novo' pain during the study with one of the pulse rate settings, although only five (18\%) reported the pain as being bothersome in daily life. Figure 2 shows the number of patients that experienced onset of pain symptoms for each pulse rate. Statistical analysis showed no significant relation between one the four pulse rates and the occurrence of pain symptoms. 
Figure 2. Patients without stimulation-related pain symptoms at baseline $(\mathrm{N}=28)$. For every pulse rate, the number of patients that perceived onset of stimulation-related pain symptoms during the study is shown.

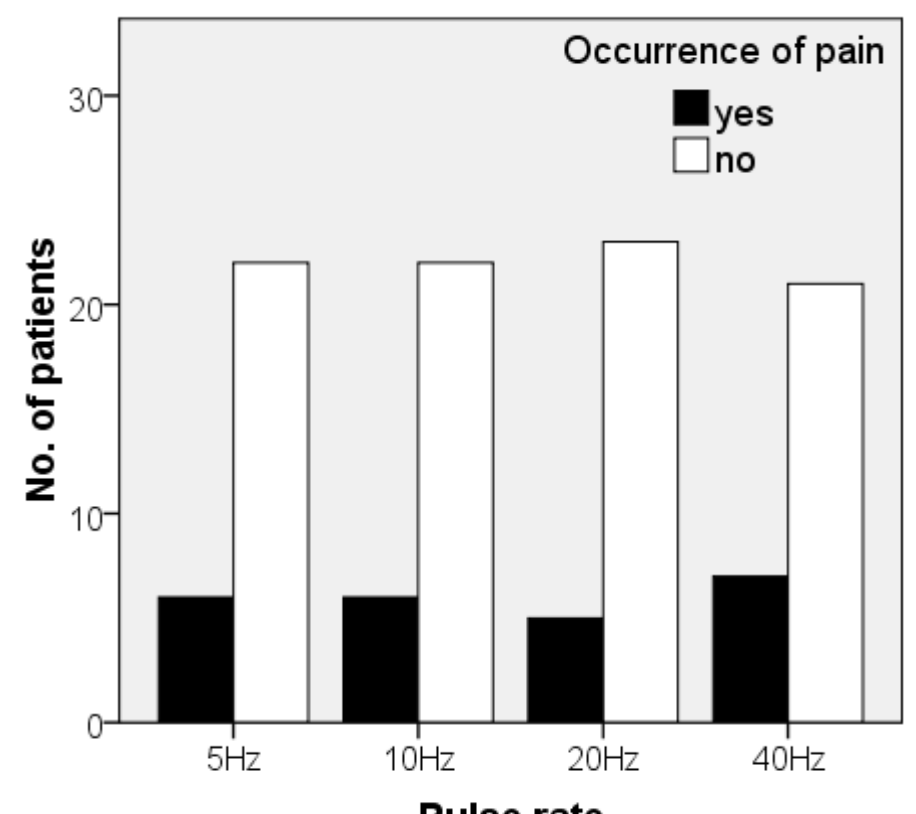

Pulse rate

Twenty-two of the 50 patients reported stimulation related pain at baseline, and four of these patients experienced the pain as being bothersome in daily life. Eighteen of the 22 patients (82\%) reported a decrease in pain symptoms with at least one of the pulse rate settings during the study. For each pulse rate, the number of patients that experienced decrease in pain symptoms are shown in figure 3. No significant relation was found between one of the four settings and decrease in pain symptoms. There was no relation between the disappearance of pain at a certain pulse rate and the clinical efficacy. 
Figure 3. Patients with perceived stimulation-related pain symptoms at baseline $(\mathrm{N}=22)$. For every pulse rate, the number of patients that perceived a decrease in pain symptoms during the study is shown.

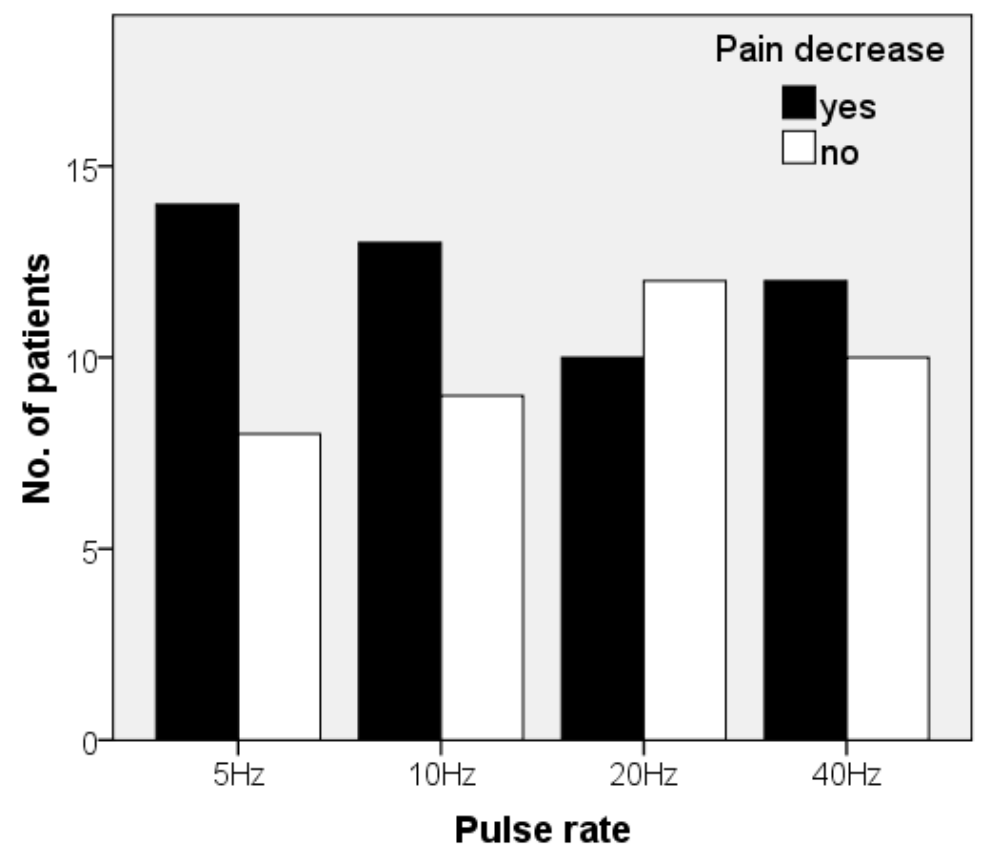

\section{DISCUSSION}

Sacral neuromodulation is a well-accepted treatment option for patients with overactive bladder or non-obstructive urinary retention who are refractory to conservative treatment. In most clinics where SNM is applied, it is customary to set the pulse rate of the INS between 10 and $16 \mathrm{~Hz}^{5-7}$ However, these settings are based on early experiments in SNM, in which the optimal stimulation parameters were determined according to the effect on urethral closure pressure. ${ }^{8}$ At present, it is generally assumed that the mechanism of action of SNM involves modulation of spinal cord reflexes and brain networks by peripheral afferents, rather than direct stimulation of the motor response of the detrusor or urethral sphincter. ${ }^{11}$

In electrophysiological experiments on dorsal root ganglion neurons of the rat, the pulse rates by natural physiological stimuli were found to be approximately 5 $\mathrm{Hz}$ in $\mathrm{C}$ fibers, $15 \mathrm{~Hz}$ in $A \delta$ fibres and $100 \mathrm{~Hz}$ in $A \beta$ fibres. ${ }^{12,13}$ Therefore, 
alteration of the pulse rate could have different effects on different fibre types, and treatment efficacy in SNM might be optimized by evaluating the clinical effect of different pulse rates.

In a study by Tai et al. evaluating pudendal nerve stimulation with different pulse rates $(3$ or $20 \mathrm{~Hz})$ in chronic spinal cord injured rats, different effects were observed on bladder capacity and voiding efficiency. ${ }^{14}$

Up to now, few clinical studies have evaluated the effect of different pulse rates in SNM. In 2003, Malaguti et al. used Somatosensory Evoked Potentials (SEP's) of the pudendal nerve to evaluate the suprasacral action of SNM. ${ }^{15}$ Measurements were performed with $21 \mathrm{~Hz}$ and $40 \mathrm{~Hz}$. They found a higher decrease in pudendal SEP latency when the pulse rate was set to $40 \mathrm{~Hz}$, indicating that a $40 \mathrm{~Hz}$ setting more effectively facilitates the afferent transmission to the central nervous system.

In patients with faecal incontinence, Dudding et al. showed that a pulse rate of $31 \mathrm{~Hz}$ resulted in a significant increase in rectal compliance compared to 14 $\mathrm{Hz} .{ }^{16}$ Although these findings indicate that pulse rate alterations can influence nerve transmission or rectal compliance, the effect of pulse rate alteration on clinical outcome has never been evaluated in a large group of patients.

In our study population, no specific pulse rate appeared to be superior regarding clinical effect. Younger age has already been implicated as a positive predictive factor for clinical success ${ }^{17-20}$, and in our study the $40 \mathrm{~Hz}$ setting resulted in a significantly lower number of voids per day, in younger patients. However, to our opinion, the clinical relevance of this finding seems limited.

Although no significant difference was found between the different pulse rates, the results in our study clearly show that alterations in pulse rate can improve the clinical response in individual patients, as $76 \%$ of all patients experienced improvement of voiding symptoms with at least one of the pulse rate settings. Furthermore, $20 \%$ of the OAB patients became completely dry, and $22 \%$ of the retention patients had no more need for catheterization. This means that changing the pulse rate can be useful in improving treatment efficacy in patients who experience suboptimal effect of SNM.

In general, sensation sites are used as a guide for proper stimulation during screening or reprogramming visits in SNM. It has been assumed that the optimal 
sensory response is located in the anal or genital area, since this is the most commonly observed response during stimulation of the S3 nerve root. ${ }^{21}$ However, there is not much evidence in the literature for this assumption, and no studies have clearly evaluated the relation between the sensation site and clinical effect. In our study, the majority of patients noticed a change in sensation site with at least one of the pulse rate settings. In some patients, the sensation site changed from a desired area, such as the anus, to an undesired area such as the buttock. We found no significant relation between pulse rate and sensation site, nor between sensation site and clinical effect. Hence, these data question the role of sensation site as predictive factor for optimal stimulation.

The effect of pulse rate settings on stimulation-related pain symptoms has never been evaluated, although it is believed that higher stimulation frequencies may result in painful stimulation. A pulse rate higher than $50 \mathrm{~Hz}$ is not recommended due to the possibility of nerve injury, and therefore it is advised to set the pulse rate at 10 to $16 \mathrm{~Hz}{ }^{10,22}$ We evaluated the effect on pain symptoms of four different pulse rates. None of the pulse rates was significantly related to the onset of stimulation-related pain. Although pain could be reduced by changing the pulse rate in individuals who experienced pain symptoms at baseline, no relation was found between a specific pulse rate and the decrease in pain.

These findings imply that all of the four pulse rates can be effectively used during reprogramming of the neurostimulator, and that there does not seem to be a preference for one particular setting. However, since the number of patients in this pilot study is relatively small, the power may be to low to detect a significant difference between the pulse rates. Furthermore, we only evaluated the effect of each pulse rate during one week, and therefore the effect with chronic stimulation cannot be predicted. It would be interesting to evaluate the effect of different pulse rates in a group of patients directly after implantation. Also, we included patients who have been treated with SNM for many years, which might have influenced our results. Unfortunately, we did not evaluate the effect of turning the stimulator off in these patients before the start of the trial. Finally, we 
are aware that we did not include a control group, and therefore the role of a possible placebo effect cannot be evaluated.

\section{CONCLUSION}

In this pilot study, none of the four pulse rates appears to have a significantly different effect on clinical outcome or stimulation-related pain. Nevertheless, a tailor-made approach for optimizing treatment efficacy by changing the pulse appears to be useful.

\section{REFERENCES}

1. Aboseif $\mathrm{S}$, Tamaddon $\mathrm{K}$, Chalfin $\mathrm{S}$, Freedman $\mathrm{S}$ and Kaptein J: Sacral neuromodulation as an effective treatment for refractory pelvic floor dysfunction. Urology. 60: 52-6, 2002.

2. Aboseif S, Tamaddon K, Chalfin S, Freedman S, Mourad MS, Chang JH and Kaptein JS: Sacral neuromodulation in functional urinary retention: an effective way to restore voiding. BJU Int. 90: 662-5, 2002.

3. Abrams $P$ AK, Birder $L$, Brubaker $L$ et al. : Recommendations of the International Scientific Committee: Evaluation and treatment of urinary incontinence, pelvic organ prolapse and faecal incontinence, in Abrams P CL, Khoury S, Wein A: Incontinence. Plymouth, England, Health Publication Ltd, 2009, pp 1767-816.

4. van Kerrebroeck PE, van Voskuilen AC, Heesakkers JP, Lycklama a Nijholt AA, Siegel S, Jonas U, Fowler CJ, Fall M, Gajewski JB, Hassouna MM, Cappellano F, Elhilali MM, Milam DF, Das AK, Dijkema HE and van den Hombergh U: Results of sacral neuromodulation therapy for urinary voiding dysfunction: outcomes of a prospective, worldwide clinical study. J Urol. 178: 2029-34, 2007.

5. Schmidt RA, Jonas U, Oleson KA, Janknegt RA, Hassouna MM, Siegel SW and van Kerrebroeck PE: Sacral nerve stimulation for treatment of refractory urinary urge incontinence. Sacral Nerve Stimulation Study Group. J Urol. 162: 352-7, 1999.

6. Jonas U, Fowler CJ, Chancellor MB, Elhilali MM, Fall M, Gajewski JB, Grunewald V, Hassouna MM, Hombergh U, Janknegt R, van Kerrebroeck PE, Lylcklama a Nijeholt 
AA, Siegel SW and Schmidt RA: Efficacy of sacral nerve stimulation for urinary retention: results 18 months after implantation. J Urol. 165: 15-9, 2001.

7. Hassouna MM, Siegel SW, Nyeholt AA, Elhilali MM, van Kerrebroeck PE, Das AK, Gajewski JB, Janknegt RA, Rivas DA, Dijkema H, Milam DF, Oleson KA and Schmidt RA: Sacral neuromodulation in the treatment of urgency-frequency symptoms: a multicenter study on efficacy and safety. J Urol. 163: 1849-54, 2000.

8. Thon WF, Baskin LS, Jonas U, Tanagho EA and Schmidt RA: Neuromodulation of voiding dysfunction and pelvic pain. World J Urol. 9: 138-141, 1991.

9. Hohenfellner M, Schultz Lampel D, Dahms S, Matzel K and Thuroff JW: Bilateral chronic sacral neuromodulation for treatment of lower urinary tract dysfunction. Journal of urology. 160: 821-4, 1998.

10. Agnew WF, McCreery DB, Yuen TG and Bullara LA: Histologic and physiologic evaluation of electrically stimulated peripheral nerve: considerations for the selection of parameters. Ann Biomed Eng. 17: 39-60, 1989.

11. Kessler TM and Fowler CJ: Sacral neuromodulation for urinary retention. Nat Clin Pract Urol. 5: 657-66, 2008.

12. Handwerker HO, Anton F and Reeh PW: Discharge patterns of afferent cutaneous nerve fibers from the rat's tail during prolonged noxious mechanical stimulation. Exp Brain Res. 65: 493-504, 1987.

13. Koga K, Furue H, Rashid MH, Takaki A, Katafuchi T and Yoshimura M: Selective activation of primary afferent fibers evaluated by sine-wave electrical stimulation. Mol Pain. 1: 13, 2005.

14. Tai C, Wang J, Wang X, de Groat WC and Roppolo JR: Bladder inhibition or voiding induced by pudendal nerve stimulation in chronic spinal cord injured cats. Neurourol Urodyn. 26: 570-7, 2007.

15. Malaguti S, Spinelli M, Giardiello G, Lazzeri M and Van Den Hombergh U: Neurophysiological evidence may predict the outcome of sacral neuromodulation. Journal of urology. 170: 2323-6, 2003.

16. Dudding TC, Vaizey CJ, Gibbs A and Kamm MA: Improving the efficacy of sacral nerve stimulation for faecal incontinence by alteration of stimulation parameters. $\mathrm{Br} \mathrm{J}$ Surg. 96: 778-84, 2009.

17. Govaert B, Melenhorst J, Nieman FH, Bols EM, van Gemert WG and Baeten CG: Factors associated with percutaneous nerve evaluation and permanent sacral nerve modulation outcome in patients with fecal incontinence. Dis Colon Rectum. 52: 168894, 2009.

18. Gourcerol G, Gallas S, Michot F, Denis P and Leroi AM: Sacral nerve stimulation in fecal incontinence: are there factors associated with success? Dis Colon Rectum. 50: 3-12, 2007. 
19. Amundsen CL, Romero AA, Jamison MG and Webster GD: Sacral neuromodulation for intractable urge incontinence: are there factors associated with cure? Urology. 66: 746-50, 2005.

20. Amundsen CL and Webster GD: Sacral neuromodulation in an older, urge-incontinent population. Am J Obstet Gynecol. 187: 1462-5; discussion 1465, 2002.

21. Schmidt RA, Senn E and Tanagho EA: Functional evaluation of sacral nerve root integrity. Report of a technique. Urology. 35: 388-92, 1990.

22. Agnew WF and McCreery DB: Considerations for safety with chronically implanted nerve electrodes. Epilepsia. 31 Suppl 2: S27-32, 1990. 
Chapter 5 
THE USE OF BILATERAL SACRAL NERVE STIMULATION IN PATIENTS WITH LOSS OF UNILATERAL TREATMENT

EFFICACY

T. Marcelissen

R. Leong

J. Serroyen

P. Van Kerrebroeck

S. De Wachter

J Urol. 2011 Mar;185(3):976-80 


\section{ABSTRACT}

Purpose: To evaluate if bilateral sacral nerve stimulation can be effective in restoring treatment efficacy in patients who experience failure of unilateral SNM treatment.

Patients and Methods: Patients who failed unilateral SNM treatment were included. The percutaneous nerve evaluation (PNE) test was used to evaluate the effect of contra- and bilateral stimulation. The stimulation electrode was placed in the contralateral S3 foramen, and symptoms were self-recorded using a three-day voiding diary. Clinical success was defined as more than $50 \%$ improvement in at least one of the relevant voiding diary parameters compared to baseline.

Results: Fifteen patients were included in this study, and underwent test stimulation with PNE. In three patients lead migration was suspected and therefore they were not included in the analysis. Of the remaining 12 patients, four showed a successful response to PNE. Three of these patients were eventually implanted with a contralateral lead. After 12 months treatment, two of the three patients had a successful outcome.

Conclusion: In this pilot study, only a selected group of patients appear to benefit from bilateral stimulation after unilateral therapy failure. Further investigation is necessary to determine the predictive factors and costeffectiveness of this treatment. 


\section{INTRODUCTION}

Sacral neuromodulation (SNM) is an accepted therapeutic option for patients with overactive bladder syndrome $(\mathrm{OAB})$ and chronic non-obstructive urinary retention (UR) with symptoms that are refractory to conservative treatment. ${ }^{1,2}$ SNM activates afferent fibres of the sacral nerves with electrical stimulation in order to modulate sensory processing and micturition reflex pathways in the central nervous system. ${ }^{3,4}$ Before definitive treatment with SNM, patients first undergo a test stimulation, during which the response to S3 stimulation with an external device is evaluated. ${ }^{2}$ The test outcome is at present the only proven predictive factor for long-term success with SNM. Despite this patient selection, treatment efficacy decreases in some patients and after 5 years the success rate is reported to be approximately $70 \%{ }^{5}$ Symptom recurrence can initially be dealt with by reprogramming the stimulation parameters, or in case of device malfunction (e.g. lead disruption, battery depletion) revision surgery can be effective. However, some patients do not benefit from these interventions. These patients are considered refractory to SNM treatment and often require more invasive treatments to control their bladder dysfunction.

Unilateral stimulation of the sacral nerve root is currently the standard technique in SNM, although data from animal studies indicate a stronger modulatory effect of bilateral stimulation. ${ }^{6,7}$ Furthermore, some studies suggest that the pudendal afferent nerve activity can be asymmetrically distributed in humans. ${ }^{8,9}$ Hence, bilateral stimulation might be valuable in restoring treatment efficacy in patients who experience failure of unilateral stimulation. The primary objective of this study was to evaluate the clinical effect of bilateral sacral nerve stimulation in patients with unilateral therapy failure. In addition, we evaluated the effect of contralateral stimulation alone and the difference between contra- and bilateral stimulation.

\section{PATIENTS AND METHODS}

This study was approved by the ethical committee and all participants signed an informed consent. In this prospective pilot study, data were collected from patients who were previously implanted with a sacral neurostimulator for 
overactive bladder symptoms (both OAB wet and dry) or chronic non-obstructive urinary retention. Patients were implanted with the Interstim model 3023 with the lead positioned in the third sacral foramen at either the left or right side. Patients who experienced loss of treatment efficacy (return of baseline symptoms on voiding diary) were considered eligible candidates. Before inclusion in the study, impedance and battery life were checked and the clinical response was evaluated to at least five reprogramming sessions during a period of 4 weeks for each session. Treatment failure due to device malfunction was an exclusion criterion. Furthermore, a clinical and neurological evaluation was conducted, as well as urodynamics and cystoscopy to rule out the onset of new urinary pathologies as a possible reason for the treatment failure.

Before the start of the protocol all patients filled out a 3-day voiding diary to evaluate the effect of unilateral stimulation, which served as baseline measurement. The percutaneous nerve evaluation (PNE) test was used to evaluate the effect of contra- and bilateral stimulation. The stimulation electrode was placed in the contralateral S3 foramen, and sensory as well as motor responses were used to ensure correct positioning of the lead. The lead position which provoked adequate responses with the lowest possible amplitude was chosen to ensure the lead was in close proximity to the nerve root. In addition, $\mathrm{X}$ ray was used to verify the position of the lead.

Symptoms were again self-recorded with a three-day voiding diary. The test duration lasted eight days: three-day stimulation of only the temporary lead (contralateral stimulation), followed by three-day stimulation of both leads (bilateral stimulation) or vice versa, determined by concealed randomization (fig. 1). Between the two stimulation periods, a wash-out period of two days was incorporated to avoid carry-over effect. At the end of the test, another X-ray was taken to evaluate possible lead migration. Furthermore, patients were asked whether the location and intensity of the sensory response had changed during the test. If lead migration was suspected, the patient data were not included in the analysis. 
Figure 1. Overview of the study design.

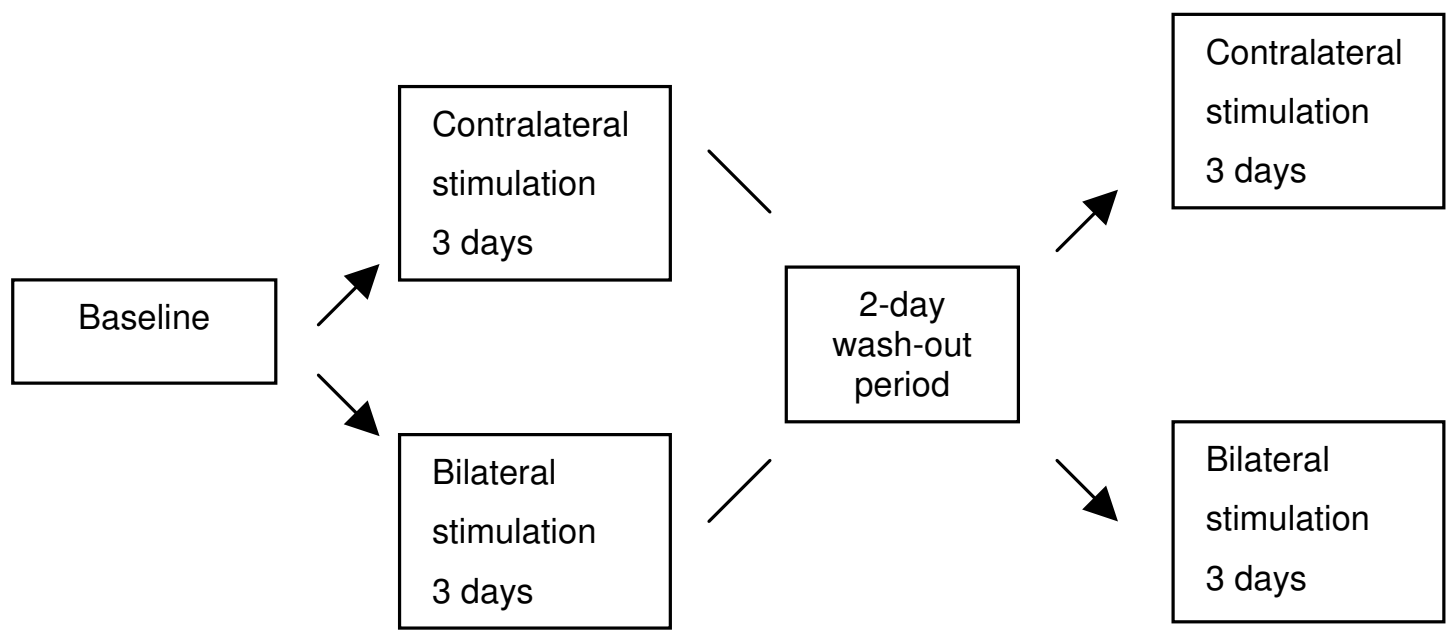

A successful response was defined as $>50 \%$ improvement in at least one of the relevant voiding diary parameters compared to baseline. For OAB wet patients these included: a reduction in the daily episodes of incontinence or pad usage, for OAB dry patients: a reduction in the number of daily voids or an increase in voided volume per void, and for patients with non-obstructive urinary retention: a reduction in the catheterized volume per catheterization. Wilcoxon signed ranks test with correction for multiple testing (Bonferroni) was used to compare the clinical response to contralateral vs. baseline stimulation, bilateral vs. baseline stimulation and contralateral vs. bilateral stimulation. $\mathrm{P}<0.05$ was considered the level of significance. For all data analyses SPSS software version 16.0 was used. 


\section{RESULTS}

Fifteen patients were included in the study (13 women and 2 men), of whom 8 started with contralateral stimulation and 7 with bilateral stimulation. In three patients lead migration was suspected. Therefore the voiding diary data of these patients were considered unreliable and they were excluded from analysis. Of the remaining 12 patients, nine had urgency incontinence (OAB wet), two had urgency/frequency (OAB dry) and one had chronic non-obstructive urinary retention. The relevant baseline characteristics of the analyzed patients are shown in table 1.

Table 1. Characteristics of all patients who underwent test stimulation with PNE. Patients 2, 4, 5 and 7 showed a positive response to contralateral and bilateral stimulation. The duration of treatment from device implantation to PNE is shown in the last column. Ul= urgency incontinence, $U / F=$ urgency/frequency, $U R=$ urinary retention. $M M K=$ Marshall-Marchetti-Kranz procedure, $T V T=$ transvaginal tape.

\begin{tabular}{|c|c|c|c|c|c|}
\hline & Gender & Symptoms & $\begin{array}{c}\text { Age } \\
\text { (years) }\end{array}$ & Relevant history & $\begin{array}{c}\text { Duration of } \\
\text { treatment } \\
\text { (years) }\end{array}$ \\
\hline Pt 1 & Female & UI & 57 & MMK, vaginal wall repair & 8 \\
\hline Pt 2 & Female & UI & 58 & Burch suspension & 7 \\
\hline Pt 3 & Female & $\mathrm{U} / \mathrm{F}$ & 64 & Appendectomy & 5 \\
\hline Pt 4 & Female & UI & 60 & - & 12 \\
\hline Pt 5 & Female & UI & 60 & $\begin{array}{l}\text { Hysterectomy, Burch } \\
\text { suspension }\end{array}$ & 1 \\
\hline Pt 6 & Female & UI & 44 & $\begin{array}{l}\text { Hysterectomy, Raz- } \\
\text { suspension }\end{array}$ & 5 \\
\hline Pt 7 & Female & UI & 54 & $\begin{array}{l}\text { Hysterectomy, TVT, } \\
\text { discectomy }\end{array}$ & 3 \\
\hline Pt 8 & Female & UI & 47 & $\begin{array}{l}\text { Hysterectomy, Btx- } \\
\text { injection }\end{array}$ & 2 \\
\hline Pt 9 & Female & UI & 55 & Hysterectomy & 8 \\
\hline Pt 10 & Male & $\mathrm{U} / \mathrm{F}$ & 73 & TUR-prostate, urethrotomy & 7 \\
\hline Pt 11 & Male & UI & 75 & - & 2 \\
\hline Pt 12 & Female & UR & 39 & Urethrotomy, Discectomy & 2 \\
\hline
\end{tabular}


During test stimulation with PNE, eight showed a negative response (i.e. less than $50 \%$ improvement in all of the relevant parameters) to contralateral as well as bilateral stimulation. The other four patients (table 1: patients 2, 4, 5, and 7) showed more than $50 \%$ improvement in at least one parameter to both contralateral and bilateral stimulation. The changes in voiding diary parameters during PNE are shown in table 2, and the mean differences between baseline, contralateral, and bilateral stimulation are illustrated in figure 2. Examining the whole patient group, the clinical response was higher with bilateral stimulation compared to contralateral stimulation in all of the voiding diary parameters. A significant difference was only found in the number of voids per day $(p=0.02)$ and the number of pads per day $(p=0.03)$.

Table 2. The results of voiding diary analysis at baseline (bas) and during contralateral (con) and bilateral $(b i)$ test stimulation. The relevant voiding diary parameters for patients with $O A B$ are shown.

\begin{tabular}{lcccccccccccc}
\hline & \multicolumn{1}{c}{ voided volume/void } & \multicolumn{3}{c}{ \# voids/day } & \multicolumn{3}{c}{ \# leakages/day } & \multicolumn{3}{c}{ \# pads/day } \\
\hline Pt & Bas & Con & Bi & Bas & Con & Bi & Bas & Con & Bi & Bas & Con & Bi \\
\hline 1 & 85 & 76 & 123 & 13.9 & 13.7 & 13.4 & 11.9 & 12.2 & 7.6 & 2.2 & 2.1 & 1.2 \\
2 & 96 & 158 & 163 & 11.5 & 11.2 & 8.3 & 11.3 & 9.1 & 6.4 & 5.9 & 1.5 & 1.6 \\
3 & 160 & 222 & 173 & 11.4 & 12.9 & 6.9 & 0.0 & 0.0 & 0.0 & 0.0 & 0.0 & 0.0 \\
4 & 187 & 203 & 193 & 8.1 & 8.2 & 7.2 & 3.5 & 1.6 & 1.0 & 2.1 & 1.0 & 0.5 \\
5 & 226 & 250 & 301 & 11.9 & 9.5 & 7.6 & 11.2 & 4.4 & 4.9 & 5.2 & 2.6 & 1.1 \\
6 & 115 & 136 & 122 & 9.0 & 11.2 & 10.9 & 9.0 & 11.2 & 10.9 & 9.0 & 11.2 & 10.9 \\
7 & 71 & 184 & 211 & 15.8 & 6.8 & 6.8 & 4.4 & 0.4 & 0 & 4.0 & 0.4 & 0 \\
8 & 103 & 90 & 92 & 13.3 & 13.0 & 12.9 & 13.3 & 13.0 & 12.9 & 7.5 & 6.0 & 4.9 \\
9 & 112 & 128 & 134 & 12.5 & 13.1 & 11.6 & 12.5 & 13.1 & 11.6 & 3.8 & 3.8 & 3.4 \\
10 & 81 & 102 & 99 & 13.6 & 12.8 & 10.4 & 0.0 & 0.0 & 0.0 & 0.0 & 0.0 & 0.0 \\
11 & 141 & 156 & 138 & 8.4 & 9.5 & 8.4 & 6.0 & 6.8 & 6.8 & 1.3 & 1.8 & 1.3 \\
\hline Mn & 125 & $\mathbf{1 5 5}$ & $\mathbf{1 5 9}$ & $\mathbf{1 1 . 6}$ & $\mathbf{1 1 . 1}$ & $\mathbf{9 . 5}$ & $\mathbf{7 . 6}$ & $\mathbf{6 . 5}$ & $\mathbf{5 . 6}$ & $\mathbf{3 . 4}$ & $\mathbf{2 . 8}$ & $\mathbf{2 . 3}$ \\
SD & $\mathbf{4 9}$ & $\mathbf{5 6}$ & $\mathbf{6 0}$ & $\mathbf{2 . 5}$ & $\mathbf{2 . 3}$ & $\mathbf{2 . 4}$ & $\mathbf{5 . 0}$ & $\mathbf{5 . 4}$ & $\mathbf{4 . 9}$ & $\mathbf{2 . 9}$ & $\mathbf{3 . 3}$ & $\mathbf{3 . 2}$ \\
\hline
\end{tabular}


Figure 2. Mean differences between baseline (base), contralateral (con) and bilateral (bi) stimulation for each voiding diary parameter. Significance levels are provided comparing baseline versus contralateral stimulation (base vs. con), baseline versus bilateral stimulation (base vs. $b i$ ) and contralateral versus bilateral stimulation (con vs. bi). Wilcoxon signed rank test was used for analysis of differences between groups, with correction for multiple testing (Bonferroni).
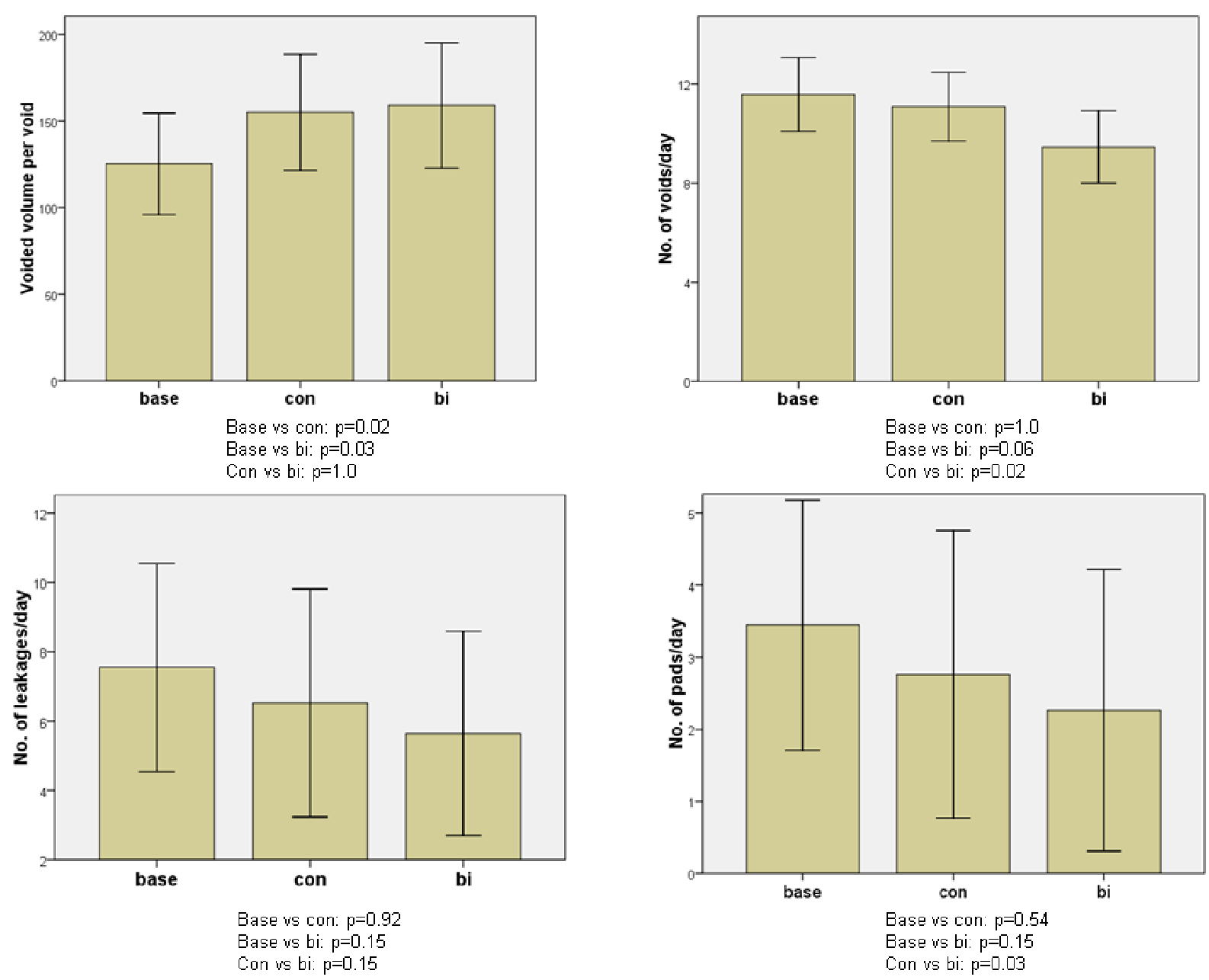

The results of patient 12 (patient with urinary retention) were not shown, since different parameters were used. This patient had a voided volume of $93 \mathrm{ml}$ per void and a catheterized volume of $491 \mathrm{ml}$ per catheterization at baseline. Test stimulation did not increase the voided volume and only reduced the catheterized volume by $40 \mathrm{ml}$, with similar results for contra- and bilateral stimulation. 
Of the four patients who showed a successful response to PNE, all except patient number 2 received permanent bilateral stimulation. Patient 2 refused to undergo implantation of a second device, despite the positive response to test stimulation.

Twelve months after implantation, patients 4, 5 and 7 were again asked to record their symptoms with a 3-day voiding diary. Two of the three patients (4 and 5) still experienced more than $50 \%$ improvement in at least one of the voiding diary parameters compared to baseline. Both reported to be satisfied with the current treatment. Patient 7 was also satisfied with current treatment and showed symptomatic improvement, but the voiding diary showed only $41 \%$ improvement compared to baseline. No painful stimulation or side effects were reported with chronic bilateral stimulation.

\section{DISCUSSION}

Sacral neuromodulation is a well accepted treatment with good long-term results for patients with detrusor overactivity or chronic non-obstructive urinary retention. ${ }^{5}$ However, decrease in efficacy with SNM is not uncommon and may result from different causes. Gaynor-Krupnick et al. previously developed an algorithm for troubleshooting in SNM, which provided an organized and stepwise approach to the malfunctioning neurostimulator. ${ }^{10}$ Yet, in some patients no evident cause for treatment failure can be found and conservative treatment (reprogramming the stimulation parameters) is unsatisfactory. The development of approaches to restore treatment efficacy in these patients is therefore needed. Bilateral stimulation has been suggested to be a more effective treatment for patients with voiding dysfunction ${ }^{6,11}$, and therefore might be a useful method for restoring treatment efficacy in patients with failure of unilateral SNM treatment. Animal studies have shown that bilateral stimulation induces a stronger modulatory effect compared to unilateral stimulation. ${ }^{6}$ In a recent study on detrusor overactivity in a porcine model, bilateral stimulation demonstrated a significantly higher reduction of the amplitude and number of autonomous detrusor contractions compared to unilateral stimulation. ${ }^{7}$ Although these data 
suggest that bilateral stimulation is superior to unilateral stimulation, in our study we only found a significant difference between contra- and bilateral stimulation for the number of voids and daily pad use. Previously, Scheepens et al. compared the response to unilateral and bilateral PNE in the selection of eligible candidates for SNM. ${ }^{12}$ They found no significant differences in voiding diary parameters between unilateral and bilateral stimulation in a group of 25 patients with $\mathrm{OAB}$ and retention. However they concluded that in selected patients bilateral stimulation might be beneficial, since 2 patients with urinary retention only responded to bilateral stimulation. The main difference with the current study is that Scheepens et al. evaluated "naïve" patients, meaning that patients did not previously receive neuromodulation therapy. However, the results in the current study are comparable and show that in certain patients bilateral stimulation may be superior to unilateral stimulation. Nevertheless, it is still unclear which factors can predict the response to bilateral stimulation.

The reason why SNM treatment fails in some patients during follow-up is unclear. A possible hypothesis could be adaptation of the nervous system. ${ }^{13}$ The responsiveness of the sacral afferents that modulate the micturition reflexes might decrease over time with continuous electrical stimulation. In patients with failure of SNM treatment, stimulation of the sacral nerves on the contralateral side might result in enough input to compensate for the adapted nerve system. Along with this assumption, bilateral stimulation might be more effective than contralateral stimulation since it provides more electrical input to the sacral nerves, resulting in a higher clinical response. Another theory that has been suggested is fibrosis forming around the lead, which might cause insufficient stimulation of the sacral nerve root. $^{14}$ Since the duration of treatment from implantation to treatment failure varied between 1-12 years in our study (table 1), this theory seems to be less plausible.

The reason why only a small number of our patients in turn showed a successful response to contra- or bilateral test stimulation is also unclear, although natural progression of the initial bladder dysfunction cannot be ruled out and some patients therefore might no longer be able to benefit from SNM. The use of the PNE test can also be accounted for the low success rate, as prolonged 
screening with the tined lead has proven to induce a more profound clinical response. ${ }^{15}$ For this pilot study, we decided to use PNE because of the low costs, the minimal invasive nature of the procedure and the unknown outcome of bilateral stimulation. With PNE, in four of the 12 patients treatment efficacy could be restored during the test period, and after 1 year follow-up, two patients (17\%) were successfully treated with bilateral SNM. Contralateral stimulation with a test lead might theorectically be considered in patients with therapy failure, yet the success rate seems to be rather low. Although the number of patients in this pilot study is too small to draw any firm conclusions, the results suggest that the role of bilateral stimulation in restoring treatment efficacy is currently limited.

\section{CONCLUSION}

In this pilot study, only a selected group of patients appear to benefit from bilateral stimulation after unilateral therapy failure. Further investigation is necessary to determine the predictive factors and cost-effectiveness of this treatment.

\section{REFERENCES}

1. Shaker HS and Hassouna M: Sacral nerve root neuromodulation: an effective treatment for refractory urge incontinence. J Urol. 159: 1516-9, 1998.

2. Schmidt RA, Senn E and Tanagho EA: Functional evaluation of sacral nerve root integrity. Report of a technique. 35: 388-92, 1990.

3. Schurch B, Reilly I, Reitz A and Curt A: Electrophysiological recordings during the peripheral nerve evaluation (PNE) test in complete spinal cord injury patients. World $\mathrm{J}$ Urol. 20: 319-22, 2003.

4. van der Pal F, Heesakkers JP and Bemelmans BL: Current opinion on the working mechanisms of neuromodulation in the treatment of lower urinary tract dysfunction. Curr Opin Urol. 16: 261-7, 2006.

5. van Kerrebroeck PE, van Voskuilen AC, Heesakkers JP, Lycklama a Nijholt AA, Siegel S, Jonas U, Fowler CJ, Fall M, Gajewski JB, Hassouna MM, Cappellano F, Elhilali MM, Milam DF, Das AK, Dijkema HE and van den Hombergh U: Results of sacral neuromodulation therapy for urinary voiding dysfunction: outcomes of a prospective, worldwide clinical study. J Urol. 178: 2029-34, 2007. 
6. Schultz-Lampel D: Neurophysiologische Grundlagen und Klinische Anwendung der sakralen Neuromodulation zur Therapie der Blasenfunctionsstörungen: Klinik für Urologie und Kinderurologie. Wuppertal, Universität Witten/Herdecke, 1997.

7. Kaufmann S, Naumann CM, Hamann MF, Seif C, Braun PM, Junemann KP and van der Horst C: Unilateral vs bilateral sacral neuromodulation in pigs with formalininduced detrusor hyperactivity. BJU Int. 103: 260-3, 2009.

8. Huang JC, Deletis V, Vodusek DB and Abbott R: Preservation of pudendal afferents in sacral rhizotomies. Neurosurgery. 41: 411-5, 1997.

9. Deletis V, Vodusek DB, Abbott R, Epstein FJ and Turndorf H: Intraoperative monitoring of the dorsal sacral roots: minimizing the risk of iatrogenic micturition disorders. Neurosurgery. 30: 72-5, 1992.

10. Gaynor-Krupnick DM, Dwyer NT, Rittenmeyer $\mathrm{H}$ and Kreder KJ: Evaluation and management of malfunctioning sacral neuromodulator. Urology. 67: 246-9, 2006.

11. Hohenfellner M, Schultz-Lampel D, Dahms S, Matzel K and Thuroff JW: Bilateral chronic sacral neuromodulation for treatment of lower urinary tract dysfunction. J Urol. 160: 821-4, 1998.

12. Scheepens WA, de Bie RA, Weil EH and van Kerrebroeck PE: Unilateral versus bilateral sacral neuromodulation in patients with chronic voiding dysfunction. J Urol. 168: 2046-50, 2002.

13. Zvara $\mathrm{P}$, Sahi $\mathrm{S}$ and Hassouna MM: An animal model for the neuromodulation of neurogenic bladder dysfunction. Br J Urol. 82: 267-71, 1998.

14. Deng DY, Gulati M, Rutman M, Raz S and Rodriguez LV: Failure of sacral nerve stimulation due to migration of tined lead. J Urol. 175: 2182-5, 2006.

15. Kessler TM, Madersbacher $\mathrm{H}$ and Kiss $\mathrm{G}$ : Prolonged sacral neuromodulation testing using permanent leads: a more reliable patient selection method? Eur Urol. 47: 660-5, 2005. 


\section{SACRAL NEUROMODULATION AS A TREATMENT FOR CHRONIC PELVIC PAIN: A REVIEW OF THE LITERATURE}

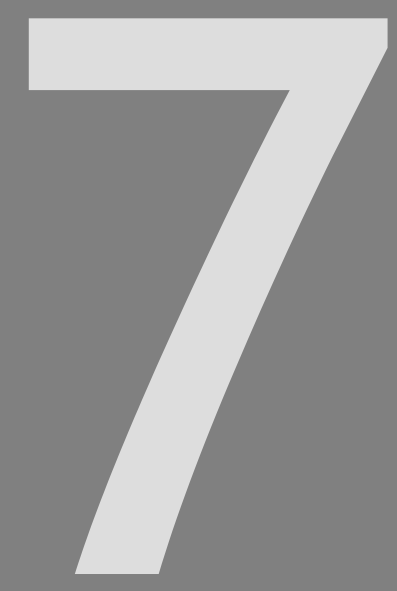

T. Marcelissen

R. Jacobs

P. Van Kerrebroeck

S. De Wachter 


\section{ABSTRACT}

Purpose: Chronic pelvic pain syndrome is a debilitating disease which often has a major impact on quality of life. Sacral neuromodulation (SNM) has been suggested as a useful treatment of chronic pelvic pain. This review provides an overview of the published literature on SNM as a treatment for chronic pelvic pain.

Materials and Methods: A PubMed® search was performed to identify articles in English from 1990 to February 2010 reporting treatment of pelvic pain with sacral neuromodulation. Also, the current definitions of pelvic pain syndromes are discussed as well as the mechanism of action.

Results: A total of 12 relevant articles were identified. Ten articles mainly addressed the efficacy of SNM in patients with interstitial cystitis/bladder pain. The duration of follow-up ranged between 5-87 months. The mean reduction in pain scores was reported between 40 and $72 \%$. The re-operation rate ranged between 27 and 50\%. Two articles included patients with miscellaneous urogenital pain syndromes. The success rates after implantation ranged from 60 $77 \%$, with duration of follow-up ranging between 19-36 months.

Conclusion: Although the results seem promising, there is currently insufficient evidence to determine the role of SNM in the treatment of chronic pelvic pain. Larger prospective trials with long-term evaluation are required. 


\section{INTRODUCTION}

Chronic pelvic pain (CPP) syndrome is a debilitating disease which often has a major impact on quality of life. ${ }^{1,2}$ There are often associated negative cognitive, behavioural, sexual, and emotional consequences. This clinical condition presumably has a multifactorial aetiology and patients with CPP often tend to undergo a multitude of treatments for controlling symptoms. ${ }^{3}$ However, a subset of patients do not respond to conventional treatments. Patients with bladder pain syndrome (BPS) or interstitial cystitis (IC) are often faced with the decision to undergo radical surgery such as urinary diversion or bladder augmentation. Unfortunately, these major interventions are associated with significant morbidity and often these treatments fail to alleviate pain symptoms. ${ }^{4,5}$ As many as $50 \%$ of patients who underwent cystectomy for interstitial cystitis continue to have pelvic pain, presumably secondary to the centralization of pain. ${ }^{6}$

Currently, minimally-invasive treatments have been suggested as possible alternatives in the treatment of CPP. These include sacral neuromodulation (SNM) and intravesical injections with botulinum toxin. Both treatments have shown positive results in the treatment of overactive bladder syndrome, and SNM has previously gained FDA-approval for this indication. ${ }^{7-10}$ Over the past years, several studies have evaluated the efficacy of sacral neuromodulation in the treatment of CPP. In order to assess the current evidence for this indication, we reviewed the published literature on sacral neuromodulation for chronic pelvic pain. In addition, the current definitions of CPP and the possible mechanism of action are discussed.

\section{MATERIALS AND METHODS}

A literature search was conducted using PubMed. Relevant articles in English regarding sacral neuromodulation in the treatment of chronic pelvic pain were identified. This included patients with IC/BPS as well as patients with nonspecific pelvic pain symptoms (e.g. genital, urethral, perineal pain). Only the results of clinical trials were included. In this review, the emphasis was on studies that evaluated transforaminal S3 nerve root stimulation. Studies that evaluated other neuromodulatory techniques were separately discussed. 
Relevant articles were selected from these searches and the reference lists from the identified articles were checked for additional sources. The search terms used were: 'sacral neuromodulation' or 'sacral nerve stimulation'. These terms were combined using 'AND' with the term 'pain'. This resulted in a search count of 70 and 145 respectively. The search was specified by using the terms 'pelvic pain', 'bladder pain', 'interstitial cystitis', 'urogenital pain' and 'genital pain'. All clinical trials, meeting abstracts and case reports were reviewed. Only the results of clinical trials were reported. The last search was carried out in October 2010.

\section{DEFINITIONS}

Identifying the location and cause of chronic pelvic pain is complex, because the visceral innervation of the pelvic structures share common pathways along the sacral plexus. ${ }^{11}$ It is therefore difficult to properly define CPP. The latest EAU guidelines on chronic pelvic pain developed a classification system where pain syndrome terms were introduced to emphasize the heterogeneity of the concept CPP and to indicate the multiple mechanisms involved, both physical and psychological. ${ }^{12}$ According to these guidelines, chronic pelvic pain is defined as nonmalignant pain perceived in structures related to the pelvis. In the case of documented nociceptive pain that becomes chronic, pain must have been continuous or recurrent for at least 6 months. The pain can be associated with symptoms suggesting lower urinary tract, sexual, bowel, or gynaelogical dysfunction. Urologic pelvic pain syndromes are divided into bladder pain syndrome, urethral pain syndrome, penile pain syndrome, prostate pain syndrome, and others. In 2007, the European Society for the Study of Interstitial Cystitis (ESSIC) proposed the term bladder pain syndrome (BPS) as more accurate terminology. ${ }^{13}$ The term Interstitial Cystitis (IC) assumes a special type of chronic inflammation of the bladder, whereas BPS refers to pain perceived in the bladder region. Moreover, inflammation or the presence of Hunner's ulcers on cystoscopy with hydrodistention are important features in only a few patients. The increase of pain on bladder filling was left out of the description because this association is not always present. Although persistent urge to void or frequency 
are included as typical symptoms in the definition, it must be stressed that the presence of these symptoms is not necessary to suspect or diagnose BPS.

\section{MECHANISM OF ACTION}

Neuromodulation has been used for many years as a treatment for various chronic pain conditions. The most accepted neuromodulatory technique is spinal cord stimulation, in which electrical signals are delivered to the spinal cord by electrodes in the epidural space. In addition, peripheral nerve stimulation has been successfully used for various indications, such as post-traumatic and postsurgical neuropathy, occipital neuralgia and chronic regional pain syndromes. ${ }^{14}$ Peripheral nerve stimulation is likely to recruit larger number of nerve fibers for the purpose of activating inhibitory interneurones than spinal cord stimulation, which exerts its effect through layers of dura and cerebrospinal fluid. It also permits recruitment of primary afferent delta fibers, which project to the spinothalamic tract and probably not to the dorsal column. ${ }^{15}$

The etiology and pathophysiology of chronic pelvic pain remains a mystery, although central neurological mechanisms are probably involved. There are suggestions that dysregulated central nervous system responses may play a major role in the aetiology. ${ }^{3,12}$ These dysregulated responses may maintain the perception of pain in the absence of acute injury. In addition, these changes may magnify perception in such manner that non-painful stimuli are perceived as painful and painful stimuli may be perceived as stronger than normal. ${ }^{12}$ Therefore, it has been suggested that therapies aimed at modulating the nervous system such as centrally acting medications, posterior tibial nerve stimulation (PTNS) and sacral neuromodulation (SNM) might be effective. A possible working mechanism for neuromodulation in the treatment of pain is based on the gate-control theory. This theory states that pain perception depends on a pattern of peripheral nervous input. It is believed that a gate-control mechanism at the spinal segment level is present, which regulates the interaction between afferent nerve signals and pain sensation. ${ }^{16}$ Interneurons of the spinal cord dorsal horn create gating components, and inhibition or facilitation of afferent fibres modulates the input to the spinal transmission neurons. Furthermore, it is 
believed that the impulses from the dorsal horn are controlled by a descending system containing fibres from the brainstem, thalamus and limbic lobes. ${ }^{17}$ Neuromodulation is believed to restore the control at the spinal segmental 'gate' as well as at supraspinal sites such as the brainstem and the limbic system nuclei.

Another possible mechanism of action lies in the treatment of underlying pelvic floor dysfunction. Hypertonia of the pelvic floor is a common source of pelvic pain and is also an important feature in the etiology of lower urinary tract disorders. ${ }^{18}$ SNM has been postulated to inhibit inappropriate excitation of the pelvic floor muscles, therefore facilitating voiding by interrupting the outflow to the urethral sphincter. ${ }^{19}$ However, In a study of 30 women with Fowler's syndrome, elevated maximum urethral closure pressure did not change significantly, and hypertonicity persisted during SNM; the return of voiding ability seemed to be attributable to a slight increase in detrusor contractility. ${ }^{20}$ Thus, instead of a direct efferent inhibition, SNM might work by inhibition of afferent signals from urethral sphincter activity.

\section{SNM FOR CHRONIC PELVIC PAIN}

\section{BPS/IC}

Eleven articles were found that reported on SNM in the treatment of bladder pain syndrome/interstitial cystitis. The results are summarized in table 1 . Three articles only reported the results of test stimulation. Chai et al. ${ }^{21}$ followed six consecutive patients with symptoms and cystoscopic findings compatible with IC. These patients underwent five days of continuous bilateral S3 test stimulation with the percutaneous nerve evaluation (PNE). Frequency diaries and pain and urgency questionnaires were filled in before placement and again after five days, when the leads were removed. In addition, urine samples were taken at the same moments and were measured for heparin-binding epidermal growth factor (HB-EGF) and antiproliferative factor (APF). Comparison of the questionnaires with baseline showed that S3 stimulation significantly improved voiding symptoms and significantly decreased pelvic pain scores (scale 0-10) from 7.0 to 2.3. Patients also reported a $70 \%$ improvement in their pelvic pain after being 
treated with SNM for five days. In addition, HB-EGF significantly increased sevenfold and urinary APF activity significantly decreased from $-76.1 \%$ to $-4,5 \%$, which shows reduced inflammatory activity. Maher et al. ${ }^{22}$ prospectively evaluated the effect of unilateral S3 test stimulation with PNE in 15 patients with IC who were unresponsive to standard oral or intravesical therapy. Besides an improvement in voiding symptoms, a significant reduction $(p<0,001)$ in mean bladder pain from 8.9 to 2.4 on a scale of 0 to 10 was reported in this study. There was at least a $50 \%$ decrease in bladder pain in $87 \%$ of the cases and at least a 50\% decrease in 24-hour urinary voiding in 47\% after PNE. In addition, several quality-of-life parameters, including social functioning, bodily pain and general health significantly improved during the stimulation period. Of all tested patients, $73 \%$ requested to proceed to complete implantation of the Interstim device. Whitmore et al. ${ }^{23}$ included a total of 33 patients with intractable IC. In most cases, test stimulation with bilateral PNE leads was performed. Test stimulation was delivered for 7-14 days, with a minimum of 3 days to each side. Statistically significant differences between pre-treatment and treatment values were seen in frequency, bladder pain, average voided volume and maximum voided volume. In addition, significant improvements were seen in the Interstitial Cystitis Symptom Inventory (ICSI) and Interstitial Cystitis Problem Index (ICPI) scores with decreases from 16.4 to 10.3 and 13.8 to 8.6 respectively.

Four articles evaluated treatment success after short-term follow-up (5-15 months). Peters et al. ${ }^{24}$ performed test stimulation in 37 patients with refractory interstitial cystitis. Patients had been refractory to an average of six previous therapies. Twenty-one underwent a traditional PNE and 14 (67\%) had a positive response. Of the 16 patients who underwent a staged tined lead procedure, 15 (94\%) had a positive response. In total, 26 patients received a permanent implant, and the mean follow-up time from the implant was 5.6 months. Pelvic pain moderately improved in 35\% and markedly improved in 30\% of the patients, making a total positive response of $65 \%$. Also, the quality-of-life improved significantly and $95 \%$ of the IC subjects stated that they would undergo an implant again. In another publication Peters et al. $^{25}$ blindly randomized 22 patients for SNM or pudendal nerve stimulation (PNS). 
Table 1. Published data on the outcome of sacral neuromodulation for bladder pain syndrome / interstitial cystitis. $P N E=$ percutaneous nerve evaluation. $F U=$ follow up. $S N M=$ sacral neuromodulation. $P N S=$ pudendal nerve stimulation. $V A S=$ visual analogue scale.

\begin{tabular}{|c|c|c|c|c|}
\hline Author (year) & Technique & $\mathbf{n}$ & $\begin{array}{l}\text { Duration test } \\
\text { stimulation }\end{array}$ & Success PNE \\
\hline Maher et al. (2001) & $\begin{array}{l}\text { uniltateral } \\
\text { PNE S3 }\end{array}$ & 15 & 7-10 days & $73 \%$ \\
\hline $\begin{array}{l}\text { Chai et al. } \\
\text { (2002) }\end{array}$ & $\begin{array}{l}\text { bilateral } \\
\text { PNE S3 }\end{array}$ & 6 & 5 days & Not available \\
\hline $\begin{array}{l}\text { Peters } \\
\text { (2002) }\end{array}$ & $\begin{array}{l}\text { PNE and } \\
\text { staged S3 }\end{array}$ & 33 & 2 weeks & $67 \%(14 / 21)$ \\
\hline $\begin{array}{l}\text { Comiter } \\
\text { (2003) }\end{array}$ & $\begin{array}{c}\text { bilateral } \\
\text { PNE S3 } \\
\text { and unilateral } \\
\text { staged S3 }\end{array}$ & 25 & 9 days & $40 \%(4 / 10)$ \\
\hline $\begin{array}{l}\text { Whitmore et al. } \\
\text { (2003) }\end{array}$ & bilateral PNE S3 & 33 & 7-14 days & $78 \%$ \\
\hline $\begin{array}{l}\text { Steinberg et al. } \\
(2007)\end{array}$ & Staged S3 & 15 & Not available & - \\
\hline Peters et al. (2007) & $\begin{array}{l}\text { pudendal vs. } \\
\text { S3 stimulation }\end{array}$ & 22 & 7 days & - \\
\hline Powell et al. (2010) & $\begin{array}{l}\text { PNE and } \\
\text { staged S3 }\end{array}$ & 39 & $1-3$ weeks & $40 \%(13 / 33)$ \\
\hline $\begin{array}{l}\text { Marinkovic et al. } \\
\text { (2010) }\end{array}$ & staged S3 & 34 & Not available & - \\
\hline $\begin{array}{l}\text { Gajewski et al. } \\
\text { (2010) }\end{array}$ & unilateral PNE S3 & 78 & 5-7 days & $67 \%$ \\
\hline
\end{tabular}




$\begin{array}{cccc}\begin{array}{c}\text { Success } \\ \text { Two-staged } \\ \text { procedure }\end{array} & \begin{array}{c}\text { permanent } \\ \text { implant }\end{array} & \begin{array}{c}\text { Mean FU } \\ \text { (months) }\end{array} & \begin{array}{c}\text { Treatment success } \\ \text { post-implant }\end{array}\end{array}$

$92 \%(11 / 12)$

$67 \%$

5

Pain moderately improved in $35 \%$ and markedly improved in $30 \%$

$87 \%(13 / 15)$

$68 \%$

14

Mean reduction in VAS pain scores by $72 \%$.

$52 \%$

Not available

14

$44 \%$ reduction in Urinary Distress

Inventory. Mean decrease in post-

treatment medication use was 1.4.

$77 \%$

6

Mean VAS pain scores decreased $49 \%$ for SNM and $29 \%$ for PNS.

$81.8 \%(9 / 11)$

$56 \%$

60

$77 \%$ long-term success

$65 \%$ free of pain symptoms

$88 \%$

$88 \%$

87

Mean reduction in VAS pain scores by $63 \%$

$59 \%$

62

$72 \%$ long-term success 
A quadripolar tined lead was successfully placed at the sacral and pudendal sites in all patients. Of the 22 patients, 17 (77\%) had a significant clinical response and had an IPG placed. In the 17 responding to neuromodulation, PNS gave an overall 59\% improvement in symptoms, whereas SNM gave an overall $44 \%$ improvement $(P=0.05)$. Thirteen of 17 patients chose the pudendal lead for the final implant and four chose the sacral lead. After 6 months of follow-up the visual analogue scale (VAS) scores for pain decreased by $49 \%$ for sacral and $29 \%$ for pudendal nerve stimulation.

Comiter et al. ${ }^{26}$ evaluated a group of 25 patients with refractory IC. The success rates of PNE and staged procedure were $40 \%$ (4 of 10) and 87\% (13 of 15) respectively. After a mean follow-up of 14 months, average pain scores (scale 0 to 10$)$ decreased in all patients from a mean of 5.8 to 1.6 (73\% improvement). ICSI scores improved on average by $59 \%$ and ICPI scores improved by $63 \%$. Peters et al. $^{27}$ assessed the influence of SNM on narcotic use. Twenty-one patients with refractory IC were reviewed retrospectively. All had a permanent device implanted after responding to a temporary test. Data were collected from chart reviews and patient questionnaires. Intramuscular morphine dose equivalents (MDEs) were calculated before and after implantation. The mean follow up was 15.4 months. Of the 18 patients using chronic narcotics before the implantation the mean MDE decreased from 81.6 to $52.0 \mathrm{mg} /$ day (36\%) after implantation $(P=0.015)$. Four of 18 patients $(22 \%)$ stopped all narcotics after implantation. Twenty patients reported moderate or marked improvement in pain afterward.

Three articles evaluated treatment success after long-term follow-up. Powell et al. $^{28}$ included 39 patients with urgency-frequency syndrome due to BPS/IC who failed to respond to conventional therapy. A total of 22 patients $(56 \%)$ underwent permanent implantation. Of the 33 patients who underwent PNE, 13 (39\%) met the criteria for permanent generator placement while 9 of the $11(82 \%)$ evaluated with the staged procedure had permanent generators placed. The mean followup after implantation was 59 months. Postoperatively, $77 \%$ of the patients who received a permanent generator reported long-term cure or more than $50 \%$ improvement in urgency-frequency symptoms. Of the 17 patients initially 
complaining of pain, 11 (65\%) reported no dysuria or pelvic pain postoperatively at last follow-up visit. Medication use also decreased after implantation. Forty-six percent ( 6 of 13 patients) dependent on amitriptyline stopped their medication completely. For patients on hydroxyzine and pentosan polusulfate these rates were $55 \%$ and $60 \%$ respectively. Furthermore, $60 \%$ (6 of 10) no longer required DMSO bladder instillations and $20 \%$ (2 of 10 ) no longer requiring narcotics postoperatively. Eventually, 11 of $22(50 \%)$ patients underwent explantation for various reasons. Depleted batteries were responsible in 4 of 11 explants. Other reasons were loss of efficacy, infection, and technical malfunction.

Marinkovic et al. ${ }^{29}$ retrospectively evaluated a group of 30 patients with interstitial cystitis implanted with an Interstim device. The median follow-up period was 86 (SD 9.8) months, with a minimum follow-up of 72 months. Before implantation, 34 patients were tested with a staged procedure ( $88 \%$ success rate). At followup, a significant decrease in VAS pain scores from 6.5 to $2.4(64 \%)$ was observed at last follow-up. Mean PUF-scores decreased from 21.7 to 9.2 (58\%). There were five cases of lead migration and three implantable pulse generator erosions, leading to a re-operation rate of $27 \%$. Most complications were due to accidents.

Recently, Gajewski et al. reported long-term results of 78 patients with BPS/IC in a retrospective study. After showing a positive response to test stimulation with PNE, 46 patients $(59 \%)$ were implanted with a permanent device. The average follow-up was 62 months (SD 28, range 12-132 months). The long-term success rate was $72 \%$ and the average improvement in Global Response Assessment (GRA) scale was $80 \%$. The improvement in GRA was $>75 \%$ in 23 patients $(70 \%)$ and between $50 \%$ and $75 \%$ in 10 patients $(30 \%)$. The explantation rate was $28 \%$. The most common indications for removal was poor outcome and painful stimulation. The reoperation rate was $50 \%$, with $53 \%$ due to loss of efficacy and $47 \%$ due to pain. The median time for revision was 13 months.

\section{Non-specific pelvic pain}

Two publications were found that addressed the efficacy of SNM in patients with non-specific intractable pelvic and/or urogenital pain. Everaert et al. performed a 
percutaneous nerve evaluation in 26 patients after failure of conservative treatment for intractable chronic pelvic pain (including genital, urethral, inguinal and perineal pain). ${ }^{30}$ Patients with interstitial cystitis were excluded. Significant pain relief was obtained in 16 patients (62\%). Pain relief was significantly better in patients with symptoms of voiding dysfunction and dyschezia than in those with dyspareunia. Relief was also better with decreasing age $(P<0.0001)$ and better in men than in women $(\mathrm{P}<0.05)$. Eventually 11 patients were implanted successfully with a unilateral quadripolar electrode (S3 root). Patients were followed for $36 \pm 8$ months. Eight of the 11 patients (73\%) were satisfied with the treatment. One patient was explanted due to infection of the device and one patient underwent re-operation due to electrode migration.

Siegel et al. measured the effectiveness of SNM in patients with a history of pelvic and/or urogenital pain that persisted for at least 6 months and was refractory to conventional treatment. ${ }^{31}$ Surgical implantation of the Interstim device was performed in 10 patients. At a median follow-up of 19 months, $60 \%$ of the patients reported significant improvement in pelvic pain symptoms. Eight patients $(80 \%)$ had a decrease in the number of hours of worst pain and 9 had an increased number of hours of least pain at long-term follow-up. At baseline, the average rate of pain was 9.7 versus 4.4 at long-term follow-up. A total of 27 adverse events were noted in the 10 patients with the implant. Three patients requested permanent explantation due to a return to baseline pain and 2 required revision, resulting in a re-operation rate of $50 \%$.

\section{DISCUSSION}

Sacral neuromodulation has shown to be a good treatment option for patients with lower urinary tract dysfunction, and has been approved by the U.S. Food and Drug Administration for refractory nonobstructive urinary retention, urgency/frequency and urgency incontinence. ${ }^{25}$ Although bladder pain is often accompanied by voiding symptoms, SNM currently has no FDA-approval for the treatment of chronic pelvic pain. Since many patients with CPP experience insufficient effect of conservative treatment, minimally-invasive alternatives such as SNM have been advocated in order to prevent major surgery. The currently 
published results might suggest that SNM could be used as a valuable alternative treatment option in patients with refractory chronic pelvic pain. However, the majority of published studies used a retrospective approach, evaluated small groups of patients and provided data on a limited follow-up duration. Therefore the results should be read with some caution. Furthermore, some studies included patients with BPS/IC with confirmed findings on cystoscopic examination according to the ESSIC-criteria, whereas others included patients who did not meet these criteria, or patients with non-specific pelvic pain. Another difficulty is the inconsistent use of the terms urgency/frequency and IC/BPS in some studies. Although IC/BPS is often accompanied by urgency/frequency symptoms and voiding symptoms are often accompanied by pain symptoms, the exact symptoms and diagnosis should be clearly stated.

Chronic pelvic pain is a collective term to describe a group of patients with pain arising from different heterogeneous mechanisms. This makes comparisons difficult as different studies may evaluate different patient groups. Clear and well described inclusion criteria are needed to evaluate which chronic pelvic pain patients are most likely to benefit from SNM, and which predictive factors can help to select the most suitable candidates. According to the current data, concomitant voiding symptoms might be a positive predictor for treatment success. $^{30,32}$ The presence of pelvic floor dysfunction on urodynamic investigation was also found to be significantly related to successful outcome. ${ }^{30}$ Therefore, screening for pelvic floor dysfunction might be important in the selection of eligible candidates for SNM. In addition, the duration of test stimulation could also be of influence. Everaert et al. found that of the 10 patients that failed test stimulation, 6 had pain relief for 24-48 hours and 1 for 4 days. ${ }^{30}$ Therefore, prolonged test stimulation by using a two-stage implant is advisable. Another important aspect to consider is the type of outcome measurement that should be used. Different pain and symptom inventories are currently used which makes it difficult to compare the various outcomes. It is also important to properly define treatment success in CPP patients: what amount of decrease in pain score is considered successful? Furthermore, some studies only mention the mean reduction in pain scores, and therefore the success rates cannot be 
defined. $^{25,26,33}$ In another study, SNM showed to have a positive effect on narcotics use, with associated decrease in pain scores. ${ }^{33}$ However, some patients who reported no more pain with SNM still used narcotics. This raises concern about the study validity and makes interpretation of treatment efficacy difficult.

Finally, publication bias should also be considered, as some data have only been presented as abstracts. Berman et al. ${ }^{34}$ evaluated a total of 20 patients who were implanted with a permanent device after showing a positive response to test stimulation. After an unknown follow-up duration, only 2 patients reported the pain as none or minimal. In addition, Bade et al. ${ }^{35}$ showed that the percentage of symptom improvement in patients with BPS/IC decreased from $85 \%$ at 3 months post implant to $45 \%$ at 25 months post implant, suggesting that the long-term efficacy of SNM in patients with BPS/IC shows tendency to decrease. Furthermore, of the 3 articles that only evaluated test stimulation of SNM for IC, only one (Whitmore et al.) has published a subsequent report of long-term use. ${ }^{21-23}$ This could also be indicative of publication bias.

Besides SNM, other neuromodulatory techniques have been used in the treatment of refractory pelvic pain patients, including posterior tibial nerve stimulation (PTNS), pudendal nerve stimulation and caudal epidural S2-4 stimulation. Kim et al. evaluated the effect of PTNS in 15 patients (10 women and 5 men) with CPP in an open prospective clinical trial. After 12 weeks of PTNS, $9(60 \%)$ had an improvement of $>50 \%$ in the VAS score for pain. Six patients $(40 \%)$ ended up with a mean VAS $<3 .{ }^{36}$ Van Balken et al. evaluated PTNS in 33 patients with CPP. In 21\% mean VAS decreased >50\%. After 12 weeks of treatment, seven patients $(21 \%)$ ended up with a mean VAS $<3$.

In a retrospective study by Peters et al., 84 patients underwent pudendal nerve stimulation for IC/PBS and overactive bladder. ${ }^{37}$ Overall, positive pudendal response ( $>50 \%$ improvement on the pudendal lead) was achieved in $71.4 \%$. Almost all subjects (93\%) with a history of having failed sacral neuromodulation responded to the pudendal lead. The potential benefit of stimulating the pudendal nerve is increased afferent stimulation through the S2-S4 nerve roots. Another technique that provides stimulation of the S2-4 nerve roots is the caudal 
epidural approach. Using an introducer, a quadripolar lead is deployed in a retrograde fashion under fluoroscopy over the S2-S4 sacral nerve roots. Zabihi et al. ${ }^{3}$ evaluated the efficacy of bilateral caudal epidural SNM for the treatment of refractory chronic pelvic pain and PBS/IC. Of the 30 patients $23(77 \%)$ had a successful trial stimulation and were permanently implanted. The mean follow-up duration was 15 months. Among these patients the pain score improved by $40 \%$. The ICSI and ICPI scores improved by $35 \%$ and $38 \%$ respectively. On average, patients reported a $42 \%$ improvement in their symptoms. Four patients were eventually explanted due to treatment failure. Future studies should investigate the clinical utility of different neuromodulatory treatments in well-defined patient populations. Currently, SNM should only be considered as a treatment in refractory pelvic pain patients when all other treatment options have failed. Still, the results are suboptimal and adverse events are relatively common.

\section{CONCLUSION}

Currently, there is insufficient evidence to determine the role of SNM in the treatment of chronic pelvic pain. Although initial results seem promising, populations are small and follow-up durations are relatively short. Furthermore, it is unclear which patients are most likely to benefit from SNM. Larger prospective trials with long-term evaluation are required to determine the ultimate efficacy of this treatment.

\section{REFERENCES}

1. Ku JH, Kim SW and Paick JS: Quality of life and psychological factors in chronic prostatitis/chronic pelvic pain syndrome. Urology. 66: 693-701, 2005.

2. Burkman RT: Chronic pelvic pain of bladder origin: epidemiology, pathogenesis and quality of life. J Reprod Med. 49: 225-9, 2004.

3. Zabihi N, Mourtzinos A, Maher MG, Raz S and Rodriguez LV: Short-term results of bilateral S2-S4 sacral neuromodulation for the treatment of refractory interstitial 
cystitis, painful bladder syndrome, and chronic pelvic pain. International Urogynecology Journal. 19: 553-557, 2008.

4. Hohenfellner M, Black P, Linn JF, Dahms SE and Thuroff JW: Surgical treatment of interstitial cystitis in women. Int Urogynecol J Pelvic Floor Dysfunct. 11: 113-9, 2000.

5. Hughes OD, Kynaston HG, Jenkins BJ, Stephenson TP and Vaughton KC: Substitution cystoplasty for intractable interstitial cystitis. Br J Urol. 76: 172-4, 1995.

6. Baskin LS and Tanagho EA: Pelvic pain without pelvic organs. J Urol. 147: 683-6, 1992.

7. Sahai A, Khan MS and Dasgupta P: Efficacy of botulinum toxin-A for treating idiopathic detrusor overactivity: results from a single center, randomized, doubleblind, placebo controlled trial. J Urol. 177: 2231-6, 2007.

8. Flynn MK, Amundsen CL, Perevich M, Liu F and Webster GD: Outcome of a randomized, double-blind, placebo controlled trial of botulinum A toxin for refractory overactive bladder. J Urol. 181: 2608-15, 2009.

9. Janknegt RA, Hassouna MM, Siegel SW, Schmidt RA, Gajewski JB, Rivas DA, Elhilali MM, Milam DC, van Kerrebroeck PE, Dijkema HE, Lycklama a Nyeholt AA, Fall M, Jonas U, Catanzaro F, Fowler CJ and Oleson KA: Long-term effectiveness of sacral nerve stimulation for refractory urge incontinence. Eur Urol. 39: 101-6, 2001.

10. Hassouna MM, Siegel SW, Nyeholt AA, Elhilali MM, van Kerrebroeck PE, Das AK, Gajewski JB, Janknegt RA, Rivas DA, Dijkema H, Milam DF, Oleson KA and Schmidt RA: Sacral neuromodulation in the treatment of urgency-frequency symptoms: a multicenter study on efficacy and safety. J Urol. 163: 1849-54, 2000.

11. Ryder RM: Chronic pelvic pain. Am Fam Physician. 54: 2225-32, 2237, 1996.

12. Fall M, Baranowski AP, Elneil S, Engeler D, Hughes J, Messelink EJ, Oberpenning $F$ and De C. Williams AC: EAU Guidelines on Chronic Pelvic Pain. European Urology. 57: 35-48, 2010.

13. van de Merwe JP, Nordling J, Bouchelouche P, Bouchelouche K, Cervigni M, Daha LK, Elneil S, Fall M, Hohlbrugger G, Irwin P, Mortensen S, van Ophoven A, Osborne JL, Peeker R, Richter B, Riedl C, Sairanen J, Tinzl M and Wyndaele JJ: Diagnostic criteria, classification, and nomenclature for painful bladder syndrome/interstitial cystitis: an ESSIC proposal. Eur Urol. 53: 60-7, 2008.

14. Slavin KV: Peripheral nerve stimulation for neuropathic pain. Neurotherapeutics. 5: 100-6, 2008.

15. Kothari S: Neuromodulatory approaches to chronic pelvic pain and coccygodynia. Acta Neurochirurgica Supplements. 97: 365-371, 2007.

16. Melzack R and Wall PD: Pain mechanisms: a new theory. Science. 150: 971-9, 1965.

17. van der Pal F, Heesakkers JP and Bemelmans BL: Current opinion on the working mechanisms of neuromodulation in the treatment of lower urinary tract dysfunction. Curr Opin Urol. 16: 261-7, 2006. 
18. Butrick CW: Pathophysiology of pelvic floor hypertonic disorders. Obstet Gynecol Clin North Am. 36: 699-705, 2009.

19. Leng WW and Chancellor MB: How sacral nerve stimulation neuromodulation works. Urol Clin North Am. 32: 11-8, 2005.

20. Kessler TM and Fowler CJ: Sacral neuromodulation for urinary retention. Nat Clin Pract Urol. 5: 657-66, 2008.

21. Chai TC, Zhang C, Warren JW and Keay S: Percutaneous sacral third nerve root neurostimulation improves symptoms and normalizes urinary HB-EGF levels and antiproliferative activity in patients with interstitial cystitis. UROLOGY. 55: 643-646, 2000.

22. Maher CF, Carey MP, Dwyer PL and Schluter PL: Percutaneous sacral nerve root neuromodulation for intractable interstitial cystitis. The Journal of Urology. 165: 884886, 2001.

23. Whitmore KE, Payne CK, Diokno AC and Lukban JC: Sacral neuromodulation in patients with interstitial cystitis: a multicenter clinical trial. International Urogynecology Journal. 14: 305-309, 2003.

24. Peters KM, Carey JM and Konstandt DB: Sacral neuromodulation for the treatment of refractory interstitial cystitis: outcomes based on technique. Int Urogynecol J Pelvic Floor Dysfunct. 14: 223-8; discussion 228, 2003.

25. Peters KM, Feber KM and Bennett RC: A prospective, single-blind, randomized crossover trial of sacral vs pudendal nerve stimulation for chronic interstitial cystitis. British Journal of Urology International. 100: 835-839, 2007.

26. Comiter CV: Sacral neuromodulation for the symptomatic treatment of refractory interstitial cystitis: a prospective study. The Journal of Urology. 169: 1369-1373, 2003.

27. Peters $\mathrm{KM}$ and Konstandt D: Sacral neuromodulation decreases narcotic requirements in refractory interstitial cystitis. British Journal of Urology International. 93: 777-779, 2004.

28. Powell CR and Kreder KJ: Long-Term Outcomes of Urgency-Frequency Syndrome Due to Painful Bladder Syndrome Treated with Sacral Neuromodulation and Analysis of Failures. The Journal of Urology. 183: 173-176, 2010.

29. Marinkovic SP, Gillen LM and Marinkovic CM: Minimum 6-year outcomes for interstitial cystitis treated with sacral neuromodulation. Int Urogynecol J Pelvic Floor Dysfunct, 2010.

30. Everaert K, Devulder J, De Muynck M, Stockman S, Depaepe H, De Looze D, Van Buyten $\mathrm{J}$ and Oosterlinck W: The Pain Cycle: Implications for the Diagnosis and Treatment of Pelvic Pain Syndromes. International Urogynecology Journal. 12: 9-14, 2001. 
31. Siegel S, Paszkiewicz E, Kirkpatrick C, Hinkel B and Olsen K: Sacral Nerve Stimulation in Patients with Chronic Intractable Pelvic Pain. The Journal of Urology. 166: 1742-1745, 2001.

32. Gajewski JB and Al-Zahrani AA: The long-term efficacy of sacral neuromodulation in the management of intractable cases of bladder pain syndrome: 14 years of experience in one centre. BJU Int, 2010.

33. Marinkovic SP, Gillen LM and Marinkovic CM: Minimum 6-year outcomes for interstitial cystitis treated with sacral neuromodulation. Int Urogynecol J Pelvic Floor Dysfunct.

34. Berman C, Itano N, Gore J, Rodriguez L and Raz S: Poor results using sacral nerve stimulation (Interstim) for treating pelvic pain patients. J Urol. 169: 94-94, 2003.

35. Bade $\mathrm{J}$ and Smans $\mathrm{A}$ : Long-term efficacy of sacral neuromodulation (interstim) in patients with refractory interstitial cystitis (IC) shows tendency to decrease. J Urol. 175: 98-98, 2006.

36. Kim SW, Paick JS and Ku JH: Percutaneous posterior tibial nerve stimulation in patients with chronic pelvic pain: a preliminary study. Urol Int. 78: 58-62, 2007.

37. Peters KM, Killinger KA, Boguslawski BM and Boura JA: Chronic pudendal neuromodulation: expanding available treatment options for refractory urologic symptoms. Neurourol Urodyn. 29: 1267-71, 2010. 


\section{GENERAL DISCUSSION}


Chapter 8 
Chronic lower urinary tract dysfunction, including urgency incontinence, urgencyfrequency, and non-obstructive urinary retention present a therapeutic challenge. Patients are initially treated with traditional therapies, including pelvic floor exercises, biofeedback, and anticholinergic drugs. However, a significant proportion of patients do not achieve sufficient therapeutic benefit or cannot tolerate the side effects. ${ }^{1}$ These refractory patients often face more invasive treatments, such as augmentation cystoplasty or urinary diversion with high recurrence rates and a large number of complications. As pointed out in Chapter 1, less invasive procedures such as sacral neuromodulation (SNM) have been searched for in order to prevent these major surgical procedures. In 1989, Tanagho and colleagues pioneered the initial investigations into electrical stimulation of the sacral nerves. ${ }^{2}$ It is assumed that by modulating sensory processing and micturition reflex pathways in the central nervous system, bladder control can be restored. ${ }^{3}$ Ultimately, an implantable system was developed for SNM, in which a neurostimulator is subcutaneously connected to an electrode in the third sacral foramen. Since this early work, clinical studies have demonstrated the efficacy of this treatment and SNM has become an important tool in the treatment of bladder dysfunction. ${ }^{4}$

\section{Technical advances}

Originally, the permanent lead was implanted during an open surgical procedure under general anesthesia. An incision was made over the midline of the sacrum and the lead was placed under direct vision in the sacral foramen. After correct positioning, the lead was secured to the sacral fascia with non-absorbable sutures. Due to the invasive nature of the procedure, less invasive methods were searched to allow for lead implantation. In 2002 a percutaneous implantation technique was introduced using a self-anchoring "tined" lead, also called the tined lead procedure (TLP). ${ }^{5}$ This technique allows placement of the lead under local anesthesia and consequently, sensory responses to intraoperative stimulation can be evaluated. Due to the minimally-invasive nature of the TLP, the classic technique has been generally abandoned. Still, there are some uncertainties about the impact of the TLP on long-term safety and efficacy. Although the self-anchoring technique seems sufficient for fixing the lead in the 
short-term, there is still concern with regard to anterior dislocation of the lead in the long-term. Furthermore, during the classic technique, the lead can be placed under direct vision, parallel to the nerve root, and it is theoretically less likely to migrate once it is anchored in position. The position and orientation of the electrode in relation to the nerve root and achievement of a low motor stimulation threshold during permanent lead placement has been suggested to have the greatest impact on subsequent treatment efficacy. ${ }^{6,7}$

Dudding et al. directly compared the clinical results between the TLP and the classic open technique. ${ }^{8}$ Eighteen patients had undergone open lead placement and 30 patients percutaneous placement with the TLP. They found no significant differences regarding clinical outcome. The incidence of wound infections in this study was higher in patients undergoing open placement (11 percent) compared with those undergoing percutaneous placement (no infections occurred). We evaluated the long-term outcome of patients implanted in our centre between 2002 and 2005 by using the TLP. The results are shown in Chapter 2 and treatment outcome appears to be comparable to previous studies using the nontined lead. This indicates that the TLP is a safe and durable technique. The number of lead migrations in our study was rather low (1.6\%), indicating that the self-anchoring lead fixation of the TLP is not inferior to the classic technique. Deng et al. evaluated the problem of lead migration in a larger group of patients $(n=235)$ implanted with the TLP. ${ }^{9}$ They found lead migration in 5 patients $(2.1 \%)$. Migration occurred between first and second stage implantation in 1 of the 5 cases, and occurred after the second stage in 4 of 5 . This was seen as early as 3 weeks and as late as 8 months after the procedure. Although the TLP seems to reduce the incidence of lead migration, it can still occur in a later stage and therefore routine radiographs should not be abandoned when failure of treatment is encountered. The cause of early migration may be technical in nature. As many of the tines as possible should be outside the foramen to grip the subcutaneous tissue. After the immediate postoperative period, the assumption is that fibrosis of the surrounding tissue aids in maintaining the lead in position. However, given the occurrence of late migration, attenuated musculofascial tissue of the sacrum and inadequate fibrotic reaction may be another underlying cause. 
The TLP has also been used in the selection of eligible candidates for SNM. Originally, test stimulation was conducted with a basic wire electrode during the percutaneous nerve evaluation (PNE). The TLP allows a better fixation in the subcutaneous tissue and prevents lead migration and subsequent change in therapeutic efficacy. ${ }^{10}$ As a result, a longer trial phase can be conducted to assess improvement in voiding symptoms. Also, the TLP has four electrodes, allowing for a more accurate placement along the course of the nerve. This explains the higher success rate of the TLP in comparison with the PNE. ${ }^{10,11}$ Advantages of the PNE include low cost and non-invasiveness. In addition, the test phase can be conducted in an outpatient setting under local anesthesia, and the lead can be easily removed at the end of the trial. This still leaves the possibility of additional screening with the TLP in case of a suboptimal response, but also offers the advantage of implantation of the entire device in a single surgical procedure for those who show a successful response. Furthermore, the PNE provides an easy way to assure whether a patient is capable of dealing with SNM and gives a good indication of patient compliance to the therapy. Chapter 3 shows that the long-term outcome with definitive SNM treatment seems to be independent of the test stimulation method (PNE or TLP) that is used. This indicates that different screening strategies can be utilized to evaluate eligibility for SNM in clinical practice. The choice of the screening method should be tailored to the particular needs and symptoms of the patient.

\section{Predictive factors}

Currently, test stimulation is considered the only reliable predictive factor for success with permanent SNM. During test stimulation, symptoms are measured with self-recorded voiding diaries, and the relevant parameters are dependent on the type of complaint. For patients with urgency urinary incontinence, the response to SNM is evaluated by looking mainly at the improvement of incontinence parameters (number of leakages and pad usage). For patients with urgency/frequency symptoms, the voiding frequency and voided volume are considered the key voiding diary variables. In general, more than 50\% improvement in voiding symptoms is considered a clinically significant response. Although arbitrary, this degree of symptom improvement is used as a cut-off 
value in the selection of eligible candidates for permanent SNM. ${ }^{12-14}$ Chapter 3 suggests that patients who show an excellent response (>90\% symptom improvement) have a better long-term outcome than patients who showed between 50 and $90 \%$ improvement. Presumably, patients who show a high response to test stimulation are more sensitive to respond to sacral neuromodulation, and therefore treatment failure is less likely in these patients. It is also possible that treatment efficacy gradually decreases over time with SNM. Hence, in patients who showed a borderline response (just above the $50 \%$ improvement margin) during test stimulation, the degree of symptom improvement might decline to a level below this margin after several years of treatment. Furthermore, Chapter 3 indicates that $\mathrm{OAB}$ wet patients who experience a significant improvement in both the incontinence and urgencyfrequency parameters, have higher long-term success rates. These results point out that test stimulation is an important tool in SNM and that selection of the best responders improves long-term efficacy.

Although some authors previously suggested possible predictors for success in SNM including age, duration of symptoms or the type of complaint, the reports are inconsistent. ${ }^{15-17}$ Clinical experience suggests that a history of psychiatric disease might have an influence on the response to SNM. Since functional disorders of the lower urinary tract often coincide with psychological and emotional problems, these factors might have an influence on treatment outcome. Weil et al. found that 12 of the 16 patients with treatment failure after implantation had a psychiatric disorder in their previous history. ${ }^{18}$ Everaert et al. stated that a decrease in clinical effect directly after implantation compared to the effect during test stimulation was significantly related to a history of psychiatric disease. ${ }^{16}$ In addition, White et al. reported a high rate $(21 \%)$ of implant removal in patients with a psychiatric history, but could not demonstrate a significant relation between psychiatric history and adverse events. ${ }^{19}$ However, they did find that patients who were previously enrolled in a pain clinic had a significantly higher chance of experiencing adverse events. Moreover, Everaert et al. showed that in patients with dysuria or perineal pain, device-related pain was found more frequently. ${ }^{16}$ Chapter 4 evaluates the role of a broad spectrum of psychological and psychiatric factors in relation to SNM. Although no relation 
was found between psychological problems (e.g. anxiety, insomnia, depression) and treatment outcome, psychiatric co-morbidity was found to be a positive predictor for the occurrence of adverse events with permanent treatment. Patients with pain syndromes are more likely to develop pain symptoms related to SNM after implantation. These findings indicate that psychological factors might play an important role in the selection of eligible candidates. It would be interesting to develop a reliable psychological screening instrument that can be routinely used in the diagnostic work-up of SNM.

\section{Treatment failure}

After permanent implantation of a neurostimulator, approximately $30 \%$ of all patients with an initially favourable result of test stimulation fail to respond after 5 years of treatment. ${ }^{4}$ Patients are routinely followed after implantation, and symptom recurrence is a challenging topic. Most patients can be treated by reprogramming the stimulation parameters, including polarity, amplitude, pulse rate and pulse width. In our centre, reprogramming starts with adjusting the amplitude and polarity. Correct reprogramming is based on the principle of perineal sensation at the lowest possible amplitude, which presumably reflects the closest proximity to the nerve root. However, not much research has been done regarding the optimal stimulation parameters that are used in SNM. ${ }^{20-22}$ The role of one of these parameters, the pulse rate, is evaluated in Chapter $\mathbf{5}$. According to our preliminary results, none of the 4 pulse rates $(5.2 \mathrm{~Hz}-10 \mathrm{~Hz}$ $20 \mathrm{~Hz}-40 \mathrm{~Hz}$ ) was significantly related to an improvement in clinical outcome. Yet, the majority of patients experienced an improvement in voiding symptoms for at least one of the 4 pulse rate settings. This means that although none of the 4 pulse rates seems to be superior, changing the pulse rate during reprogramming can indeed be effective. In our study, we only evaluated the effect of each pulse rate during one week, and therefore the effect with chronic stimulation cannot be predicted. It would be interesting to evaluate the effect of different pulse rates in a group of patients directly after implantation.

Dudding et al. evaluated the role of pulse rate and pulse width in 12 patients with faecal incontinence. ${ }^{20}$ All patients had undergone chronic stimulation for more than 6 months and had achieved a greater than 50\% reduction in incontinence 
episodes. Three different pulse rates $(6.9 \mathrm{~Hz}-14 \mathrm{~Hz}-31 \mathrm{~Hz})$ and pulse widths $(90 \mu s-210 \mu s-450 \mu s)$ were tested. Optimal settings, determined by greatest increase in rectal complicance, were shorter pulse width in five patients and higher frequency in seven. Optimized stimulation resulted in a significant decrease in the mean incontinence episodes one month after the procedure. Hence, in patients with a suboptimal response to chronic SNM, alterations in stimulation parameters could be made in order to improve clinical efficacy.

Another interesting suggestion by McLennan et al. is the use of neurophysiological monitoring during reprogramming. ${ }^{23}$ They recorded the compound muscle action potential (CMAP) of the urethral sphincter in response to different electrode configurations in patients with decreased clinical effect over time. The use of neurophysiological techniques helped to differentiate between patients who already experienced a maximal response and patients who had a suboptimal or absent response with their current electrode. In patients with a maximal response, reprogramming or re-operation is unlikely to be beneficial. In patients with a suboptimal response, reprogramming should certainly be attempted before re-operating. Patients with an absent response represent either device failure or significant lead migration, and are probably not going to benefit from reprogramming, but may be helped with a re-operation. This technique has promise as a tool for reprogramming and for helping to direct future therapy for the individual patient with therapy failure.

Some patients with symptom recurrence do not benefit from conventional treatment, such as reprogramming. When these patients have an adequate sensory response to stimulation and there are no signs of device malfunction or lead migration, they are considered refractory to SNM treatment. Although the underlying cause of this phenomenon is unclear, possible theories are adaptation of the nervous system and fibrosis around the lead. ${ }^{9,24}$ These patients represent a true management difficulty and often more invasive treatments are required to control bladder dysfunction. The development of approaches to restore treatment efficacy is therefore needed. As discussed in Chapter 6, bilateral stimulation of the sacral nerves has been postulated to give a stronger modulatory response, and might be of use in restoring treatment efficacy. The results of our pilot study showed that bilateral stimulation was only effective in a 
selected group of patients. The reason why only a small number of patients showed a successful response is unclear, although natural progression of the initial bladder dysfunction cannot be ruled out and some patients therefore might no longer be able to benefit from SNM. The use of the PNE test can also be accounted for the low success rate, as prolonged screening with the tined lead has proven to induce a more profound clinical response. Evaluation of contraand bilateral stimulation in a larger patient group by using the tined lead would be interesting. Other approaches in the treatment of patients with therapy failure, such as multi-segmental or pudendal nerve stimulation could also be explored in the future.

\section{Future perspectives}

In the past decade, technical advances in SNM have remarkably reduced the invasiveness of the surgical procedure, resulting in less postoperative complications and improvement of patient comfort. ${ }^{10}$ Future developments should be directed at further improvement of patient comfort, since adverse events such as pain at the implant site are still a common problem. ${ }^{19} \mathrm{~A}$ good example is the development of the Interstim II device. This device was introduced in 2006 and is 50\% lighter and smaller than the original implantable neurostimulator. The smaller generator allows for a smaller incision and pocket to be created presumably leading to less discomfort and higher patient acceptance. Bearing in mind that with the expanding use of SNM more and more younger patients are being implanted, this device is especially suitable for slim and active patients. Due to the smaller size, the average battery life is only 3 to 5 years. The newer system also provides additional patient programming and data tracking opportunities. Future research should evaluate whether the Interstim II device actually improves patient comfort and reduces device related pain symptoms. Development of an MRI compatible, rechargeable, device with a long functional life will be the ultimate purpose.

Although functional MRI and PET studies in the recent years have led to a better understanding of the neurophysiological changes during SNM, the exact working mechanism still remains unclear. ${ }^{25,26}$ Future research should further investigate the potential working mechanisms. Since approximately $30 \%$ of patients lose 
therapeutic efficacy after implantation for unknown reasons, the pathophysiology of treatment failure after permanent implantation needs to be clarified. ${ }^{4}$ In turn, adequate treatment strategies can be developed, such as contra- or bilateral stimulation in order to restore treatment efficacy in these patients. It is also important to identify reliable predictive factors for long-term treatment failure. Consequently, patients who are likely to experience treatment failure can be filtered out in the early stage of patient selection. This could certainly reduce the number of adverse events and reduce the affiliated costs.

With the increasing use of SNM, new indications will arise. Treatment of faecal incontinence and chronic constipation with SNM has shown promising results, also in the long-term. ${ }^{27-29}$ Successful treatment has been reported for patients with interstitial cystitis and chronic pelvic pain. Chapter 7 provides an overview of the current evidence in the literature regarding SNM treatment for pelvic pain. The currently published results might suggest that SNM could be used as a valuable alternative treatment option in patients with refractory chronic pelvic pain. However, the majority of published studies used a retrospective approach, evaluating small groups of patients and providing data on a limited follow-up duration. Future studies should investigate the clinical utility of SNM for this indication by using a prospective study design and by using strict inclusion criteria. Currently, SNM should only be considered as a treatment in refractory pelvic pain patients when all other treatment options have failed.

Another neuromodulatory approach for the treatment of lower urinary tract dysfunction is pudendal nerve stimulation. The pudendal nerve originates from the sacral nerve roots S2, S3 and S4. Although direct pudendal nerve stimulation provides a broader afferent stimulation in comparison to conventional S3 stimulation, the implantation technique is more difficult and clinical experience is limited. A prospective cross-over study was conducted by Peters et al. comparing SNM with pudendal nerve stimulation in 30 patients. After a 7-day trial $80 \%$ experienced a positive response and were subsequently implanted. ${ }^{30}$ While objective changes in voiding symptoms were not significantly different, a majority of the patients preferred pudendal stimulation. Bosch et al. reported on a novel technique that can be used in pudendal nerve stimulation, the so-called 
BIONTM therapy. ${ }^{31,32}$ This is a self-contained, battery-powered minineurostimulator (size $28 \mathrm{~mm}$ by $3.3 \mathrm{~mm}$, weight $0.7 \mathrm{~g}$ ). It has integrated electrodes which can be telemetrically programmed. It can be implanted at its target location, adjacent to the pudendal nerve at Alcock's Canal, with a specially developed tool kit after making a 3 to $4 \mathrm{~mm}$ skin incision medial to the ischial tuberosity. This minimally-invasive technique might contribute to an improvement in patient comfort in the future. Future studies will have to determine the efficacy and feasibility of this new approach.

Sacral neuromodulation has also been successfully used in patients with neurogenic bladder dysfunction. ${ }^{33,34}$ An interesting observation was made by Sievert et al. in 2010. ${ }^{35}$ They showed that early bilateral implantation of a neurostimulator during the bladder-acontractility phase after complete spinal cord injury might preserve nerve plasticity. Ten patients with neurologicallyconfirmed complete spinal cord lesions were provided with bilateral SNM. The implants were placed 2.9 (range, 0.8-4.5) months after the initial trauma. Six patients declined and served as controls. After a mean follow-up of 26.2 months, the mean catheterized volumes of the implanted patients were $582 \mathrm{ml}$ (range, 480-650ml). They did not report involuntary urine leakage and the mean number of urinary tract infections was 0.5 per year. Despite taking antimuscarinics, the control patients had lower bladder capacities and reported a lower mean catheterized volume of $294 \mathrm{ml}$. The control group performed more frequent selfcatheterizations and used urinary condoms because of involuntary urine loss caused by low bladder capacity. The mean number of urinary tract infections was 3.8 per year. Based on these results, early SNM implantation in patients with complete spinal cord injury might play an important role in the future.

\section{REFERENCES}

1. Diokno AC, Appell RA, Sand PK, Dmochowski RR, Gburek BM, Klimberg IW and Kell $\mathrm{SH}$ : Prospective, randomized, double-blind study of the efficacy and tolerability of the extended-release formulations of oxybutynin and tolterodine for overactive bladder: results of the OPERA trial. Mayo Clin Proc. 78: 687-95, 2003. 
2. Schmidt RA, Bruschini $\mathrm{H}$ and Tanagho EA: Sacral root stimulation in controlled micturition. Peripheral somatic neurotomy and stimulated voiding. Invest Urol. 17: 130-4, 1979.

3. van der Pal F, Heesakkers JP and Bemelmans BL: Current opinion on the working mechanisms of neuromodulation in the treatment of lower urinary tract dysfunction. Curr Opin Urol. 16: 261-7, 2006.

4. van Kerrebroeck PE, van Voskuilen AC, Heesakkers JP, Lycklama a Nijholt AA, Siegel S, Jonas U, Fowler CJ, Fall M, Gajewski JB, Hassouna MM, Cappellano F, Elhilali MM, Milam DF, Das AK, Dijkema HE and van den Hombergh U: Results of sacral neuromodulation therapy for urinary voiding dysfunction: outcomes of a prospective, worldwide clinical study. J Urol. 178: 2029-34, 2007.

5. Spinelli M, Giardiello G, Gerber M, Arduini A, van den Hombergh U and Malaguti S: New sacral neuromodulation lead for percutaneous implantation using local anesthesia: description and first experience. J Urol. 170: 1905-7, 2003.

6. Dudding TC, Pares D, Vaizey CJ and Kamm MA: Predictive factors for successful sacral nerve stimulation in the treatment of faecal incontinence: a 10-year cohort analysis. Colorectal Dis. 10: 249-56, 2008.

7. Testerman RL, Rise MT and Stypulkowski PH: Electrical stimulation as therapy for neurological disorder. IEEE Eng Med Biol Mag. 25: 74-8, 2006.

8. Dudding TC, Pares D, Vaizey CJ and Kamm MA: Comparison of clinical outcome between open and percutaneous lead insertion for permanent sacral nerve neurostimulation for the treatment of fecal incontinence. Dis Colon Rectum. 52: 463-8, 2009.

9. Deng DY, Gulati M, Rutman M, Raz S and Rodriguez LV: Failure of sacral nerve stimulation due to migration of tined lead. J Urol. 175: 2182-5, 2006.

10. Spinelli $M$ and Sievert KD: Latest technologic and surgical developments in using InterStim Therapy for sacral neuromodulation: impact on treatment success and safety. Eur Urol. 54: 1287-96, 2008.

11. Janknegt RA, Weil EH and Eerdmans $\mathrm{PH}$ : Improving neuromodulation technique for refractory voiding dysfunctions: two-stage implant. Urology. 49: 358-62, 1997.

12. Siegel SW, Catanzaro F, Dijkema HE, Elhilali MM, Fowler CJ, Gajewski JB, Hassouna MM, Janknegt RA, Jonas U, van Kerrebroeck PE, Lycklama a Nijeholt AA, Oleson KA and Schmidt RA: Long-term results of a multicenter study on sacral nerve stimulation for treatment of urinary urge incontinence, urgency-frequency, and retention. Urology. 56: 87-91, 2000.

13. Jonas U, Fowler CJ, Chancellor MB, Elhilali MM, Fall M, Gajewski JB, Grunewald V, Hassouna MM, Hombergh U, Janknegt R, van Kerrebroeck PE, Lylcklama a Nijeholt $A A$, Siegel SW and Schmidt RA: Efficacy of sacral nerve stimulation for urinary retention: results 18 months after implantation. J Urol. 165: 15-9, 2001. 
14. Schmidt RA, Jonas U, Oleson KA, Janknegt RA, Hassouna MM, Siegel SW and van Kerrebroeck PE: Sacral nerve stimulation for treatment of refractory urinary urge incontinence. Sacral Nerve Stimulation Study Group. J Urol. 162: 352-7, 1999.

15. Scheepens WA, Jongen MMGJ, Nieman FHM, de Bie RA, Weil EHJ and van Kerrebroeck PEV: Predictive factors for sacral neuromodulation in chronic lower urinary tract dysfunction. Urology. 60: 598, 2002.

16. Everaert K, De Ridder D, Baert L, Oosterlinck W and Wyndaele JJ: Patient satisfaction and complications following sacral nerve stimulation for urinary retention, urge incontinence and perineal pain: a multicenter evaluation. Int Urogynecol J Pelvic Floor Dysfunct. 11: 231-5; discussion 236, 2000.

17. Koldewijn EL, P. F. Rosier, et al.: Predictors of success with neuromodulation in lower urinary tract dysfunction: results of trial stimulation in 100 patients. J Urology. 152: 2071-2075., 1994.

18. Weil EH, Ruiz-Cerda JL, Eerdmans PH, Janknegt RA and Van Kerrebroeck PE: Clinical results of sacral neuromodulation for chronic voiding dysfunction using unilateral sacral foramen electrodes. World J Urol. 16: 313-21, 1998.

19. White WM, Mobley JD, 3rd, Doggweiler R, Dobmeyer-Dittrich C and Klein FA: Incidence and predictors of complications with sacral neuromodulation. Urology. 73: 731-5, 2009.

20. Dudding TC, Vaizey CJ, Gibbs A and Kamm MA: Improving the efficacy of sacral nerve stimulation for faecal incontinence by alteration of stimulation parameters. $\mathrm{Br} \mathrm{J}$ Surg. 96: 778-84, 2009.

21. Tai C, Wang J, Wang X, de Groat WC and Roppolo JR: Bladder inhibition or voiding induced by pudendal nerve stimulation in chronic spinal cord injured cats. Neurourol Urodyn. 26: 570-7, 2007.

22. Malaguti S, Spinelli M, Giardiello G, Lazzeri $M$ and Van Den Hombergh U: Neurophysiological evidence may predict the outcome of sacral neuromodulation. $\mathrm{J}$ Urol. 170: 2323-6, 2003.

23. McLennan MT: The role of electrodiagnostic techniques in the reprogramming of patients with a delayed suboptimal response to sacral nerve stimulation. Int Urogynecol J Pelvic Floor Dysfunct. 14: 98-103, 2003.

24. Zvara P, Sahi S and Hassouna MM: An animal model for the neuromodulation of neurogenic bladder dysfunction. Br J Urol. 82: 267-71, 1998.

25. Blok BF, Groen J, Bosch JL, Veltman DJ and Lammertsma AA: Different brain effects during chronic and acute sacral neuromodulation in urge incontinent patients with implanted neurostimulators. BJU Int. 98: 1238-43, 2006.

26. Blok BF: Central pathways controlling micturition and urinary continence. Urology. 59: 13-7, 2002. 
27. Melenhorst J, Koch SM, Uludag O, van Gemert WG and Baeten CG: Sacral neuromodulation in patients with faecal incontinence: results of the first 100 permanent implantations. Colorectal Dis. 9: 725-30, 2007.

28. Kenefick $\mathrm{NJ}$ : Sacral nerve neuromodulation for the treatment of lower bowel motility disorders. Ann R Coll Surg Engl. 88: 617-23, 2006.

29. Matzel KE, Kamm MA, Stosser M, Baeten CG, Christiansen J, Madoff R, Mellgren A, Nicholls RJ, Rius $\mathrm{J}$ and Rosen $\mathrm{H}$ : Sacral spinal nerve stimulation for faecal incontinence: multicentre study. Lancet. 363: 1270-6, 2004.

30. Peters KM, Feber KM and Bennett RC: A prospective, single-blind, randomized crossover trial of sacral vs pudendal nerve stimulation for interstitial cystitis. BJU Int. 100: 835-9, 2007.

31. Bosch JL: The bion device: a minimally invasive implantable ministimulator for pudendal nerve neuromodulation in patients with detrusor overactivity incontinence. Urol Clin North Am. 32: 109-12, 2005.

32. Groen J, Amiel C and Bosch JL: Chronic pudendal nerve neuromodulation in women with idiopathic refractory detrusor overactivity incontinence: results of a pilot study with a novel minimally invasive implantable mini-stimulator. Neurourol Urodyn. 24: 226-30, 2005.

33. Lombardi $G$ and Del Popolo G: Clinical outcome of sacral neuromodulation in incomplete spinal cord injured patients suffering from neurogenic lower urinary tract symptoms. Spinal Cord. 47: 486-91, 2009.

34. Hohenfellner M, Humke J, Hampel C, Dahms S, Matzel K, Roth S, Thuroff JW and Schultz-Lampel D: Chronic sacral neuromodulation for treatment of neurogenic bladder dysfunction: long-term results with unilateral implants. Urology. 58: 887-92, 2001.

35. Sievert KD, Amend B, Gakis G, Toomey P, Badke A, Kaps HP and Stenzl A: Early sacral neuromodulation prevents urinary incontinence after complete spinal cord injury. Ann Neurol. 67: 74-84, 2010. 


\section{SUMMARY}

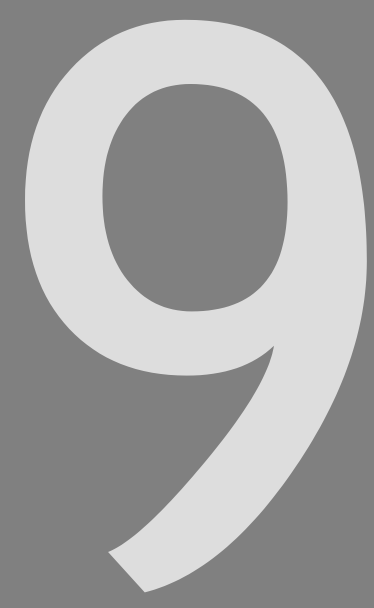


Chapter 9 
Chapter 1 provides an introduction to this thesis which contains background information from a historical perspective. In sacral neuromodulation (SNM) an electrical current is used to stimulate the third sacral nerve root in order to modulate reflex pathways that control the bladder. The current indications for SNM are discussed, including refractory overactive bladder symptoms and chronic non-obstructive urinary retention. The existing theories on the mechanism of action in SNM are also presented. In addition, an overview is provided of the clinical results of SNM for lower urinary tract dysfunction. Adverse events and troubleshooting during follow-up are separately discussed.

Chapter 2 describes a study evaluating the long-term outcome of patients who were implanted by using a new, minimally-invasive implantation technique (TLP). This technique was introduced to reduce the invasiveness of the surgical procedure in sacral neuromodulation. However, the effect of using the TLP on long-term treatment outcome is currently unevaluated. Patients who received an implantable neurostimulator in our centre between 2002 and 2005 were included. Sixty-four patients were implanted with an neurostimulator using the tined lead. The mean follow-up was 53 months (range 35-77 months). Five patients died of causes unrelated to SNM, and they were not included in the analysis. Voiding diary analysis showed that 38 of the 59 patients $(64 \%)$ were successfully treated. Twenty-one patients $(33 \%)$ underwent a surgical revision due to an adverse event. One patient (1.6\%) underwent lead revision, because of suspected lead migration. Using the tined lead technique appears to reduce the occurrence of lead migration, but does not increase the long-term success rate when compared to previous reports using the classic technique.

Chapter 3 investigates if the method of screening in sacral neuromodulation has an influence on long-term outcome. Patients who were evaluated with the percutaneous nerve evaluation (PNE) were compared to patients who were evaluated with the staged tined lead procedure (TLP). All patients who were screened since the introduction of the tined lead technique in our centre in 2002 were included. In total, 92 patients underwent test stimulation. Of the 76 patients who were screened with PNE, 35 (46\%) met the criteria for permanent 
implantation, whereas 11 of the 16 patients (69\%) who underwent direct screening with TLP had permanent stimulators placed. The 41 patients who failed PNE subsequently underwent test stimulation with TLP. Eventually, 18 of these patients (44\%) were implanted with a neurostimulator after showing a successful response. Statistical analysis showed no relation between the method of screening and long-term success $(p=0.94)$. Although TLP is a more sensitive tool than PNE, long-term success seems to be independent of the screening method.

Chapter 4 discusses the role of psychological and psychiatric factors in sacral neuromodulation. In a prospective study, a broad range of psychological factors was evaluated by using two validated psychological screening questionnaires. These included the Amsterdam Biographical Questionnaire (ABQ) and the Symptom Check-List-90-Revised (SCL-90-R). The ABQ is a self-report personality inventory, which measures different personality traits. The SCL-90-R is a widely used psychological status symptom inventory. It is a 90 item multidimensional questionnaire designed to screen for a broad range of current psychological problems. In addition to the questionnaires, a history of psychiatric disease was included as a potential predictive factor. Fifty-four patients (10 men and 44 women) were included. Univariate analysis showed no relation between the psychological characteristics and the outcome of test stimulation or the occurrence of adverse events with permanent treatment. A history of psychiatric disease was not related to the outcome of test stimulation, but was shown to be a positive predictor for the occurrence of adverse events with permanent SNM treatment $(p=0.001)$.

Chapter 5 presents a study that evaluated the role of pulse rate changes on treatment outcome in sacral neuromodulation. The effect of 4 different pulse rates $(5.2 \mathrm{~Hz}-10 \mathrm{~Hz}-21 \mathrm{~Hz}-40 \mathrm{~Hz})$ was evaluated in patients who showed a suboptimal response to chronic treatment. The changes in clinical response and pain symptoms were compared between the four pulse-rates using multivariate analysis. Fifty patients were included of which 40 were female. Of all patients, $76 \%$ experienced clinical improvement (>20\% change in voiding diary 
parameters) with at least one of the four pulse rate settings. Yet, no significant difference was found regarding clinical outcome (voiding diary and questionnaire) between the different pulse rates. Furthermore, none of the four pulse rates was significantly related to the occurrence of SNM-related pain. Although none of the four pulse rates seems to be superior, an individualized approach to optimize treatment efficacy by changing the pulse rate appears to be useful.

Chapter 6 describes the results of a pilot study evaluating the effect of bilateral sacral nerve stimulation in restoring treatment efficacy in patients who experience failure of unilateral SNM treatment. Patients with failure of treatment due to device malfunction were excluded. The percutaneous nerve evaluation (PNE) test was used to evaluate the effect of contra- and bilateral stimulation. The stimulation electrode was placed in the contralateral S3 foramen, and symptoms were self-recorded using a three-day voiding diary. Clinical success was defined as more than $50 \%$ improvement in at least one of the relevant voiding diary parameters compared to baseline. Fifteen patients were included in this study, and underwent test stimulation with PNE. In three patients lead migration was suspected and therefore they were not included in the analysis. Of the remaining 12 patients, four showed a successful response to PNE. Three of these patients were eventually implanted with a contralateral lead. After 12 months treatment, two of the three patients had a successful outcome. In this pilot study, only a selected group of patients appear to benefit from bilateral stimulation after unilateral therapy failure. Further investigation is necessary to determine the predictive factors and cost-effectiveness of this approach.

Chapter 7 reviews the current literature on sacral neuromodulation as a treatment for chronic pelvic pain (CPP). Although currently no FDA approval exists for this indication, several studies have demonstrated promising results. Since many patients with CPP experience insufficient effect of conservative treatment, minimally-invasive alternatives such as SNM have been advocated in order to prevent major surgery. A total of 12 relevant articles were identified. Ten articles mainly addressed the efficacy of SNM in patients with interstitial 
cystitis/bladder pain. Seven of the 10 articles reported treatment success after implantation, ranging from 65 to $95 \%$. The duration of follow-up ranged between 5-87 months. The mean reduction in pain scores was reported between 40 and $72 \%$. The re-operation rate ranged between 27 and 50\% after long-term followup. Two articles included patients with miscellaneous urogenital pain syndromes. The success rates after implantation ranged from $60-77 \%$, with the duration of follow-up ranging between 19-36 months. Sacral neuromodulation might be a promising minimally-invasive treatment for CPP refractory to traditional therapy. Still, larger prospective trials with long-term evaluation are required to determine the ultimate efficacy of this treatment. 

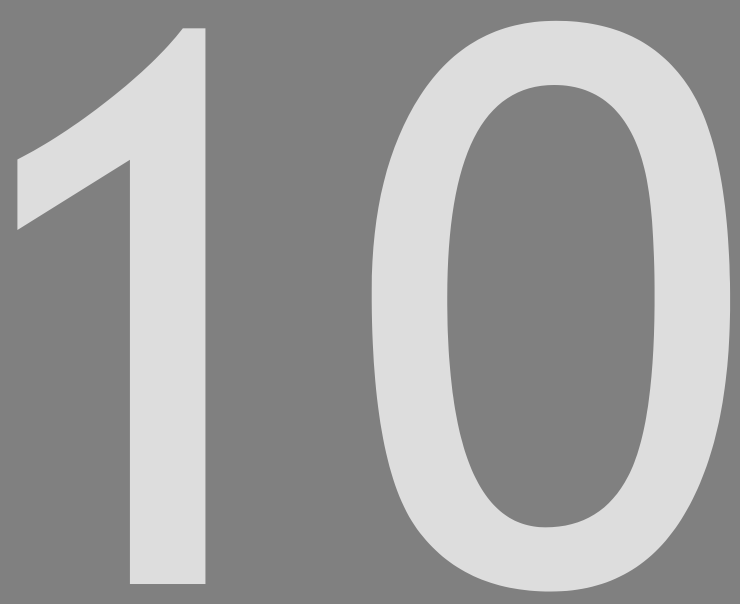

NEDERLANDSE SAMENVATTING

DANKWOORD

\section{LIJST VAN PUBLICATIES}

CURRICULUM VITAE 
Chapter 10 


\section{SAMENVATTING}

Chronische blaasklachten, waaronder symptomen van een overactieve blaas en niet-obstructieve blaasledigingsklachten, vormen een therapeutische uitdaging. De meeste patiënten worden in eerste instantie behandeld met conservatieve therapieën zoals training van de bekkenbodemspieren, biofeedback en anticholinerge medicatie. Echter, een groot deel van deze patiënten heeft onvoldoende baat bij deze behandelingen of kan de bijwerkingen niet verdragen. Als gevolg hiervan ondergaan zij vaak meer ingrijpende behandelingen, zoals een blaasvergrotende of blaasvervangende operatie met een hoog risico op complicaties. Om deze grote operaties te kunnen vermijden, is er gezocht naar minder invasieve behandelingen. In 1989 startten Tanagho en zijn team met onderzoek naar elektrische stimulatie van de sacrale zenuwen bij patiënten met blaasklachten. Er werd aangenomen dat de blaascontrole kan worden hersteld door modulatie van opstijgende zenuwprikkels en blaasreflexen in het centrale zenuwstelsel. Deze behandeling wordt sacrale neuromodulatie (SNM) genoemd. Uiteindelijk werd een implanteerbaar systeem ontwikkeld, waarbij een neurostimulator onder de huid is verbonden met een elektrode in een opening van het heiligbeen. Hiermee kunnen de sacrale zenuwen continu worden gestimuleerd. Sinds dit pionierswerk is de effectiviteit van SNM aangetoond in klinische studies en heeft het een belangrijke plaats ingenomen in de behandeling van functionele blaasklachten. Oorspronkelijk werd de permanente elektrode geïmplanteerd tijdens een open operatie, waarbij het heiligbeen moest worden blootgelegd. Later werd een techniek geïntroduceerd waarbij een zelfverankerende elektrode door de huid kan worden ingebracht, de zogenaamde "tined lead procedure" (TLP). Door deze ontwikkeling is SNM een minimaal invasieve behandeling geworden. Het effect van deze nieuwe techniek op het resultaat van de behandeling is echter tot op heden niet bekend. Een van de doelstellingen van dit proefschrift betreft het evalueren van dit effect door alle patienten die met de TLP zijn geopereerd op te volgen. Ook is er gekeken naar het vóórkomen van complicaties met de TLP in vergelijking met de oude techniek. 
Geschikte kandidaten voor SNM worden geselecteerd door middel van een proefstimulatie. Hierbij wordt een testnaald in de derde opening van het heiligbeen (S3) gebracht en vervolgens dicht in de buurt van de sacrale zenuw gepositioneerd. Door te kijken naar de motorische en sensorische reacties kan de juiste positie van de elektrode worden bepaald. Een typische S3 reactie bestaat uit een reflexcontractie met intrekkende beweging van de bekkenbodemspieren, plantaire flexie van de grote teen en tintelingen in het anale of genitale gebied. Vervolgens wordt de elektrode aangesloten op een uitwendige stimulator. Een proefstimulatie kan ofwel gebeuren met een eenvoudige draadelektrode (PNE) of met een geavanceerde elektrode (TLP). Voordelen van de PNE in vergelijking met de TLP zijn de lage kosten en het weinig invasieve karakter. Een nadeel is dat minder patiënten goed reageren op de PNE, waarschijnlijk doordat de gebruikte elektrode makkelijker kan verschuiven. De proefstimulatie wordt gezien als de enige betrouwbare voorspellende factor voor het slagen van permanente behandeling met SNM. Echter, het is de vraag of de methode van proefstimulatie (PNE vs. TLP) van invloed is op het therapeutische resultaat op lange termijn. Dit proefschrift probeert een antwoord te geven op deze vraag.

Een ander doel van dit proefschrift is het zoeken naar nieuwe methoden om patiënten waarbij het therapeutisch effect van SNM is afgenomen te helpen. Alle patiënten worden regelmatig teruggezien op de polikliniek na implantatie, en sommige patiënten melden afname van het effect van de behandeling. De meeste patiënten kunnen worden behandeld door de instellingen van de neurostimulator aan te passen. Hierbij kan o.a. de amplitude, frequentie en pulsbreedte worden veranderd. Echter, er is niet veel onderzoek gedaan naar de optimale instelling van deze parameters. De rol van één van deze parameters, de frequentie, wordt onderzocht in dit proefschrift. Hiermee kan mogelijk het effect van SNM worden verbeterd of kunnen patiënten met terugkerende klachten worden geholpen.

Sommige patiënten waarbij het effect van SNM afneemt hebben geen baat bij het opnieuw instellen van de stimulatieparameters. Deze patiënten worden gezien als resistent voor de behandeling en vaak is een ingrijpende operatie de enige oplossing. Er zijn aanwijzingen dat dubbelzijdige stimulatie van de sacrale 
zenuwen mogelijk een sterker effect heeft op de blaascontrole. Dit zou bruikbaar kunnen zijn bij de behandeling van patiënten die geen baat meer hebben bij enkelzijdige stimulatie. Dit proefschrift onderzoekt de rol van deze experimentele benadering.

Het ontstaan van blaasklachten is afhankelijk van meerdere factoren en gaat vaak gepaard met andere klachten van de bekkenbodem, zoals darmklachten en pijn in het kleine bekken. Er is reeds een positief effect aangetoond van SNM bij patiënten met incontinentie voor ontlasting en hardnekkige obstipatie. Er zijn ook aanwijzingen dat SNM effectief kan zijn bij patienten met chronische pijnklachten in het kleine bekken, zoals blaaspijn of genitale pijn. De huidige bewijskracht van SNM als een mogelijk behandeling voor chronische pijn wordt in dit proefschrift onderzocht middels een literatuurstudie.

Hoofdstuk 1 geeft een introductie van dit proefschrift, bestaande uit een historisch overzicht en achtergrondinformatie over de ontwikkeling van sacrale neuromodulatie (SNM). De huidige indicaties voor deze behandeling worden besproken, evenals de bestaande theorieën over het werkingsmechanisme van SNM. Daarnaast wordt een overzicht gegeven van de klinische resultaten van deze behandeling bij patiënten met functionele blaasklachten. De mogelijke complicaties en problemen na implantatie worden apart besproken. De doelstellingen van dit proefschrift komen aan het eind van dit hoofdstuk aan bod.

Hoofdstuk 2 beschrijft de resultaten van SNM na lange termijn bij patiënten die zijn geïmplanteerd met de TLP techniek. Met deze techniek kan op minder invasieve wijze de elektrode worden ingebracht. In het onderzoek werd gekeken naar alle patiënten die tussen 2002 en 2005 met behulp van de TLP werden geïmplanteerd. Het effect van SNM werd gemeten door patiënten plasdagboeken te laten bijhouden vóór en tijdens behandeling. In totaal werden 64 patiënten geïncludeerd, met een gemiddelde follow-up van 53 maanden. Analyse van de plasdagboeken toonde dat $64 \%$ van de patiënten succesvol was behandeld. Bij 21 patiënten werd een heroperatie uitgevoerd vanwege een complicatie. Bij één patiënt was er sprake van verschuiving van de elektrode. Concluderend lijkt implantatie met de TLP de kans op verschuiving van de 
elektrode te doen afnemen, maar het therapeutisch effect van SNM in vergelijking met de oude techniek blijft gelijk.

Hoofdstuk 3 beoordeelt of de methode van proefstimulatie van invloed is op het therapeutisch effect van SNM. Patiënten die een proefstimulatie ondergingen met de "percutaneous nerve evaluation" (PNE) werden vergeleken met patiënten die werden getest met de "tined lead procedure" (TLP). Alle patiënten die een proefstimulatie ondergingen in ons centrum vanaf 2002 werden beoordeeld en in totaal werden er 92 patiënten geïncludeerd. Van de 76 patiënten die werden getest met de PNE kwamen er 35 (46\%) in aanmerking voor definitieve behandeling. Van de 16 patiënten die werden getest met de TLP kwamen er 11 (69\%) in aanmerking. De 41 patiënten die negatief reageerden op de PNE werden aanvullend getest met de TLP. Hiervan ondergingen uiteindelijk 18 patiënten (44\%) de definitieve behandeling. Statistische analyse toonde geen verband tussen de methode van proefstimulatie en het resultaat van behandeling op lange termijn. Alhoewel de TLP een sensitievere screeningsmethode is dan de PNE, lijkt het therapeutisch resultaat op lange termijn onafhankelijk te zijn van de gebruikte methode.

Hoofdstuk 4 onderzoekt de rol van psychologische en psychiatrische factoren rondom de behandeling met SNM. In een prospectieve studie werd een breed scala aan psychologische factoren bestudeerd door gebruik te maken van 2 gevalideerde vragenlijsten. Dit betreft de Amsterdam Biografische Vragenlijst (ABV) en de Symptom Checklist-90-Revised (SCL-90-R). De ABV is een vragenlijst waarmee verschillende persoonlijkheidstrekken kunnen worden beoordeeld. De SCL-90-R is een veelgebruikte psychologische vragenlijst voor het opsporen van psychische problemen. Naast de 2 vragenlijsten werd de psychiatrische voorgeschiedenis onderzocht als mogelijke voorspellende factor voor het resultaat van SNM behandeling. In totaal werden 54 patiënten (10 mannen en 44 vrouwen) geïncludeerd. Statistische analyse toonde geen relatie tussen de verschillende psychologische factoren uit de vragenlijsten en het resultaat van proefstimulatie of permanente behandeling. Een voorgeschiedenis met een psychiatrische aandoening was niet gerelateerd aan het resultaat van 
proefstimulatie, maar bleek wel een positief voorspellende waarde te hebben voor het ontstaan van complicaties met permanente SNM behandeling.

Hoofdstuk 5 beschrijft een onderzoek naar de invloed van verschillende stimulatiefrequenties op het therapeutisch effect van SNM. Het effect van 4 verschillende frequenties $(5.2 \mathrm{~Hz}, 10 \mathrm{~Hz}, 21 \mathrm{~Hz}, 40 \mathrm{~Hz})$ werd onderzocht bij patiënten die een suboptimaal resultaat hadden van SNM behandeling. Bij elke frequentie werden de blaasklachten en stimulatiegerelateerde pijnklachten geëvalueerd. Met behulp van multivariate analyse werd de relatie tussen de verschillende frequenties en klinisch effect onderzocht. In totaal werden 50 patiënten geïncludeerd, waarvan 40 vrouwen. Zesenzeventig procent van alle patiënten ondervonden een positief resultaat op hun plasklachten bij ten minste één bepaalde frequentie. Er werd echter geen significant verschil gevonden tussen de verschillende frequenties in relatie tot klinisch effect. Ook werd er geen verband gevonden tussen één specifieke frequentie en het ontstaan van pijnklachten. Alhoewel geen van de 4 frequenties superieur lijkt te zijn, blijkt het veranderen van de frequentie bij de meeste patiënten met suboptimaal effect van SNM een positieve werking te hebben.

Hoofdstuk 6 evalueert het effect van dubbelzijdige stimulatie van de sacrale zenuwen bij patiënten met onvoldoende effect van permanente SNM behandeling. Alle patiënten waarbij er een technische reden was voor de afname in het klinisch effect werden niet in het onderzoek opgenomen. Het effect van dubbelzijdige stimulatie werd onderzocht middels een proefstimulatie. Hierbij werd een tijdelijke elektrode aan de andere kant van het heiligbeen geplaatst. De plasklachten werden met een plasdagboek bijgehouden vóór en tijdens de proefstimulatie. Er werden 15 patiënten geïncludeerd. Bij 3 patiënten werd verschuiving van de elektrode waargenomen, en deze patiënten werden niet meegenomen in de analyse. Van de 12 overgebleven patiënten toonden er 4 een goede respons op proefstimulatie. Bij 3 van de 4 patiënten werd uiteindelijk een tweede neurostimulator geïmplanteerd. Twaalf maanden na de implantatie hadden 2 van de 3 patiënten een blijvend succesvol resultaat. Uit deze pilot studie blijkt dat slechts een beperkte groep patiënten voordeel heeft van 
dubbelzijdige stimulatie. Meer onderzoek is daarom nodig om voorspellende factoren te identificeren en de kosteneffectiviteit te bepalen.

Hoofdstuk 7 geeft een overzicht van de huidige literatuur betreffende SNM als een mogelijke behandeling voor chronische (blaas)pijn. Hoewel er momenteel geen goedkeuring is voor deze indicatie door de Amerikaanse Food and Drug Administration (FDA), zijn er verschillende studies die een positief effect tonen van SNM bij deze aandoening. In totaal werden 12 relevante artikelen gevonden. Tien van deze artikelen hebben hoofdzakelijk het effect van SNM bij patiënten met chronische blaaspijn onderzocht. Zeven van de 10 artikelen vermeldden het succespercentage van definitieve SNM behandeling, variërend van 65 tot 95\%. De gemiddelde follow-up lag tussen de 5 en 87 maanden. De gemiddelde afname in pijnscores werd beschreven tussen de 40 en $72 \%$. Het percentage patiënten dat een heroperatie moest ondergaan was $27-50 \%$. Twee artikelen includeerden patiënten met verschillende urogenitale pijnsyndromen. Het succespercentage na implantatie lag tussen de 60 en $70 \%$, met een gemiddelde follow-up van 19-36 maanden. Sacrale neuromodulatie is mogelijk een effectieve behandeling voor patiënten met chronische (blaas)pijn. Echter, grotere prospectieve studies met langere follow-up zijn nodig om het effect van deze behandeling te evalueren. 


\section{DANKWOORD}

Toen ik in 2009 begon met promotieonderzoek had ik vaak de gedachte "waar ben ik aan begonnen...". Nu in de eindfase van mijn onderzoek denk ik vaak: "dit had ik voor geen goud willen missen". Deze periode heeft gezorgd voor persoonlijke en wetenschappelijke ontwikkeling waar ik de rest van mijn leven profijt van zal hebben. Ik wil dan ook graag iedereen bedanken die direct en indirect heeft geholpen bij mijn onderzoek. Een persoonlijk woord van dank wil ik graag richten tot:

Professor Van Kerrebroeck, als promotor en opleider wil ik u bedanken voor de mogelijkheid die ik heb gekregen om me te kunnen ontwikkelen als arts, wetenschapper en uiteindelijk uroloog. Ik hoop nog veel van $u$ te mogen leren in de toekomst.

Dr. De Wachter, mijn tweede promotor. Beste Stefan, zonder jou was dit proefschrift nooit binnen zo'n korte tijd tot stand gekomen. Ondanks dat je de onmogelijke taak had om 5 promovendi tegelijk te begeleiden naast je klinische werk, kon ik altijd bij je terecht voor overleg. Bedankt voor je kritische blik en de leermomenten binnen de functionele urologie.

Prof. De Bie, beste Rob, bedankt voor de hulp bij het opzetten van mijn onderzoek. Dankzij jou kreeg ik meer inzicht in de basisprincipes van de methodiek. Nu weet ik dat met "loss to follow-up" niet de mensen worden bedoeld die je uit het onderzoek gooit vanwege afwijkende resultaten.

Fred en Jan, bedankt voor jullie hulp bij de statistiek. Fijn dat jullie zo veel geduld hadden bij de uitleg van de (voor mij) soms onbegrijplijke formules.

Mijn paranimfen, Bas en Stan. Beste Bas, ik weet nog dat we samen met een kater naar het inkomweekend fietsten... Daarna hebben we een onvergetelijke studententijd gehad, waar ik nog vaak aan terugdenk. Jammer dat we zo ver uit elkaar zijn gaan wonen. Beste Stan, jij was altijd degene die bij elke publicatie 
als eerste aan de telefoon hing. Ooit heb je tegen me gezegd: "je moet zorgen dat je boven het maaiveld uitsteekt". Ondanks mijn lengte is dit volgens mij aardig gelukt. Bedankt voor jullie vriendschap, ik ben er trots op dat jullie mij als paranimfen willen steunen bij de verdediging.

Beste Randall, een jaar lang hebben wij samen op een veel te kleine kamer zonder daglicht doorgebracht. Ik wil je graag bedanken voor de steun in de beginfase van mijn onderzoek. Ik mis onze squashpartijen en de belachelijke filmpjes op Youtube. Heel veel succes bij je verdere opleiding en ik kijk uit naar jouw promotie!

Beste Martijn, Bassie! Nu ben jij degene het stokje van de neuromodulatie heeft overgenomen. Ik ben ervan overtuigd dat je zowel in het onderzoek als de kliniek het ver gaat schoppen. Bedankt voor de fantastische tijd op onze "SNM Room"'. Hopelijk volgen er nog veel avonden met Schneider Weisse en saté.

Rhea, heel veel succes met je nieuwe baan en aankomende promotie. Bedankt voor alle gezellige quiz-avonden, we gaan ze zeker weer oppakken! Sajjad en Bart, al had ik weinig met jullie onderzoek in het lab te maken, we hebben wel veel lol gehad samen. Vooral de 1 april-grap van Sajjad zal ik nooit vergeten...veel succes allebei! Vera, onderzoek doen gaat altijd langzamer dan je zou willen. Maak je maar geen zorgen, ik weet zeker dat je binnen een paar jaar een mooi boekje zult neerknallen.

Alle dames op het secretariaat, in het bijzonder Anja en Nancy, bedankt voor jullie steun en medewerking. Fijn dat jullie altijd voor mij klaarstonden! De medewerkers op de polikliniek en functie-afdeling eveneens bedankt voor al jullie inspanningen. Sorry dat ik jullie belaagd heb met de vele UDO/MUDO verzoeken voor mijn studies...

Alle stafleden en arts-assistenten van de afdeling urologie wil ik bedanken voor de leerzame en gezellige momenten. Het is geweldig hoe jullie me tot nu toe hebben opgeleid. 
Beste familie, vrienden en kennissen, bedankt voor jullie interesse in mijn promotieonderzoek. Ik hoop dat de omschrijving "blaas-pacemaker" nu wat meer vorm heeft gekregen.

Pap en mam, jullie hebben me altijd de vrijheid gegeven om zelf keuzes te maken en mij vervolgens altijd gesteund in deze keuzes. Ontzettend bedankt hiervoor.

Loes, jij bent degene die ik het meeste wil bedanken. Het afgelopen jaar was wel erg druk en spannend, met een promotie, nieuwe baan, nieuw huis en zwangerschap. Desondanks stond je altijd voor me klaar. Bedankt dat je zo lief voor me bent! 
Chapter 10 



\section{LIJST VAN PUBLICATIES}

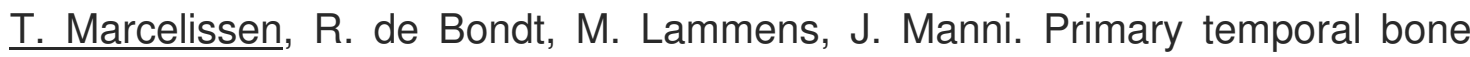
secretory meningioma presenting as chronic otitis media. Eur Arch Otorhinolaryngol. $2008 \mathrm{Jul} ; 265(7): 843-6$.

T. Marcelissen, P. van Kerrebroeck, S. de Wachter. Sacral Neuromodulation as a treatment for neuropathic clitoral pain after abdominal hysterectomy. Int Urogynecol J Pelvic Floor Dysfunct. 2010 Oct;21(10):1305-7.

T. Marcelissen, R. Leong, R. de Bie, P. van Kerrebroeck, S. de Wachter. Long term results of sacral neuromodulation with tined lead placement. J Urol. 2010 Nov;184(5):1997-2000.

R. Leong, T. Marcelissen, F. Nieman, R. de Bie, P. van Kerrebroeck, S. de Wachter. Patient satisfaction and experience in sacral neuromodulation: results of a single centre sample study. J Urol. 2011 Feb;185(2):588-92

T. Marcelissen, R. Leong, J. Serroyen, P. van Kerrebroeck, S. de Wachter. Is the method of screening in sacral neuromodulation a prognostic factor for longterm success? J Urol. 2011 Feb;185(2):583-7

T. Marcelissen, R. Leong, J. Serroyen, P. van Kerrebroeck, S. de Wachter. The use of bilateral sacral nerve stimulation in patients with loss of unilateral treatment efficacy. J Urol. 2011 Mar;185(3):976-80

T. Marcelissen, R. Leong, F. Nieman, P. van Kerrebroeck, S. de Wachter. The effect of pulse rate changes on clinical effect in sacral neuromodulation. J Urol. 2011 May;185(5):1781-5 


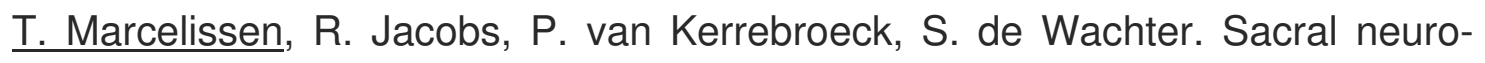
modulation as a treatment for chronic pelvic pain. J Urol. 2011 Aug;186(2):38793. Epub 2011 Jun 17.

T. Marcelissen, R. Leong, F. Nieman, J. van Lankveld, P. van Kerrebroeck, S. de Wachter. Psychological and psychiatric factors as predictors for success in sacral neuromodulation. BJU Int. 2011 Aug 2. Epub ahead of print.

D. Oerlemans, A. van Voskuilen, T. Marcelissen, R. de Bie, P. van Kerrebroeck. Is on-demand sacral nerve stimulation a feasible therapy regime? Neurourol Urodyn. 2011 Aug 8. Epub ahead of print.

T. Hermans, T. Marcelissen, P. Callewaert, S. Cörvers, P. van Kerrebroeck. Een ulcus op de penis als eerste manifestatie van Morbus Wegener. Geaccepteerd Nederlands Tijdschrift voor Urologie, Juli 2011.

T. Marcelissen, M. Smits, P. van Kerrebroeck. Een vrouw met recidiverende urineweginfecties en flankpijn. Geaccepteerd Nederlands Tijdschrift voor Geneeskunde, Aug 2011.

M. Smits, T. Marcelissen, P. van Kerrebroeck, S. de Wachter. Nieuwe ontwikkelingen op het gebied van sacrale neuromodulatie in de behandeling van functionele blaasklachten. Submitted 



\section{CURRICULUM VITAE}

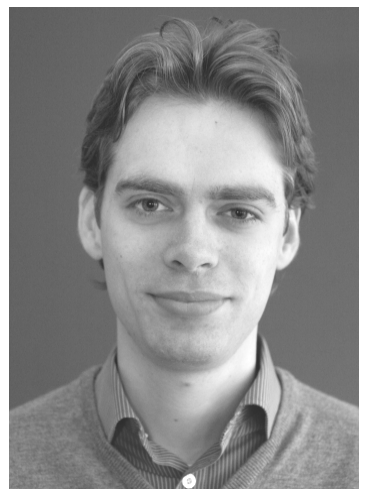

Tom Marcelissen werd op 19 juli 1982 geboren in Helden. In 2000 haalde hij zijn VWO diploma op het Bouwens van der Bojiecollege te Panningen. Aansluitend studeerde hij geneeskunde aan de Universiteit Maastricht waar hij in 2006 zijn artsenbul ontving. Daarna werkte hij 2 jaar als ANIOS heelkunde in het Viecuri Medisch Centrum te Venlo en 4 maanden als ANIOS neurochirurgie in het Maastricht Universtair Medisch Centrum. In 2009 begon hij zijn promotieonderzoek onder begeleiding van prof. dr. P.E.V. van Kerrebroeck (hoofd afdeling urologie) en dr. S.G.G. de Wachter (uroloog). Vanaf september 2010 combineert hij dit onderzoek met klinisch werk als ANIOS urologie. In januari 2012 zal hij starten met de vooropleiding chirurgie in het kader van de opleiding tot uroloog. Dit zal plaatsvinden in het Atrium Medisch Centrum te Heerlen onder leiding van dr. R. Welten. 